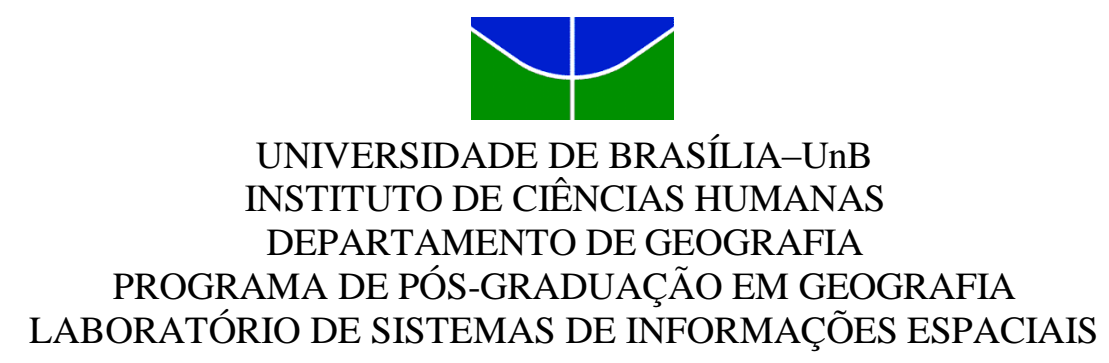

\title{
CLASSIFICAÇÃO DE BACIAS HIDROGRÁFICAS DO DISTRITO FEDERAL UTILIZANDO ANÁLISE MULTIVARIADA DE GRUPOS PARA A DEFINIÇÃO DE UNIDADES TERRITORIAIS BÁSICAS
}

\author{
Priscila Lopes Soares da Costa Taveira
}

Orientador: Roberto Arnaldo Trancoso Gomes

Co-orientador: Osmar Abílio de Carvalho Júnior

Dissertação de Mestrado

Brasília- DF: Abril/2015. 
UNIVERSIDADE DE BRASÍLIA

DEPARTAMENTO DE GEOGRAFIA

\section{CLASSIFICAÇÃO DE BACIAS HIDROGRÁFICAS DO DISTRITO FEDERAL UTILIZANDO ANÁLISE MULTIVARIADA DE GRUPOS PARA A DEFINIÇÃO DE UNIDADES TERRITORIAIS BÁSICAS}

Priscila Lopes Soares da Costa Taveira

Dissertação de Mestrado submetida ao Departamento de Geografia da Universidade de Brasília, como parte dos requisitos necessários para a obtenção do Grau de Mestre em Geografia, área de concentração Gestão Ambiental e Territorial, e linha de pesquisa Geoprocessamento para Gestão Territorial e Ambiental.

Aprovado por:

Prof. Dr. Roberto Arnaldo Trancoso Gomes, Universidade de Brasília. (Orientador)

Prof. Dr. Osmar Abílio de Carvalho Júnior, Universidade de Brasília. (Co-orientador)

Prof. Dr. Arnaldo Yoso Sakamoto,

Universidade Federal de Mato Grosso do Sul. (Examinador Externo)

Prof. Dr. Jeater Waldemar Maciel Correa Santos.

Universidade Federal de Mato Grosso do Sul.

(Examinador Externo)

Brasília-DF, 17de abril de 2015. 


\section{FICHA CATALOGRÁFICA}

COSTA, PRISCILA L. S. da

Classificação de bacias hidrográficas do Distrito Federal utilizando análise multivariada de grupos para a definição de Unidades Territoriais Básicas. 120p, 297 mm, (UnB-IH-GEA-LSIE, Mestre, Gestão Ambiental e Territorial, 2015).

Dissertação de Mestrado - Universidade de Brasília. Departamento de Geografia.

1. Zoneamento Ambiental Territorial 2. Paisagem

3. Bacias Hidrográficas 4. Morfometria

I. UnB-IH-GEA-LSIE II. Título (série)

\section{REFERÊNCIABIBLIOGRÁFICA}

COSTA, Priscila L. S. da. Classificação de bacias hidrográficas do Distrito Federal utilizando análise multivariada de grupos para a definição de Unidades Territoriais Básicas. (Dissertação de Mestrado), Curso de Pós-Graduação em Geografia, Universidade de Brasília, 2015, 90p.

\section{CESSÃO DE DIREITOS}

É concedida à Universidade de Brasília permissão para reproduzir cópias desta dissertação e emprestar ou vender tais cópias somente para propósitos acadêmicos e científicos. A autora reserva outros direitos de publicação e nenhuma parte desta dissertação de mestrado pode ser reproduzida sem a autorização por escrito da autora.

Priscila Lopes Soares da Costa 
"Quem dentre vós é sábio e entendido? Mostre pelo seu bom trato as suas obras em mansidão de sabedoria."

Tiago 3:13 - Bíblia Sagrada. 


\section{AGRADECIMENTOS}

À Deus, base da vida e de minhas escolhas, fonte de paz e de tudo o que vivencio.

Aos meus pais, Antônio e Provi, fonte de inspiração pela garra e amor por nossa família, por todo o apoio e empenho para que eu pudesse alçar maiores vôos na carreira acadêmica e profissional. Este é um trabalho concluído, sem dúvidas, graças a vocês.

Às minhas irmãs, Débora e Taísa, que se dispuseram em apoio e incentivo no decorrer de toda essa jornada.

Ao meu amado esposo Julio César pelo carinho, companheirismo e apoio. Este é o resultado de um sonho e uma batalha que você foi fundamental.

À minha pequenina filha Sofia, que com seu sorriso e brincadeiras trouxe entusiasmo para não desistir.

Aos irmãos e amigos da Igreja Presbiteriana Alvorada e do Jardim ABC: as orações, a compreensão pelas ausências e o apoio logístico foram fundamentais para a elaboração desta dissertação. O meu muito obrigada!

À equipe do IBRAM-DF que gentilmente cedeu os dados produzidos no contexto do ZEE-DF e demais informações tão úteis para a elaboração deste trabalho.

Ao meu amigo e orientador Roberto e aos queridos professores Osmar e Renato: muito obrigada é pouco para expressar a minha gratidão por todo o suporte e orientação.

Aos colegas do Departamento de Zoneamento Territorial do Ministério do Meio Ambiente por serem entusiastas e maravilhosos conselheiros na construção da dissertação.

A minha querida amiga Linda Soraya, que se empenhou na leitura e suporte, e o seu incentivo me deu mais forças para entrar no foco do trabalho.

Aos colegas do Laboratório de Sistemas de Informação Espacial - LSIE, em especial aos queridos Sandro, Potira, Verônica e Wilma. As contribuições e discussões de vocês foram valorosas. 


\section{SUMÁRIO}

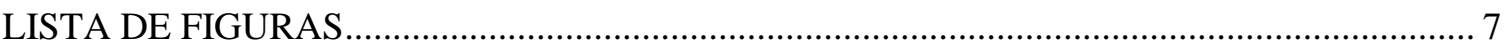

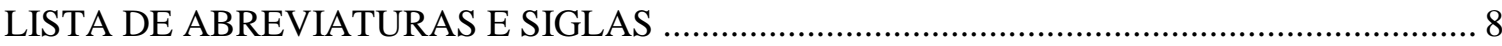

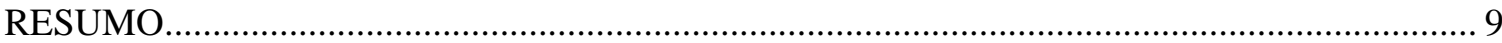

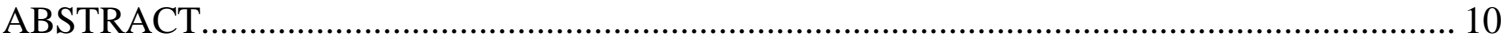

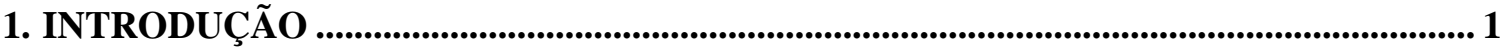

2. FUNDAMENTAÇÃO TEÓRICA

2.1 CATEGORIAS GEOGRÁFICAS E ZONEAMENTOS TERRITORIAIS ............................ 6

2.2 DELIMITAÇÃO DA PAISAGEM E BACIAS HIDROGRÁFICAS. ....................................

2.3 ORIGENS E TIPOLOGIAS DE ZONEAMENTOS AMBIENTAIS …............................... 10

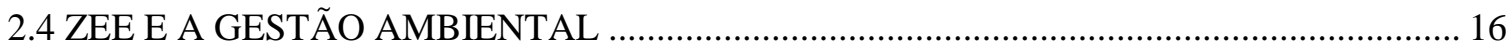

2.5 BASES CONCEITUAIS PARA A DELIMITAÇÃO DE UTB EM ZEE ............................. 21

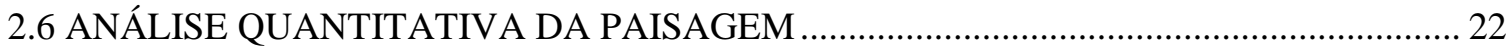

2.7 PARÂMETROS MORFOMÉTRICOS PARA A DELIMITAÇÃO DAS UTB........... 24

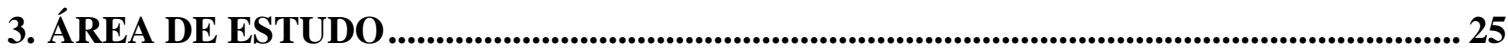

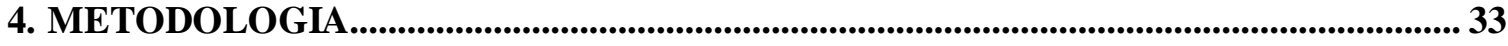

4.1. DADOS DO SPACE SHUTTLE TOPOGRAPHIC MISSION (SRTM) ............... 33

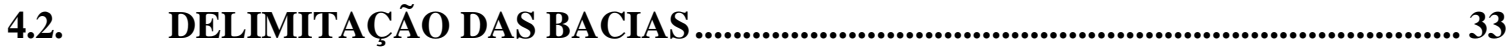

4.3. CÁLCULO DOS ATRIBUTOS MORFOMÉTRICOS DAS BACIAS DE

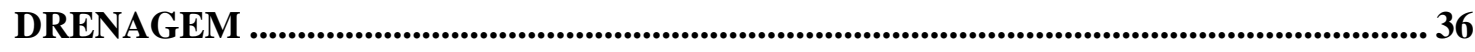

4.4. ANÁLISE DE GRUPOS PELO MÉTODO K-MÉDIAS ........................................ 38

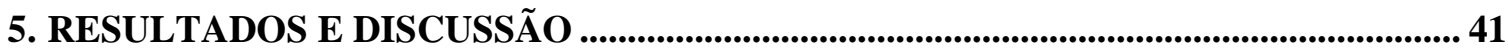

6. CONCLUSÃO

REFERÊNCIAL BIBLIOGRÁFICO................................................................................5 51 


\section{LISTA DE FIGURAS}

Figura 1: Exemplo de delimitações da paisagem (Forman, 1995).

Figura 2: Foto da Londres Vitoriana (Fonte: Pintura de Gustave Doré 1869-71).

Figura 3: Objetivos estratégicos de zoneamentos ambientais.

Figura 4: Fases para a elaboração de um ZEE (MMA, 2007).

Figura 5: Interações Gestão Ambiental. Fonte: Modificado de Santos (2004, p.27)

Figura 6: Níveis de representação do mundo real (Lisboa Filho \& Iochpe, 1999)

Figura 7: Mapa de localização DF.

Figura 8: Mapa de Geologia DF.

Figura 9: Mapa de Geomorfologia DF.

Figura 10: Mapa de Solos DF.

Figura 11: Variáveis de construção e da formulação das diretrizes para o ZEE/DF (GDF, 2014)

Figura 12: Hierarquia dos canais pelo método de Strahler.

Figura 13: Exutório das bacias hidrográficas, conforme a hierarquia de Strahler.

Figura 14: Figura demonstrativa de como é feito o cálculo dos parâmetros de: eixo maior, eixo menor e, orientação da bacia.

Figura 15: Formas do relevo obtidas a partir das curvaturas em planta e perfil do relevo (Adaptado de Dikau, 1989).

Figura 16: Esquema de como é calculado a área de contribuição

Figura 17 - Quantificação pelo método das K-médias pela distância Euclidiana (Weatherill \& Burton, 2009).

Figura 18 - (A) Mapa de elevação do relevo; (B) Mapa de declividade; (C) Mapa de área de contribuição; (D) Mapa de curvatura do relevo em planta; (E) Mapa de curvatura do relevo em perfil; (F) Mapa do índice topográfico.

Figura 19 - Gráfico de correlação das variáveis analisadas para as bacias de $1^{\mathrm{a}}$ ordem....... 


\section{LISTA DE ABREVIATURAS E SIGLAS}

APC - Análise de Principais Componentes

CCZEE - Comissão Coordenadora do Programa ZEE Brasil

COO - Classificação Orientada ao Objeto

DTED - Digital Terrain Elevation Data

IBGE - Instituto Brasileiro de Geografia e Estatística

InSAR - Interferometric Synthetic Aperture Radar

LSIE - Laboratório de Sistemas de Informações Espaciais

MDE - Modelo Digital de Elevação

MMA - Ministério do Meio Ambiente

PZEE - Programa ZEE Brasil

SOM - Self Organized - Maps

SRTM - Shuttle Radar Topographic Mission

TCU - Tribunal de Contas da União

USGS - U. S Geological Service

UTB - Unidades Territoriais Básicas

WGS - World Geodetic System

ZEE - Zoneamento Ecológico-Econômico 


\section{RESUMO}

Este trabalho tem como objetivo propor subsídios a zoneamentos ambientais territoriais quanto à definição de parâmetros quantitativos, ligados à morfometria, para a construção das suas respectivas unidades homogêneas da paisagem, também chamadas de Unidades Territoriais Básicas (UTB). Terá como foco a proposição de subsídios para a elaboração da peça técnica de Zoneamento EcológicoEconômico (ZEE), no processo de delimitação de UTB a partir da classificação das bacias hidrográficas e de parâmetros morfométricos. Realizou-se a elaboração das UTB a partir da geomorfometria e da aplicação do modelo Hydrosheds por permitir uma análise quantitativa da superfície e o uso de modelagem espacial desde a concepção de seus limites. O estudo analisou os parâmetros morfométricos - orientação da bacia, área perímetro, eixo maior, eixo menor, índice de circularidade, altimetria, declividade e área de contribuição, e foi feita a combinação dos seus valores aos mapas indicados para a fase de delimitação das UTB. A construção das UTB foi feita mediante a classificação de bacias hidrográficas pela hierarquia de Strahler (1952), com o emprego do método de análise de grupos e o uso de atributos morfométricos. O presente trabalho obteve uma classificação de bacias de drenagem do Distrito Federal, a partir das seguintes etapas: (1) tratamento do produto Hydrosheds do SRTM; (2) delimitação automatizada de bacias; (3) cálculo dos atributos morfométricos; (4) classificação das bacias de drenagem a partir da técnica de análise de agrupamento (método de K-médias) e (5) proposta de incrementos ao processo de elaboração das UTB em ZEE, a partir dos atributos morfométricos. As UTB definidas possuem correlação com os atributos morfométricos e permitiram a definição de unidades da paisagem com base nesses atributos. A delimitação das UTB a partir dos limites das bacias hidrográficas demonstrou ser uma das possibilidades práticas para a integração dos ZEE com a PNRH, e permitiu a incorporação de dados quantificáveis já na fase de elaboração das unidades territoriais básicas. O método pode ser estendido a zoneamentos em diferentes escalas, como também em âmbito regional e local, e demonstra condições favoráveis para a sua incorporação na metodologia de elaboração de ZEE.

Palavras chave: zoneamento ambiental territorial, paisagem, bacias hidrográficas, morfometria. 


\begin{abstract}
This document aims to propose subsidies for conceptual modeling of spatial data used in producing the basic territorial unit (UTB) at territorial environmental zoning. From a proposal for UTB delimitation obtained by classification of watersheds and morphometric parameters, the analysis was made of the maps generated by Hydrosheds- model orientation of the basin perimeter area, major axis, minor axis, circularity index, altimetry, slope and contribution area - with the combination of their valuesto the maps given to the scoping stage of territorial units by then guiding document of the Ecological-Economic Zoning (ZEE), considered the main type zoning subsidiary territorial environmental management set up in Brazil today. This paper proposes the construction of UTB by rating watershed by Strahler hierarchy (1952), with the use of the method of analysis groups and the use of morphometric attributes. It is suggested the preparation of UTB from geomorfometria and application of HydroSHEDS model by allowing a quantitative analysis of the surface and the use of spatial modeling from design to its limits. This work aims to get a watershed classification of the Federal District, with the following steps: (1) treating the HydroSHEDS SRTM product; (2) automated delineation of watersheds; (3) calculation of morphometric attributes; (4) classification of watersheds from the cluster analysis (K-mean method) and (5) proposed increases to the process of preparation of UTB in ZEE, from morphometric attributes. The UTB have defined correlation with morphometric attributes and allowed to define landscape units based on these attributes. The limits of UTB from the watershed boundaries proved to be one of the practical possibilities for the integration of ZEE with $\mathrm{PNRH}$, and allowed the incorporation of quantifiable data already at the stage of territorial units. The method can be extended to zoning at different scales, as well as at regional and local level, favorable characteristic for their incorporation in the development of ZEE methodology.
\end{abstract}

Keywords: ecological-economic zoning, watershed, basic territorial units of analysis groups. 


\section{INTRODUÇÃO}

O acelerado processo de urbanização em países em desenvolvimento intensificou a modificação da paisagem tanto da área urbana como das demais que serviriam de fonte de recursos naturais (Qi \& Zhang, 2014). Dentre os efeitos, foram observadas mudanças nas tipologias de forma de relevo ocupada com a associação de diversos modos de degradação do ambiente (Canil, 2006). Tal fato tem contribuído para o aumento e magnitude dos impactos ambientais negativos (Hart, 1986).

O remodelamento da paisagem no decorrer dos últimos 10.000 anos, e em particular depois da Revolução Industrial, resulta do modo de organização e do exponencial aumento populacional, dos modos de produção e da necessidade de obtenção e uso de recursos naturais em larga escala. Os grandes centros urbanos mundiais fazem parte desse cenário, e apresentaram entre o final do século XX e início do século XXI os impactos resultantes, em maior ou menor escala, de acordo com o modelo de gestão territorial adotado, ou até então não instituído (Canil, 2006).

Devido à urgência de políticas que garantam a conservação e proteção da biodiversidade mundial, trabalhada no documento Agenda $21 \mathrm{Global}^{1}$, foram propostos tipos de zoneamentos voltados à gestão e planejamento ambiental territorial, e tem sido dado destaque no Brasil ao Zoneamento Ecológico-Econômico (ZEE). A proposta de adoção de ZEE visa orientar a mudança do modelo de desenvolvimento adotado até então, que apenas busca otimizar uma relação custobenefício favorável aos lucros a curto prazo, para um que considere os efeitos prejudiciais a médio e longo prazo, ao ambiente e à sociedade (Medeiros, 1999). Tal modelo preconiza uma relação sociedade-natureza baseada na integração harmônica entre o desenvolvimento socioeconômico à conservação da natureza.

O emprego de zoneamentos ambientais como instrumento orientador de ações e respostas rápidas dos agentes públicos à sociedade tem motivado a inclusão de parâmetros quantificáveis em análises ambientais, com a proposição de algoritmos e o emprego de modelagens (Wieland et al, 2011; Friedel, 2011). Estes zoneamentos ajudam não somente na elaboração de produtos geográficos que servirão de suporte à gestão de recursos hídricos e das respectivas bacias hidrográficas (Ketabchi \&Ataie-Ashtiani, 2015; Qin et al, 2011), como também no monitoramento e na gestão ambiental territorial (Segan et al, 2011; Gordon et al, 2011).

1 Elaborado na Conferência das Nações sobre o Meio Ambiente e Desenvolvimento Humano, conhecida como Eco-92, realizada em 1992, na cidade do Rio de Janeiro. 
Esse trabalho se propõe a discutir e propor subsídios a zoneamentos ambientais territoriais quanto à definição de parâmetros quantitativos, ligados à morfometria, para a construção das suas respectivas unidades homogêneas da paisagem, também chamadas de Unidades Territoriais Básicas (UTB), visando o incremento de melhorias na documentação e no processamento dos dados geográficos. Terá como foco a elaboração das UTB de ZEE, elaboradas na fase de diagnóstico físicobiótico, e por isso não será discutido o processo político e social que envolve a construção do ZEE (Ferreira, 2011; Souza, 2008; Matteo, 2007), logo, atendo-se somente ao contexto metodológico do instrumento.

Para isso, será feita a classificação de bacias hidrográficas do Distrito Federal utilizando a técnica de análise de grupos (método K-médias) a partir de parâmetros morfométricos, com os seguintes objetivos específicos:

- Identificar e analisar a correlação entre os parâmetros morfométricos;

- Classificar as bacias hidrográficas pelo método de agrupamento;

- Propor incrementos ao processo de elaboração das UTB em ZEE a partir dos atributos morfométricos. 


\section{FUNDAMENTAÇÃO TEÓRICA}

A proposta de zoneamentos oferece subsídios para o planejamento e à gestão territorial ao considerar as problemáticas observáveis e os desafios sociais e ambientais que podem ser cenarizados. Em áreas urbanas, Sussman \& Major (2010) definem o zoneamento como o principal método de regulação do uso do solo, pois dispõe condições para o ordenamento do território, fundamental para a realização de objetivos de adaptação, e é um veículo importante para melhorar a resiliência.

As análises e propostas de um zoneamento partem da visão sistêmica e das relações existentes entre homem-natureza. Segundo Tricart (1977) a análise sistêmica é o melhor instrumento lógico do qual se dispõe para o estudo dos problemas do meio ambiente, pois permite o uso de um conceito que é, essencialmente, de caráter dinâmico e por isso adequado a fornecer os conhecimentos básicos para uma atuação e gestão territorial. O seu emprego pode auxiliar na busca de melhores respostas dos governos conscientes às perguntas e inquietações da opinião pública. Para isso, Tricart (1977) propôs uma metodologia de estudo da dinâmica dos ecótopos, também chamada de ecodinâmica. O conceito de unidades ecodinâmicas é integrado ao conceito de ecossistema, dando enfoque às relações mútuas entre os diversos componentes da dinâmica e os fluxos de energia/matéria no meio ambiente.

Da concepção metodológica desenvolvida por Tricart foram elaborados outros métodos de zoneamentos ambientais, tais como os de Ross (1994) e Crepanni (1996), que foram posteriormente comparados por Spörl \& Ross (2004) na aplicação de modelos de análise da fragilidade ambiental.

As primeiras propostas de zoneamento registradas remontam ao século XVIII e eram voltados à regulação do uso do solo urbano quanto ao saneamento e à saúde da população, conforme avançava na Europa o processo de urbanização, a partir da consolidação da Revolução Industrial (Figueiredo, 2006). Tal contexto criou a necessidade do uso do zoneamento de forma mais sistemática, inicialmente com a organização da distribuição das atividades interurbanas, estendendo-se, a seguir, para o mundo rural, ligados ao ordenamento da agricultura e a delimitação de áreas para conservação (Del Prette \& Matteo, 2006).

De acordo com Santos (2004), o zoneamento significa: "...compartimentar uma região em porções territoriais, a partir de objetivos e parâmetros pré-definidos, com a avaliação dos atributos considerados mais relevantes e de suas dinâmicas". Deste modo, cada compartimento é apresentado como uma "área homogênea", com estrutura e funcionamento uniforme com alto grau de associação entre si, contendo variáveis interligáveis (Rempel et al, 2008). Ou seja, cada compartimento pode ser delimitado numa escala geográfica própria considerando seu desenho no território (Santos, 2004).

No caso de zoneamentos ambientais, que utilizam como base para a proposição de zonas a paisagem, a definição de qual conceituação de paisagem foi utilizada, indicará quais parâmetros 
foram ou não empregados e aqueles que ganharam destaque (Bastian, 2001). Torna-se possível a identificação de casos de zoneamentos que, apesar de a documentação de referência apontar a valoração da paisagem, suas respectivas zonas não apresentam similaridades espaciais à morfodinâmica da área estudada, o que traz prejuízos à proposição de requisitos para a gestão dos recursos naturais (NH-DES, 2008, pg.157).

Os mapas subsidiários e finais construídos no decorrer de um zoneamento sintetizam as análises e conclusões tomadas em seu processo de elaboração, alguns de modo mais claro e documentado do que outros. Zacharias (2006) elaborou uma proposta metodológica para a representação gráfica das unidades de paisagens, fundamentada no paradigma estruturalista (semiologia gráfica), com a definição de um "layout" modelo, na tentativa de contribuir na sistematização da cartografia empregada em Zoneamentos Ambientais. Em seu trabalho observou-se que as incompatibilidades visuais muitas vezes refletem a falta de clareza acerca da fonte primária para a proposição do mapa, isto é, os respectivos dados finais produzidos pelo zoneamento.

A falta de detalhamento metodológico para o processamento dos dados para a delimitação de zonas e análises acaba por fragilizar toda a base de dados geográficos. Conforme Williamson (1991), as características dos dados geográficos, que não são registradas na maioria dos outros sistemas de informação, impõem barreiras à implementação das aplicações de SIG. Dentre essas características estão a grande variedade de métodos de aquisição de dados, a diferença de acurácia apresentada pelos conjuntos de dados, a falta de uma codificação adequada dos elementos modelados, a ocorrência de coberturas de dados esporádicas, a necessidade de dados temporais e a incompatibilidade entre os conjuntos de dados.

Os mapas e dados espaciais gerados em zoneamentos ambientais são utilizados em diferentes áreas do governo e da sociedade civil, o que deveria motivar uma maior padronização e detalhamento metodológico e documental. Assim poderá ser incrementada maior fluência dos dados ${ }^{2}$ e mapas (Jukes et al, 2010), bem como entendimento dos objetivos principais e das particularidades do zoneamento. Caso incorporado ao processo de organização e documentação do banco de dados geográficos do zoneamento a descrição da metodologia e das ferramentas de geoprocessamento usadas, o entendimento da proposta de zonas se torna mais claro, no que se refere à qualidade $\mathrm{e}$ consistência. Isto favorece também a estruturação de um sistema de dados geográficos de modo integrado, com instâncias e relacionamentos espaciais melhor definidos (Güting, 1994).

As diretrizes do ZEE propõem a definição de unidades homogêneas da paisagem como pontapé inicial para o diagnóstico físico-biótico da área em estudo, tendo maior destaque a paisagem

\footnotetext{
2 Segundo Jukes et al (2010), fluência de dados significa compreender as capacidades, mas também as limitações dos dados.
} 
na definição das técnicas e modelagens a serem usadas para a delimitação das UTB. 


\subsection{CATEGORIAS GEOGRÁFICAS E ZONEAMENTOS TERRITORIAIS}

O emprego de conceitos e categorias geográficas possibilitam melhores condições para uma análise integrada dos aspectos ambientais e socioeconômicos, o que favorece a base conceitual dos dados gerados, desde a delimitação de zonas. Para Sanchez (1995) o ato de zonear o território corresponde a um conceito geográfico de regionalização que significa desagregar o espaço em zonas ou áreas que delimitam algum tipo de especificidade ou alguns aspectos comuns.

Entende-se que os conceitos e categorias da Geografia auxiliam a formulação conceitual e a discussão metodológica de zoneamentos territoriais (Kerski, 2015). Estudos que combinem a epistemologia da Ciência Geográfica ao uso do geoprocessamento contribuem para avanços tanto das bases conceituais como das técnicas e processamentos utilizados (Silva \& Santos, 2004), gerando condições propícias para possíveis revisões metodológicas.

Um dos pontos primordiais para reflexão dos que estudam o território, e consequentemente, atuam na elaboração e análise de políticas de gestão pública é a compreensão das categorias e conceitos geográficos inerentes ao estudo (Morphet, 2014). E para isso, vale considerarmos a tríade das categorias de representação e de construção gráfica das análises geográficas: espaço, território e paisagem.

O uso do conceito espaço direciona para a compreensão do todo; é a categoria por intermédio da qual se busca apreender os movimentos do todo (Moreira, 2008). Câmara et al (2003), buscou entender as diferentes concepções de espaço, o alcance e a abrangência para cada uma destas concepções; comparou-as com as representações computacionais possíveis, em ambiente SIG, e buscou indicar as diferentes possibilidades à época.

Também tradicionalmente conceituado pela geografia, a categoria território também é trabalhado pela ciência política, sociologia, economia, biologia, antropologia, psicologia e mais recentemente pela Ciência da Informação. Na Ciência Política o termo é conceituado quanto ao território estatal; pela Economia, situado como base da produção; na Biologia, descreve o território animal; na Sociologia, trata sobre a sua construção a partir de relações sociais; pela Antropologia, por meio da discussão de sua dimensão simbólica a partir do estudo de comunidades tradicionais e pela Psicologia quando debatidos os fatores abstratos da busca de identidade pelo indivíduo (Haesbaert, 2009, p.37). O uso do termo tem sido aplicado na discussão dos territórios digitais que trata das diferentes representações da realidade geográfica num ambiente computacional (Câmara et $a l, 2005)$, logo, sua discussão é aproximada com a geografia.

Em geral, a geografia busca estudar as relações espaço e poder entre Estados ao discutir o conceito território (RAFFESTIN, 1993; SANTOS, 2002), em alguns trabalhos aparecem com destaque as lutas histórico-geográficas pela expansão de fronteiras nacionais (ANDERSON, 1996) e 
a corrida entre países pelo domínio sob outras nações segundo a lógica econômica instituída (HARVEY, 2003; CECEÑA et al, 2007).

A palavra território vem do latim territorium, que significa pedaço de terra apropriado, logo, tem desde a sua origem caráter político. Segundo Fernandes (2008) é insuficiente à compreensão do território a partir somente de sua concepção como um espaço de governo. Para Becker (2008) território é entendido como o espaço da prática, e tem como base o contexto de luta pelo poder, que é observável através das territorialidades ${ }^{3}$. É também um produto usado e vivido pelos atores como meio para sua prática (RAFFESTIN, 1980). Já a territorialidade humana é uma relação com o espaço que tenta afetar, influenciar ou controlar ações por meio do reforço de controle sobre uma área geográfica específica, o território (SACK, 1986).

Já a noção de paisagem, a ser mais utilizada neste trabalho, teve sua origem como categoria científica na Geografia. No caso da formulação do conceito, existem variações de acordo com a sua origem, que engloba características estáticas e dinâmicas em seus aspectos naturais como culturais (Martins et al, 2004).

$\mathrm{Na}$ Geografia o conceito de paisagem é estudado sob diferentes ênfases, mas todas consideram a relação dinâmica de elementos físicos, biológicos e antrópicos (Coelho, 2010). A escola alemã e a francesa enfatizam diferentes aspectos da paisagem. A geografia alemã, devido a sua herança naturalista desde Humboldt, buscou enfatizar a elaboração de estudos em grande escala cartográfica, visando diagnosticar as problemáticas que envolvem as fragilidades e o melhor uso das potencialidades encontradas na paisagem, bem como o estabelecimento de uma sistematização de informações e bases de dados utilizadas em seus estudos (Coelho, 2010). A escola francesa desenvolveu observações quanto à região, formada pelas culturas e sociedades em cada espaço natural. SAUER (1998) considera que região e área são, em certo sentido, termos equivalentes a paisagem.

O termo foi frequentemente empregado com o sentido mais aproximado de forma de relevo (em inglês Landform) e utilizado na caracterização fisiográfica, geológica e geomorfológica da crosta terrestre (Naveh; Leberman, 1984 in Martins etal, 2004). O espaço geográfico é assim constituído de diversas unidades de paisagem ou land units que retratam de forma integrada certas particularidades climáticas, geológicas, geomorfológicas, pedológicas, da cobertura vegetal, do uso da terra e socioeconômicas, diferenciáveis do seu entorno (Zonneveld, 1972; Ross, 1995).

Por meio de procedimentos operacionais com a denominação genérica de land systems é utilizado como referencial os padrões fisionômicos do terreno (padrões de paisagens ou unidades de paisagens) e, consequentemente são gerados produtos temáticos analítico-sintéticos (Medeiros,

3 A concepção da autora foi a base para a elaboração das diretrizes metodológicas do ZEE, tendo sido Eagler também um de seus formuladores. 
1999). Cavalcanti \&Viadana (2007, p.25-30) enquadram o estudo da paisagem como a essência para o conhecimento da base natural do meio ambiente, que é o insumo para a construção de zoneamentos ambientais. Os autores afirmam que seus métodos de análise evoluíram devido à necessidade de um conhecimento e compreensão mais seguros e dignos de confiança, o que favoreceu a construção de fundamentos metodológicos sólidos, muito úteis na elaboração do planejamento e gestão ambiental.

Conforme Bastian (2001) o emprego do conceito paisagem implica na integração dos componentes ambientais e sociais, considerando as relações recíprocas Homem-Meio em todas as esferas e dimensões (Lang, 2009). A concepção do termo não foi unificada por razões históricas, geográficas e biológicas, além de diferenças entre ciências e aplicações (Bastian, 2001) ${ }^{4}$, e sofreu alterações de conotação ao longo do tempo que, no caso das ciências sociais, apresentaram forte vínculo com o conceito território.

Sussman \& Major (2010) apontam que zoneamentos elaborados segundo critérios ambientais ou não, provocam mudanças a uma proporção crescente de áreas quanto ao uso da terra, e por isso não podem ter um impacto tão imediato como outras medidas de contenção legal. Leis de zoneamento geralmente orientam a valoração dos preços da terra (Netusil, 2003), o que torna a definição das zonas um processo com forte influência política em suas fases de debate (Boyle \& Kiel, 2001). Logo, a proposta de zonas a partir de critérios somente ambientais, como são as UTB, necessitam de clareza metodológica e de uma documentação que descreva as regras para os processamentos utilizados na geração dos produtos cartográficos, para que a mesma seja desde a sua concepção orientada por preceitos técnicos, segundo fundamentos comprovadamente ambientais.

A construção gráfica das unidades de paisagem ocorre conforme uma determinada percepção conceitual de paisagem, mas nem sempre os mapas traduzem os limites teóricos da proposta e são utilizados respeitando tal fim (Laurini \& Thompson, 1999; Zacharias \& Freitas, 2008). Além disso, Forman (1995) declara que na natureza não existem limites ou barreiras absolutas, somente filtros. As unidades de paisagem possuem limiares de diferenciação, sem rupturas abruptas das interconexões e do grau de dependência entre elas, e a proposição de limites nem sempre é baseada em situações tão perceptíveis nas dimensões horizontal e vertical, como ilustrado na Figura 1.

Qin et al (2001), por exemplo, propõem o emprego de um sistema dinâmico de modelagem ambiental hídrica (SyDWEM) que integra à gestão hídrica áreas urbanas e rurais, em casos de rápido processo de urbanização e, que por isso, demandam a análise constante e combinada de parâmetros ambientais e socioeconômicos.

\footnotetext{
$4 \quad$ Para o autor há também a fragmentação na análise, pois paisagem não se reduziria a apenas um somatório de geofatores, mas uma integração que forma um complexo geográfico, ou geossistema.
} 


\subsection{DELIMITAÇÃO DA PAISAGEM E BACIAS HIDROGRÁFICAS.}

A análise e delimitação de unidades da paisagem são consideradas ponto de partida por diferentes tipos de zoneamentos, mas a consideração de uma unidade estrutural para o entendimento da formação e da dinâmica da paisagem, como o é a bacia hidrográfica, não foi feita em suas respectivas metodologias de trabalho. $\mathrm{O}$ tratamento da bacia hidrográfica como unidade espacial é de aceitação universal, e tem sido utilizada em diversas análises de vulnerabilidade ambiental e em propostas de zoneamentos ambientais em porções urbanas (Fedeski \& Gwilliam, 2007), rurais (Lippe et al, 2011; Chagas, 2001; Sediyama et al, 2001), especialmente em países em desenvolvimento, considerados mais vulneráveis a desastres naturais (Alcántara-Ayala, 2002).

A seleção da bacia hidrográfica como área de estudo para avaliação ambiental da paisagem é presente em pelo menos um ato legal - a Resolução CONAMA (Conselho Nacional de Meio Ambiente) 001/86, que em seu artigo $5^{\circ}$, inciso III, declara:

“[...] devem-se definir os limites da área geográfica a ser direta ou indiretamente afetada pelos impactos, denominada de área de influência do projeto, considerando, em todos os casos, a bacia hidrográfica na qual se localiza".

De fato, o marco legal que define a bacia hidrográfica como unidade territorial de gestão foi a lei federal $n^{\circ}$ 9.433/97, em seu artigo $1^{\circ}$, inciso V, que institui a Política Nacional de Recursos Hídricos. Além disso, também foram constituídas, nesta lei, diretrizes gerais para a implementação da PNRH que indiretamente propõem a utilização de tipologias de zoneamentos. No caso o ZEE, instrumento de gestão da política nacional do meio ambiente, o Plano Nacional de Ordenamento Territorial (PNOT), instrumento de ordenamento territorial federal e o Plano Diretor, instrumento de planejamento e gestão municipal do uso do solo, estão indiretamente relacionados à proposta da PNRH quando observamos o artigo $3^{\circ}$, em seus incisos:

$$
\begin{array}{r}
\text { III - a integração da gestão de recursos hídricos com a gestão ambiental; } \\
\text { IV - a articulação do planejamento de recursos hídricos (...) com os planejamentos } \\
\text { regional, estadual e nacional; } \\
\text { V - a articulação da gestão de recursos hídricos com a do uso do solo; [...] }
\end{array}
$$

Para Silva \& Santos (2004), entre os principais tipos de abordagem para zoneamento - álgebra booleana e análise multivariada -, o segundo mostra-se mais promissor para a integração de dados, sendo as zonas melhor qualificadas e quantificadas pelas técnicas de agrupamento, também chamada de análise de grupos, e análise de correspondência. 
BOUNDARIES AND EDGES

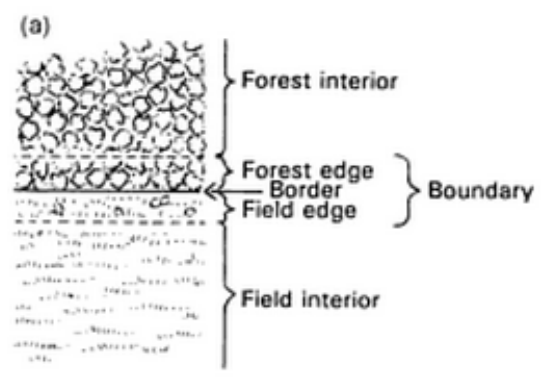

(b)

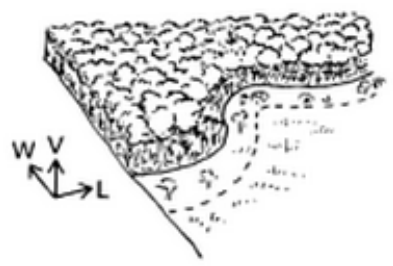

Fig. 3.4. Spatial relationships of boundary, border, and edges. Adapted from Formon \& Moore (1992). W = width dimension of edge; $V=$ vertical; $L=$ length.

Figura 1: Exemplo de delimitações da paisagem (Forman, 1995).

\subsection{ORIGENS E TIPOLOGIAS DE ZONEAMENTOS AMBIENTAIS}

A origem do zoneamento remonta ao ano de 1870, vinculado ao chamado Movimento de Reforma Urbana, iniciado simultaneamente na Europa e nos Estados Unidos. Esse movimento buscava atacar os impactos sociais negativos relacionados às condições e localizações das moradias dos operários, das indústrias e dos edifícios, através da visão de cidade (Logan, 1976; Borges, 2007; Topalov, 1996). Borges (2007) afirma que o zoneamento teve sua gênese no mesmo período do movimento intelectual e profissional chamado de Planejamento Urbano ou Urbanismo, que representou uma reação contra os males produzidos pela cidade do século XIX (Figura 2).

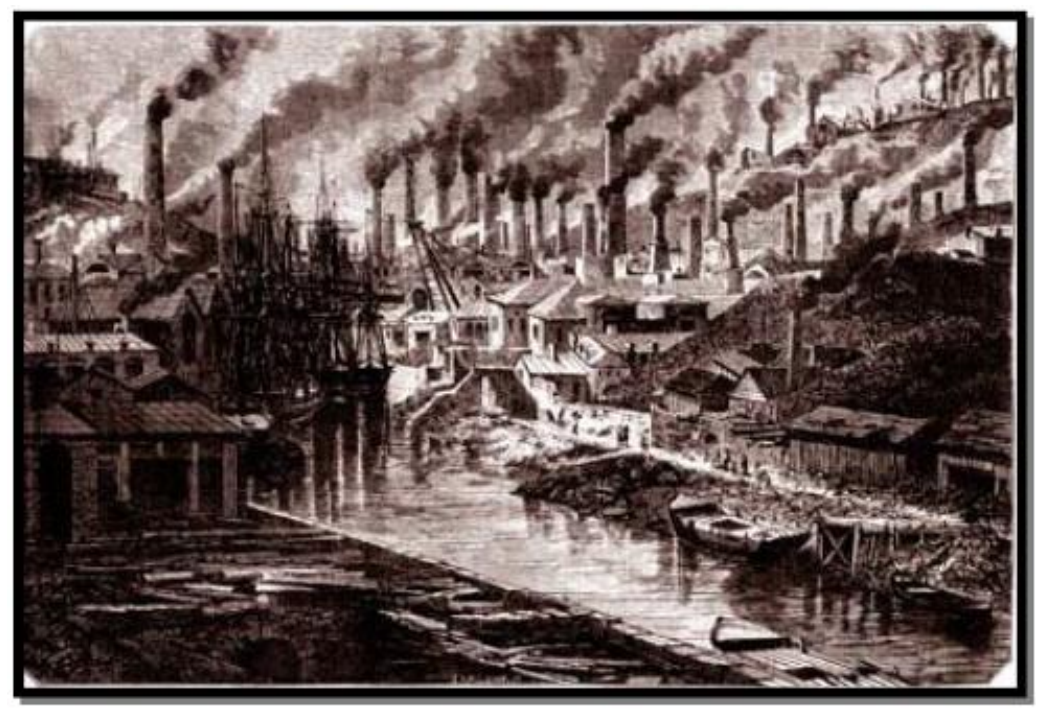

Figura 2: Foto da Londres Vitoriana (Fonte: Pintura de Gustave Doré 1869-71)

Leis de zoneamento foram estabelecidas em algumas localidades, determinando tipos e densidades de uso da terra, atingindo em maior ou menor grau os potenciais impactos ao meio 
ambiente e à saúde da população. Neste contexto, o modelo de zoneamento foi importado pelo Departamento de Comércio dos Estados Unidos um pouco antes dos anos de 1920 (Toll, 1969; Liebmann, 1966), mais precisamente para a cidade Nova York, como uma resposta à demanda popular por melhorias na qualidade de vida. Portarias semelhantes também foram implementadas em outras cidades americanas no mesmo período, em que se propunha quatro tipos de classes homogêneas quanto ao uso da terra: residencial, comercial, industrial e usos especiais.

Alguns zoneamentos geraram alguns efeitos contrários ao esperado pela população mais carente. Como exemplo, citamos o zoneamento da cidade de Nova York fora concebido como um meio de proteger a população através da retirada de usos da terra considerados "incompatíveis", e a imposição de mecanismos para a limitação ao mercado imobiliário quanto à densidade e altura dos prédios (Mantaay, 2002). No entanto, segundo a autora, o zoneamento serviu para segregar grandes categorias de uso da terra, tais como residencial, comercial e industrial, como também definir espaços de controle. Ou seja, foi um meio de segregação de minorias por restringir as opções de localização das moradias dos pobres e dos menos desejáveis.

Leite (1991) define que o zoneamento do território, indiretamente, é um instrumento de apropriação seletiva do espaço, pois ao caracteriza-lo, definindo suas formas de uso, estará beneficiando tão-somente aqueles que possuem condições de arcar com tais determinações. Por suas proposições básicas infere-se, ainda, que as populações locais, devido suas tradições regionais e/ou por baixa renda, possuem dificuldades de cumprir com o estabelecido pelo resultado do processo de zoneamento.

Para o planejamento e gestão do estado de Nova Iorque, Sussman \& Major (2010) elaboraram um estudo que aponta as bases legais para a execução de esforços de adaptação do uso da terra e aos padrões de consumo e de gestão das águas pluviais frente às mudanças climáticas, visando promover adaptação, redução da vulnerabilidade, aumento da resiliência, permitindo assim a efetiva preparação do governo nova-iorquino para desastres, a partir de leis e de um zoneamento adequado. Jepson \& Haines (2014) apontaram, a partir da análise de 32 experiências de zoneamentos nos Estados Unidos, o uso de 9 princípios de sustentabilidade inseridos nos casos avaliados, mas com grande variação e razoável consistência na abordagem das metas de sustentabilidade. Tal contexto, segundo os autores, exigirá dos planejadores melhorias na consideração dos aspectos ambientais para um maior incremento de metas para o desenvolvimento sustentável de sua comunidade.

Segundo Mancuso (1998), a Alemanha construiu uma proposta mediante a espacialização dos conflitos econômicos e sociais identificados. As zonas eram definidas com usos múltiplos, sendo instituído pelo governo federal, segundo a capacidade de suporte dos chamados "system units", reordenando também os usos considerados incompatíveis na área zoneada. Já a proposta americana era feita apenas para a identificação de tipos de uso e ocupação. O zoneamento americano 
indiretamente acabava por orientar o preço da terra, gerando forte especulação imobiliária. Apesar dos efeitos à população mais desfavorecida quanto à moradia, e além de não atacar os principais efeitos ambientais na área circundante da cidade, decorrentes da rápida urbanização, sua concretização foi considerada positiva à época, como descrito por Babcok (1966):

"The result is a view of zoning in the United States as a frighteningly successful record of protecting the single-family unit pattern of suburbia (including its complementary facilities for one-stop shopping, "convenience services", private recreation and amenity) and enticing prestige industry to locate where it will help the municipal tax base, but an ominously unsuccessful record of facing up to the consequences of this result on the future growth of the communities most directly involved, and the problems of the larger surrounding region relating to transportation, public open space and recreational needs, pollution of air and water, and most other major public facilities. "(Babcok, 1966, p.131)

Hirt (2007) fez uma comparação entre as abordagens de regulação de uso da terra na Alemanha e nos Estados Unidos estabelecidas a partir do zoneamento. A abordagem americana assume apenas um tipo de atividade humana por zona, já a alemã demonstra considerar como mais adequado o uso múltiplo, com vários tipos de atividade em cada zona, em bases sustentáveis, o que fez o autor concluir que o método de concepção e aplicação entre eles se diferem. O autor afirma que os diferentes tipos de uso de modo sustentável, observáveis no método alemão, oferece maiores possibilidades e alternativas de adaptação, tão necessários em zoneamentos de uso. Disto, podemos observar como o modo de elaboração, as concepções orientadoras e o contexto social tornam propostas de zoneamento tão diferenciáveis (Grant, 2002).

Um tipo de zoneamento ambiental a se considerar é o Zoneamento Marinho Funcional (MFZ) que se refere a divisão de áreas de espaço de mar (incluindo ilhas) em diferentes zonas funcionais. Segundo Fang et al (2011) o Marine Functional Zoning (MFZ) é a ferramenta fundamental para a regulamentação da utilização de áreas marítimas, a proteção do ambiente marinho, e promoção do uso racional e sustentável dos mares territoriais (TS) e Zona Econômica Exclusiva (ZEE) da China. A Zona Funcional é definida como uma área marítima designada para as atividades humanas com base nas suas características geográficas e ecológicas, recursos naturais, uso atual e as necessidades de desenvolvimento socioeconômico. É a menor unidade espacial de zoneamento funcional marítimo (Dong et al, 2006).

Nos últimos 10 anos, várias iniciativas de planejamento espacial marinho com o uso do MFZ foram realizados em vários países da Europa (Reino Unido, Holanda, Alemanha e Bélgica), América do Norte (Estados Unidos e Canadá), e na Austrália. A ideia era estimulada inicialmente pelos interesses nacionais no desenvolvimento de áreas marinhas protegidas (Fang et al, 2011). 
Recentemente, no entanto, foi dado ao MFZ maior atenção para a gestão dos vários usos do espaço marinho, especialmente em áreas com claros conflitos entre os setores de desenvolvimento e ambientais (Douvere, 2008). No contexto asiático podemos observar a experiência da China, que segundo Fang et al (2011) implementou o MFZ há mais de 20 anos e este é um importante sistema para a gestão do uso do mar em território chinês.

Para uma visão panorâmica de todos os tipos de zoneamento ambientais territoriais pesquisados, tendo ênfase os que de se observa forte vínculo ao conceito de paisagem para a delimitação de suas respectivas zonas, foi elaborada a Tabela 01.

$\mathrm{O}$ conceito de zoneamento ambiental no Brasil tem normalmente dois principais enfoques (NITSCH, 1998; SAE/PR, 2000; MILLIKAN \& PRETTE, 2000). O primeiro enfoque tem um caráter mais técnico e indicativo, elaborado para orientar o planejamento agrícola sob a forma dos zoneamentos agroecológicos ou agrícolas. Este formato de zoneamento ambiental subsidia o agricultor em suas decisões de investimento, ou o setor público no que concerne à concessão de créditos para a agricultura (NITSCH, 1998; SAE/PR, 2000), com base no estudo da aptidão dos solos e do clima de uma dada área para diversos tipos de cultura, ou, focado na identificação das áreas mais adequadas para uma determinada cultura. Já o segundo enfoque é voltado à regulação do uso do solo urbano, que se consubstancia, geralmente, em instrumentos legais e normativos. Nestes tipos de zoneamentos ambientais o território é dividido em parcelas nas quais se autorizam determinadas atividades ou se interdita, de modo absoluto ou relativo, o exercício de outras atividades (MACHADO, 1992, p. 96).

Alguns zoneamentos são instituídos legalmente e outros são peças técnicas que auxiliam a análise do território pelos tomadores de decisão. Como experiências internacionais que incluem zoneamentos ambientais ao planejamento espacial do território podemos citar o que considera todos os países membros da União Europeia (Albrechts et al,2003), como os específicos da Alemanha (Pahl-Weber \& Henckel, 2008); e da França, que incorpora modelagens e simulações aos zoneamentos voltados à produção agrícola (Deffontaines, 1976).

Pesquisas ligadas à gestão e planejamento ambiental sugerem a necessária adaptação dos regimes de gestão da água, seja em áreas rurais como urbanas, pois os atualmente utilizados não podem responder adequadamente a incertezas de capacidade de suporte (Brugge \& Raak, 2007). No decorrer da última década, por exemplo, a Europa passou por uma quantidade maior de inundações, fato diretamente associado às mudanças do clima, mas também aos padrões de uso da terra em áreas de várzea (Gleick, 2003). Isso indica a necessária inclusão de políticas mediante ações de transição transition management- e de adaptação - adaptive management- para a gestão das águas do continente europeu (Brugge \& Raak, 2007). 


\begin{tabular}{|c|c|c|c|c|c|}
\hline TIPO DE ZONEAMENTO & CONCEITUAÇÃO & OBJETIVO & DELIMITAÇÃO GRÁFICA & INSTITUCIONALIDADE & EMPREGO \\
\hline AMBIENTAL & $\begin{array}{l}\text { SÁNCHEZ E SILVA (1995, } \\
\text { P.47-50) }\end{array}$ & $\begin{array}{c}\text { AVALIACCÃO DOS SISTEMAS } \\
\text { AMBIENTAIS A PARTIR DE UM ESTUDO } \\
\text { TRANSDISCIPLINAR. }\end{array}$ & UNIDADES DA PAISAGEM & BR: PNMA (LEI No 6.938 DE 31/08/1981) & DIVERSIFICADO \\
\hline ECOLÓGICO & PIVELLO ET AL.(1998) & INDICAR FRAGILIDADES AMBIENTAIS & UNIDADES DA PAISAGEM & BR: LEI No 9.985 DE 18/07/00 & $\begin{array}{c}\text { CRIAÇÃO DEUNIDADES DE } \\
\text { CONSERVAÇÃO }\end{array}$ \\
\hline ECOLÓGICO-ECONÔMICO & CREPANI (1996) & $\begin{array}{c}\text { ORIENTAR A GESTÃO AMBIENTAL } \\
\text { TERRITORIAL }\end{array}$ & $\begin{array}{l}\text { UNIDADES TERRITORIAIS BÁSICAS } \\
\text { (PAISAGEM); UNIDADES TERRITORIAIS DE } \\
\text { PLANEJAMENTO/GESTÃO (TERRITORIAL) }\end{array}$ & $\begin{array}{l}\text { BR:PNMA (LEI No } 6.938 \text { DE 31/08/1981); } \\
\text { MODIFICADO PELA LEI No XXX }\end{array}$ & $\begin{array}{l}\text { LICENCIAMENTO AMBIENTAL; CRIAÇÃO } \\
\text { DE UNIDADES DE CONSERVACCÃO); } \\
\text { POLÍTICAS DE CRÉDITO RURAL;GESTÃO } \\
\text { AMBIENTAL TERRITORIAL. }\end{array}$ \\
\hline COSTEIRO & OGATA (1996) & GERENCIAMENTO COSTEIRO. & $\begin{array}{l}\text { UNIDADES AMBIENTAIS HOMOGÊNEAS; } \\
\text { ZONAS DE USO; SETORES COSTEIROS. }\end{array}$ & BR: LEI 7.661/81; DECRETO 5.300/2004 & LICENCIAMENTO AMBIENTAL. \\
\hline AGROECOLÓGICO & SÁNCHEZ (1991) & $\begin{array}{l}\text { SUSTENTABILIDADE AMBIENTAL E } \\
\text { ECONÔMICA DO MEIO RURAL E } \\
\text { FLORESTAL }\end{array}$ & ZONAS DE APTIDÃO AGROECOLÓGICA & $\begin{array}{l}\text { BR: ZAE CANA-DE-ACCÚCAR } \\
\text { (DEC. No6961 DE 17/09/09); } \\
\text { ZAE CULTURA DE PALMA } \\
\text { (DEC. № } 7.172 \text { DE 07/05/2010); }\end{array}$ & $\begin{array}{l}\text { POLÍTICAS DE FINANCIAMENTO } \\
\text { AGRÍCOLA. }\end{array}$ \\
\hline AGROFLORESTAL & $\begin{array}{l}\text { FRANKE ET AL (1998a; } \\
1998 \mathrm{~b}) \\
\text { EMBRAPA (2000) }\end{array}$ & $\begin{array}{l}\text { EVITAR O ÊXODO RURAL } \Rightarrow \text { GERAÇÃO } \\
\text { DE EMPREGO E RENDAMUDANCCA NO } \\
\text { MODELO DE DESENVOLVIMENTO }\end{array}$ & $\begin{array}{l}\text { ZONAS DE APTIDÃO AGROFLORESTAL } \\
\text { (preferencial; restrita, não-indicada) }\end{array}$ & BR: NÃO PREVISTO EM LEI. & $\begin{array}{c}\text { IMPLANTAÇÃO DE PÓLOS } \\
\text { AGROFLORESTAIS (PLANEJAMENTO DE } \\
\text { USO E DE OCUPAÇẪO). }\end{array}$ \\
\hline CLIMATICO & $\begin{array}{l}\text { GRIFFITH (1989); } \\
\text { RANIERI (2000); }\end{array}$ & GESTÃO ENERGÉTICA & ZONAS DE CLIMA HOMOGÊNEO & $\begin{array}{l}\text { EUROPA: European Directive 2002/91/EC } \\
\text { NÃO PREVISTO EM LEI BRASILEIRA. }\end{array}$ & $\begin{array}{c}\text { CERTIFICACC̃̃O DE DESEMPENHO } \\
\text { ENERGÉTICO DOS EDIFÍCIOS (CONTEXTO } \\
\text { EUROPEU) } \\
\end{array}$ \\
\hline URBANO & FAZANO (2001) & $\begin{array}{l}\text { IMPLANTAÇ̃̃O DE PLANOS DE } \\
\text { USO DO SOLO }\end{array}$ & ZONAS POR CATEGORIAS DE USO & $\begin{array}{l}\text { BR: INCORPORADO EM } \\
\text { INSTRUMENTOS COMO O PLANO } \\
\text { DIRETOR. }\end{array}$ & $\begin{array}{l}\text { LEGISLAÇ̃̃O PARA O USO E OCUPAÇÃO } \\
\text { DO SOLO URBANO MUNICIPAL } \\
\text { (SUBSÍDIO AO PLANO DIRETOR) }\end{array}$ \\
\hline $\begin{array}{c}\text { AGRíCOLA }^{6} \\
\text { OUAGROCLIMÁTICO OU } \\
\text { AGRÍCOLA DE RISCO } \\
\text { CLIMÁTICO }\end{array}$ & SEDIYAMA ET AL (2001) & $\begin{array}{l}\text { MINIMIZAÇÃO DE PERDAS NA } \\
\text { PRODUÇÃO AGRÍCOLA }\end{array}$ & $\begin{array}{l}\text { ZONAS APTAS E INAPTAS } \\
\text { (CRITÉRIOS ECOLÓGICOS, POR CULTURA). }\end{array}$ & BR: PORTARIAS DO DOU ${ }^{7}$. & POLÍTICA AGRÍCOLA. \\
\hline AGROPEDOCLIMÁTICO & CHAGAS ET AL. (2001) & MANUTENÇÃO DA BIODIVERSIDADE & $\begin{array}{l}\text { ZONAS (ÉPOCA DE SEMEADURA DAS } \\
\text { CULTURAS, SEGUNDO VARIÁVEIS } \\
\text { CLIMÁTICAS E APTIDÃO DOS SOLOS) }\end{array}$ & BR: NÃO PREVISTO EM LEI. & ASSISTÊNCIA TÉCNICA RURAL. \\
\hline GEOAMBIENTAL & $\begin{array}{c}\text { BRASIL (1984) } \\
\text { TEORIA DOS SISTEMAS }\end{array}$ & $\begin{array}{c}\text { POTENCIALIDADES, RESTRIÇÕES E } \\
\text { PROBLEMAS (LIMITES MÁX. PARA } \\
\text { EXPLORAÇÃO RACIONAL) } \\
\text { BUSCA PELA ESTABILIDADE DINÂMICA }\end{array}$ & UNIDADES GEOAMBIENTAIS & BR: NÃO PREVISTO EM LEI. & $\begin{array}{l}\text { CONCESSÃO DE ÁREAS PARA } \\
\text { PROSPECÇÃO MINERAL }\end{array}$ \\
\hline EMPREENDIMENTOS & $\begin{array}{l}\text { GRIFFITH (1989); } \\
\text { RANIERI (2000); }\end{array}$ & $\begin{array}{l}\text { LOCAÇÃO DE EMPREENDIMENTOS } \\
\text { (REDES, GASODUTO, ATERRO } \\
\text { SANITÁRIO, INDÚSTRIA, ETC) }\end{array}$ & ZONAS APTAS/INAPTAS & BR: NÃO PREVISTO EM LEI. & $\begin{array}{l}\text { INDICAÇ̃̃o DE ÁREAS PROPí́CIAS E DA } \\
\text { INFRAESTRURA NECESSÁRIA. }\end{array}$ \\
\hline
\end{tabular}

Tabela 1 - Síntese dos zoneamentos analisados em que, podemos verificar o forte vínculo do conceito de paisagem.

${ }_{6}^{5}$ Outros ZAE foram elaborados, porém não instituídos por instrumento legal. 
As propostas de zoneamentos ambientais são utilizadas como suporte ao planejamento e gestão territorial de acordo com as problemáticas observáveis, aos tipos de uso da terra empregado ou de interesse. Também são utilizados para indicar cenários quanto aos potenciais efeitos ao ambiente natural e à população conforme a manutenção ou mudanças na dinâmica de uso e exploração do território. Eles têm contribuído para a definição de políticas e estratégias de conservação e de recuperação em todo o mundo. Zoneamentos ambientais são elaborados com objetivos estratégicos voltados para (Froger \& Méral, 2012):

a) O uso e cultivo de atividades econômicas, tendo um alcance que auxilie o gerenciamento dos recursos de financiamentos agrícolas;

b) Adoção de melhorias no padrão de uso da terra a partir da compreensão das fragilidades e vulnerabilidades naturais;

c) Para a gestão de conflitos territoriais que envolvem questões fundiárias e histórico-culturais, considerando o amparo jurídico-institucional presente na área de estudo;

d) A gestão de riscos e projeção de cenários, relacionados à questão de mudanças climáticas e eventos extremos (enchentes, desmoronamentos de terra, terremotos, dentre outros), bem como no que se refere a gestão territorial em áreas com empreendimentos industriais (levantamento e monitoramento de riscos de contaminação, proposição e análise da rede logística, etc).

A construção dos zoneamentos ambientais costuma integrar objetivos estratégicos, que orientarão a elaboração de propostas com um caráter mais técnico ou político (Figura 3).

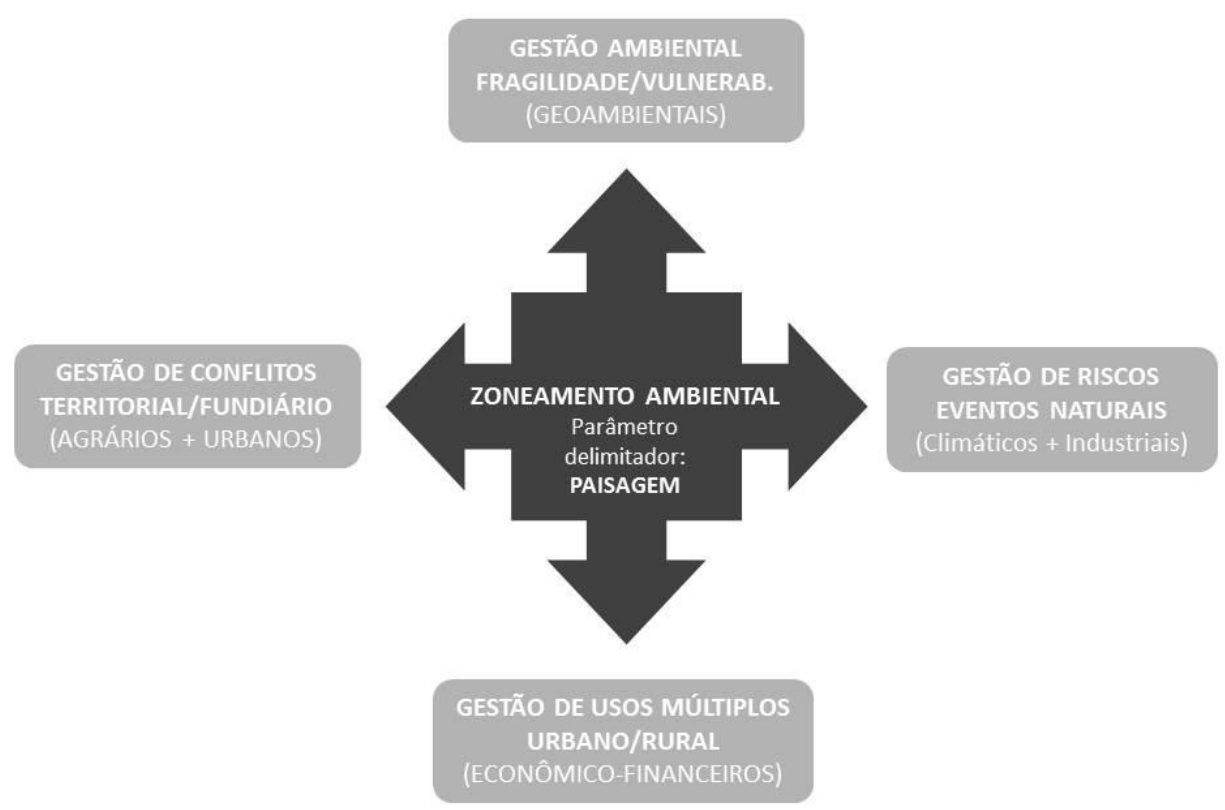

Figura 3: Objetivos estratégicos de zoneamentos ambientais. 
Metodologias de tratamento de dados espaciais em zoneamentos ambientais são estabelecidas tendo como fatores motivadores à otimização dos processos, participação social, melhorias no uso e na elaboração dos dados e dos respectivos produtos finais (Lippe et al, 2011). Um dos principais produtos gerados em zoneamentos ambientais são as unidades da paisagem ou unidades territoriais básicas, que representam cartograficamente a base conceitual e metodológica de construção do zoneamento realizado.

\subsection{ZEE E A GESTÃO AMBIENTAL}

O Zoneamento Ecológico-Econômico (ZEE), coordenado pelo Programa ZEE Brasil (PZEE) e elaborado primeiramente nos limites da Amazônia Legal, foi expandido para todas as regiões brasileiras, e em diferentes escalas (MMA, 2001). Foi instituído no âmbito da Política Nacional do Meio Ambiente (PNMA) através da lei federal $n^{\circ}$ 6.938/1981 e regulamentado através da lei federal $\mathrm{n}^{\circ} 7.661 / 1988$ como um dos instrumentos para a sua execução.

O ZEE esteve sob a coordenação da Secretaria de Assuntos Estratégicos (SAE) da Presidência da República, passando a ser coordenado pelo Ministério do Meio Ambiente após reformas ministeriais no segundo Governo de Fernando Henrique Cardoso, por meio da medida provisória $\mathrm{n}^{\mathrm{o}}$ 1.795/1999. A responsabilidade pelo ordenamento territorial foi transferida para o Ministério da Integração Nacional e o ZEE ao MMA, conforme lei federal no 10.683/2003. Assim, a partir de 1991, o governo brasileiro criou o Programa de Zoneamento Ecológico-Econômico para a Amazônia Legal (PZEEAL), que passou a ser apenas Programa ZEE Brasil (PZEE).

O ZEE tem sido apontado como um mecanismo que pode contribuir para o cumprimento das metas de redução de desmatamento até 2020 em áreas da Amazônia Legal (Nepstad et al, 2009). Tem atualmente como objetivo maior integrar aspectos naturais e sociais em uma proposta estratégica voltada à manutenção, recuperação e equilíbrio dos sistemas ecológicos, através de diretrizes que considerem as limitações e potenciais humanos da área em estudo, e assim contribua para o alcance de melhorias na qualidade de vida das populações urbanas e rurais (MMA, 2012). A integração também de instrumentos de gestão, de indicadores e cenários faz parte do conjunto das metas do PZEE.

Atualmente têm sido elaboradas diversas propostas de ZEE devido às novas exigências instituídas pelo novo Código Florestal (lei $\mathrm{n}^{\circ}$ 12.651, de 25 de maio de 2012) a alguns estímulos legais, referente à possibilidade de:

I. Ampliação da área de ocupação de apicuns e salgados (artigos 11-A, §5);

II. Redução para até $50 \%$ da reserva legal (art.12, $\S 5^{\circ}$ ); 
III. Ação do poder público a partir de indicação do ZEE (art.13, caput);

IV. Estabelecimento de prazo para elaboração de ZEE aos estados (art. 13, §2º);

V. O ZEE ser um dos critérios para a localização da reserva legal (art. 14).

Segundo suas Diretrizes Metodológicas (MMA, 2006), a elaboração de um ZEE deve seguir algumas fases, conforme a ilustração abaixo (Figura 4):

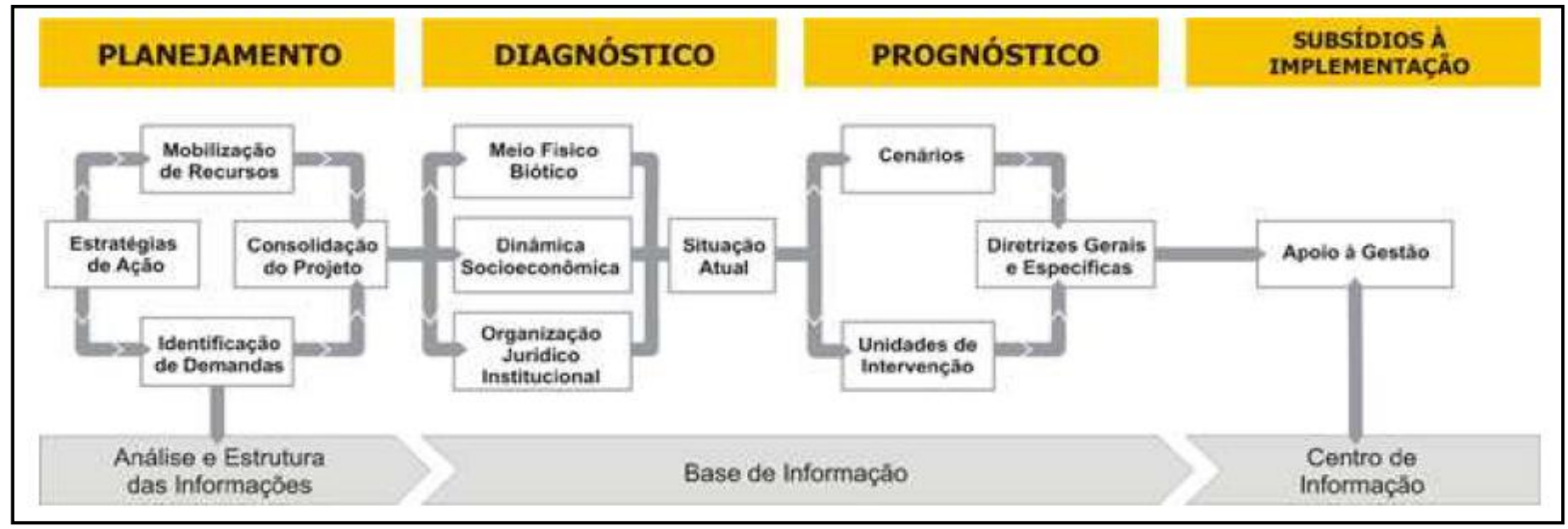

Figura 4: Fases para a elaboração de um ZEE (MMA, 2007).

O intuito da criação do PZEE foi o de oferecer uma nova proposta de atuação governamental, devido ao esgotamento do modelo desenvolvimentista, marcado pela forte atuação centralizada do governo para a retomada do planejamento em novas bases, voltado ao desenvolvimento socioeconômico em bases sustentáveis (BECKER \& EGLER, 1997).

A análise do ambiente natural é feita no diagnóstico físico-biótico, que é a primeira fase para a elaboração de uma proposta de ZEE. A partir da metodologia Crepani (1996) são propostas unidades da paisagem ou territoriais básicas, e confeccionado o mapa de vulnerabilidade natural à erosão. Um dos subsídios para as demais fases do zoneamento, é a carta de vulnerabilidade que sintetiza o diagnóstico ambiental e leva em consideração tanto as fragilidades naturais como a capacidade de suporte do território mapeado. São identificados e integrados os componentes biofísicos, que serão somados aos econômicos, sociais e institucionais para o fechamento da fase de diagnóstico. Os componentes e seus intrincados sistemas devem ser avaliados em função de um espaço e de um período de tempo (WESTMAN, 1985; SANTOS e MOZETO, 1992; BALLESTER et al.,1995; SEIFFER, 1998).

Para o atendimento dos desafios da análise físico-biótico em ZEE, entende-se que há de ser feita uma definição conceitual metodológica mais detalhada quanto aos aspectos ambientais, pois a origem normativa do ZEE, segundo apontado pela auditoria avaliativa do Programa ZEE realizado pelo TCU (2008), provém do Zoneamento Ambiental previsto na lei de Política Nacional do Meio 
Ambiente. No entanto, a definição conceitual de nenhum destes termosestá prevista em lei. Nem mesmo o Decreto 4297/2002 que expressa as funcionalidades do ZEE e o define como instrumento da Política Ambiental - o que nos remete ao Zoneamento Ambiental (art. 9 ${ }^{\circ}$, II) - não o detalha propriamente em termos conceituais.

Infere-se que seja também necessário o uso de mecanismos que facilitem a integração do ZEE a outros instrumentos de gestão territorial ambiental. Vale destacar o Plano Nacional de Recursos Hídricos $(\mathrm{PNRH})^{8}$, por possuir como objetivo, similar ao ZEE, a criação de áreas sujeitas à restrição de uso para uma melhor gestão dos recursos hídricos.

A combinação dos instrumentos de gestão da PNMA e da PNRH pode contribuir à gestão dos recursos naturais e da atuação estatal no território, a partir de uma mesma unidade espacial de análise: a bacia hidrográfica.

A Amazônia Legal tem sido fortemente afetada pela expansão da pecuária e da indústria da soja, e que por isso há mais de 30 anos registra constantes aumentos das taxas de desmatamento e de rodovias no núcleo da região ${ }^{9}$. Simulações indicam que em 2050 aproximadamente $40 \%$ da floresta amazônica terá sido eliminada pela agropecuária de expansão (Biswas, 2008). Devido ao cenário atual e aos projetados, Soares-Filho et al (2006) propõe como uma estratégia de conservação global a proteção da bacia amazônica, a sua gama de espécies e diversidade ecossistêmica. A proposta se diferenciaria das atuais políticas de gestão ambiental, que se concentraram na criação de áreas legalmente protegidas que têm inibido o aumento do desmatamento, mas não têm sido eficazes para a conservação da bacia hidrográfica.

Para Biswas (2008) existem cada vez mais instituições e profissionais da área de recursos hídricos em todo o mundo questionando a relevância e adequação potencial de implantação dos Planos de Gestão de Bacias Hidrográficas. Esta é uma situação similar ao ZEE, instrumento da PNMA amplamente adotado nos últimos dez anos, e que tem sido elaborado de acordo com metodologias e conceitos que não oferecem condições favoráveis para o seu uso integrado (TCU, 2009). A causa para tal situação, segundo Biswas (2008), é a seguinte:

“[...] esse tipo de popularidade quase universal de um conceito vago, indefinível e implementável não é um fenômeno novo na área de gestão de recursos naturais. Isso já aconteceu muitas vezes antes. (...). Tais conceitos em geral tornaram-se politicamente corretos durante o tempo de sua popularidade, e foram amplamente adotados, uma vez que

$8 \quad$ Os Planos de Recursos Hídricos - PRH foram estabelecidos como instrumentos de gerenciamento das águas em território nacional com o advento da Lei no 9.433/97, visando fundamentar e orientar a implementação da Política Nacional dos Recursos Hídricos.

$9 \quad$ Segundo dados do Departamento Nacional de Águas e Energia Elétrica (DNAEE), do Ministério de Minas e Energia, a Amazônia Legal, porção do território brasileiro com maiores estímulos à elaboração de ZEE, concentra $72 \%$ do potencial hídrico nacional e $15 \%$ em termos mundiais. 
são suficientemente vagos para que possam apresentar avanços (...). Na verdade, parece que a imprecisão de um conceito, de forma significativa, aumenta a sua popularidade, uma vez que as pessoas podem, em seguida, continuar a fazer as mesmas coisas antigas que estavam fazendo antes, mas podem simultaneamente afirmar que seguem o mais recente pensamento global. Esta situação também aumenta, muitas vezes de forma muito significativa, a possibilidade de receber apoio financeiro via doações, e também outros benefícios pessoais" (Biswas, 2008, p. 13).

No caso do Programa ZEE Brasil, mesmo sendo o instrumento de gestão ambiental territorial da Política Nacional do Meio Ambiente - PNMA e de contar desde a sua concepção com o emprego de geotecnologias, ainda não foram estabelecidos padrões mínimos de qualidade e diretrizes metodológicas para a construção de suas unidades territoriais básicas, sejam em projetos de âmbito municipal, estadual, regional e nacional. A análise e proposição de diretrizes à gestão de unidades da paisagem mediante a delimitação de áreas similares em zonas (Silva, 2003; Silva \&Santos,2004), com o uso de técnicas de geoprocessamento e modelagens espaciais automatizadas, oferece possibilidades para a concepção de diagnósticos ambientais até à instituição das Unidades de Intervenção e de suas respectivas diretrizes.

Apesar de possuir grande interação, o zoneamento ambiental não deve ser confundido quanto ao seu objetivo, e se constitui insumo para os processos de gestão, planejamento e gerenciamento ambiental (Figura 5).

No contexto ambiental, o uso de zoneamentos exige um trabalho interdisciplinar, que em geral, definem suas zonas de planejamento a serem delimitadas a partir da análise das potencialidades, vocações, fragilidades ou suscetibilidades. O processo de zoneamento ambiental oferece subsídios ao planejamento, mas não é seu sinônimo, pois o planejamento exigirá todo um trabalho de definição de diretrizes, programas, participação social, consenso entre cenários e definição de premissas gerenciais. Exigirá um esforço de sintonia, para que assim sejam acordadas as questões definidas como essenciais pelo grupo envolvido no processo de planejamento (Santos, 2004). 


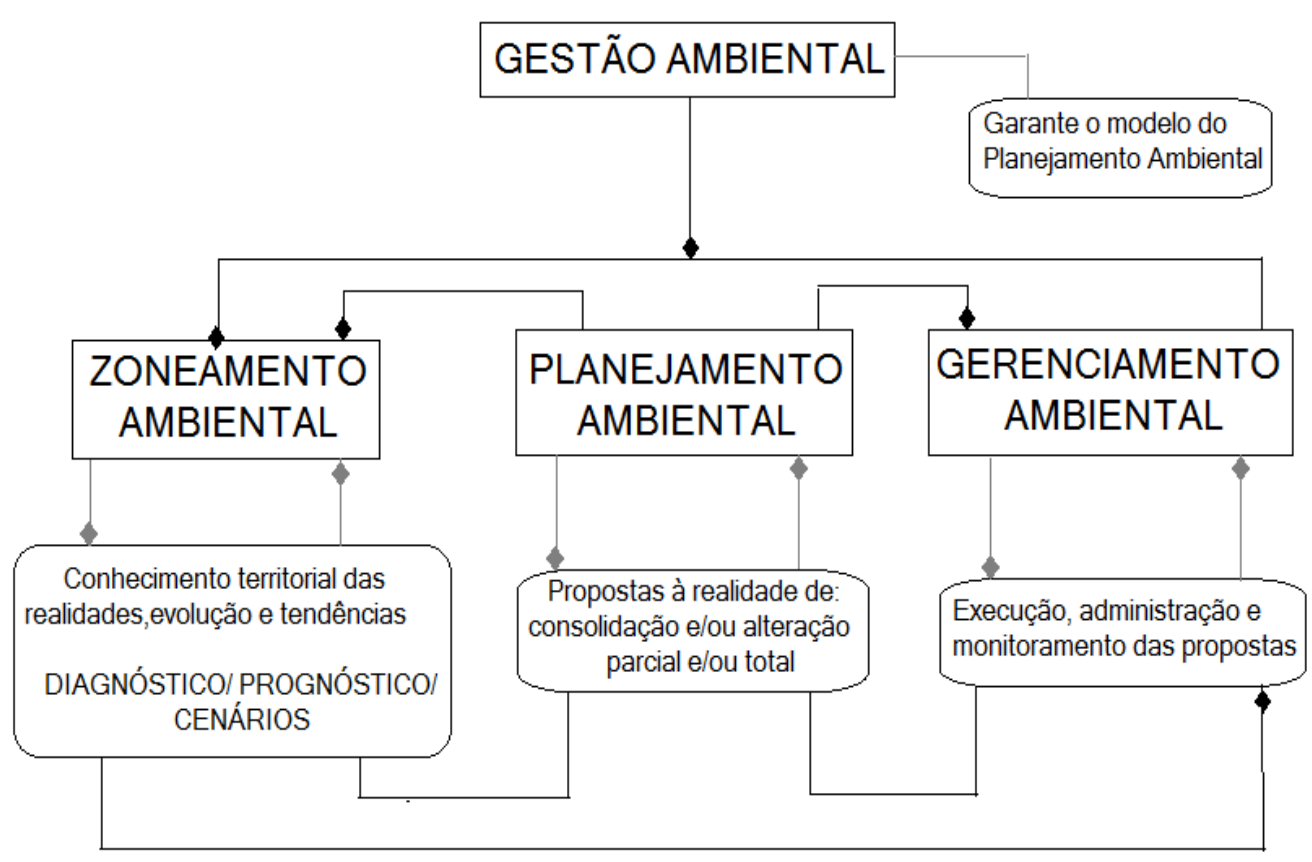

Figura 5: Interações Gestão Ambiental. Fonte: Modificado de Santos (2004, p.27)

Os modelos de zoneamento para a gestão ambiental territorial são, na sua maioria, concebidos para serem executados a partir de critérios qualitativos, e poucos possuem delimitações de zona a partir de abordagens quantitativas (Silva \& Santos, 2004). Alguns autores, como Pablo (2000), consideram a necessidade do desenvolvimento de propostas metodológicas que identifiquem zonas a partir da seleção de atributos ambientais mapeáveis, e de medidas quantitativas que agrupem ou expressem as múltiplas interações entre eles.

Devido a sua visão sistêmica, o Zoneamento Ecológico-Econômico, apresenta uma análise de causa e efeito, que visa apresentar as relações de dependência entre os subsistemas físico, biótico, social e econômico. É hoje um zoneamento muito utilizado pelos estados, e que se estabeleceu como o instrumento de gestão do território necessário ao planejamento público ambiental do país (MMA, 2007).

A expressão zoneamento ecológico-econômico teve o seu primeiro registro no Relatório do Grupo de Trabalho, instituído pelo Decreto $\mathrm{n}^{\circ}$ 83.518/1979, com o objetivo de estudar e propor medidas direcionadas à formulação de uma política florestal para a Amazônia brasileira. O sentido do termo zoneamento ecológico-econômico, conforme descrito no Anexo 3, do referido relatório, estava bem distante da concepção atual (DEL PRETTE e MATTEO, 2006, p.11), o que favoreceu o início do emprego do ZEE mais voltado a indicação de novas áreas para a proteção ambiental e a homologação das novas terras cultivadas na porção amazônica do que como um instrumento orientador à gestão ambiental do país. 
O primeiro estudo considerado marco de um processo de ZEE na esfera governamental foi elaborado em 1986. O documento "Termo de Referência para uma Proposta de Zoneamento Ecológico-Econômico do Brasil", sob a coordenação do IBGE, foi duramente criticado. Segundo Leite (1991), a proposição de zoneamento era não só diretamente consequente do modelo de desenvolvimento econômico adotado no Brasil, como também visava assegurar sua continuidade, a despeito de todas as discussões referentes ao desenvolvimento sustentado.

Desde os projetos pioneiros de ZEE, a utilização dos mapeamentos básicos para a compreensão da dinâmica natural da paisagem foram o pontapé inicial para o diagnóstico ambiental. A proposta de diagnóstico, envolvendo a elaboração das cartas temáticas e dos seus cruzamentos, era feita a partir do emprego de análises e técnicas de refinamento dos dados, conforme as possibilidades tecnológicas e do conhecimento técnico e conceitual da equipe envolvida no projeto.

Conforme Orea (1992) as elaborações de zoneamentos se diferenciaram conforme os seus objetivos, perfil da equipe técnica envolvida, prazo para elaboração, o volume e situação dos dados e análises a serem processados. Cada zoneamento proposto era voltado a um tipo de planejamento. Tal fato gerou uma diversificada gama de ZEE, contendo análises e "zonificações" com incompatibilidades conceituais e cartográficas que dificultam o processo de integração de zoneamentos, fato claramente observável quando analisadas as regiões limítrofes das unidades de gestão (Zacharias \& Freitas, 2008).

Um breve panorama metodológico do ZEE, no que se refere a elaboração do diagnóstico físico-biótico, demonstra a necessária revisita às concepções conceituais que nortearam a sua gênese. A definição e o modo de consideração da categoria geográfica paisagem, e propostas metodológicas para a delimitação de unidades da paisagem a partir de parâmetros quantificáveis indica possibilidades da integração de políticas públicas de caráter territorial, como é o caso da PNMA e da PNRH. O emprego de critérios menos qualitativos facilitará a mensuração dos quesitos ambientais aplicados, o que pode resultar em modelagens e respectivos produtos espaciais mais confiáveis.

\subsection{BASES CONCEITUAIS PARA A DELIMITAÇÃO DE UTB EM ZEE}

As unidades de paisagem, segundo Crepani (1996), são definidas a partir de critérios de fotointerpretação sobre a "âncora" representada pelas imagens orbitais, mas para isso é necessário se conhecer a sua constituição física, forma e estágio de evolução, bem como o tipo da cobertura vegetal que sobre ela se desenvolve.

Estas informações são fornecidas pela Geologia, Geomorfologia, Pedologia e Fitogeografia e precisam ser integradas para que se tenha um retrato fiel do comportamento de cada unidade frente à sua ocupação. Finalmente, é necessário o auxílio da Climatologia para que se conheçam algumas 
características climáticas da região onde se localiza a unidade de paisagem, a fim de que se anteveja o seu comportamento frente às alterações impostas pela ocupação.

Crepani (1996) definiu um conjunto de informações a serem utilizadas para a análise e definição da categoria morfodinâmica da unidade de paisagem, compreendendo:

- Geologia - informações relativas à história da evolução geológica do ambiente onde a unidade se encontra e o grau de coesão das rochas que a compõem.

- Geomorfologia - informações relativas à Morfometria (a amplitude de relevo, a declividade e o grau de dissecação da unidade de paisagem), para a caracterização do grau de estabilidade.

- Pedologia - informações que propiciem condições para a compreensão da maturidade dos solos, produto direto da balança morfogênese/pedogênese.

- Fitogeografia - compreende dados relativos à densidade de cobertura vegetal, que representa a defesa da unidade da paisagem contra os efeitos dos processos modificadores das formas de relevo (erosão) e constitui-se agente que retarda o ingresso das águas provenientes das precipitações pluviais e gera o aumento da capacidade de infiltração do solo.

- Climatologia - dados históricos da pluviosidade anual e da duração do período chuvoso, para a definição da intensidade pluviométrica, permitindo-se quantificar o grau de risco a erosão e de integridade da unidade de paisagem (análise de risco para o "runoff" a partir da disposição de água).

Estas informações são combinadas, de forma, a construir as unidades de paisagem em polígonos de intervenção, que são traçados a partir de critérios sistematizados de fotointerpretação (Soares \& Fiori, 1976; Veneziani \& Anjos, 1982). Segundo Veneziani \& Anjos (1982), se deve levar em consideração como elementos fundamentais para a fotointerpretação sistemática da imagem: os elementos de textura de relevo e drenagem e, os matizes de cores relacionadas aos padrões de resposta espectral da vegetação, solo e água.

Ressalta-se como ponto positivo a proposta de visão sistêmica para o delineamento das zonas, na qual a paisagem é concebida como um sistema integrado onde cada componente isolado não possui propriedades integradoras e um valor abstrato, já que depende da influência do resto dos demais componente (Cavalcanti e Viadana, 2007).

\subsection{ANÁLISE QUANTITATIVA DA PAISAGEM}

Na delimitação da paisagem torna-se necessária a escolha do tipo de abordagem metodológica a ser utilizada, que pode ser qualitativo ou quantitativo, bem como as regras de cruzamento entre os temas. O emprego da abordagem quantitativa é favorável por sua capacidade de expressar numericamente as relações e condicionantes observados na paisagem. Pode ser apresentada através 
de modelos determinísticos, de análise multivariada ou multidimensional, pela Teoria dos Jogos ou pela Teoria do Caos (Silva \& Santos, 2004).

As análises espaciais realizadas e os resultados obtidos necessitam de uma estrutura de integração (Yates \&Humphreys, 1998; Lisboa Filho \& Iochpe, 1999). Um modelo de dados adequado pode ser útil para identificar operações necessárias para unir, transformar e representar os dados viáveis em um SIG, não apenas para a produção de mapas, mas também para visualização e consulta dos dados no banco de dados (Carvalho \& Gherardi, 2005).Nos bancos de dados convencionais, o banco de dados tenta representar a realidade de uma forma limitada, onde, de acordo com as limitações de representação e capacidade computacional, busca-se modelar e representar o mundo real (Rugg et al 1998 apud Lisboa Filho \& Iochpe, 1999). Isto pode ser simplificado e observado conforme ilustra a Figura 6, que permite notar os níveis de representação necessários.

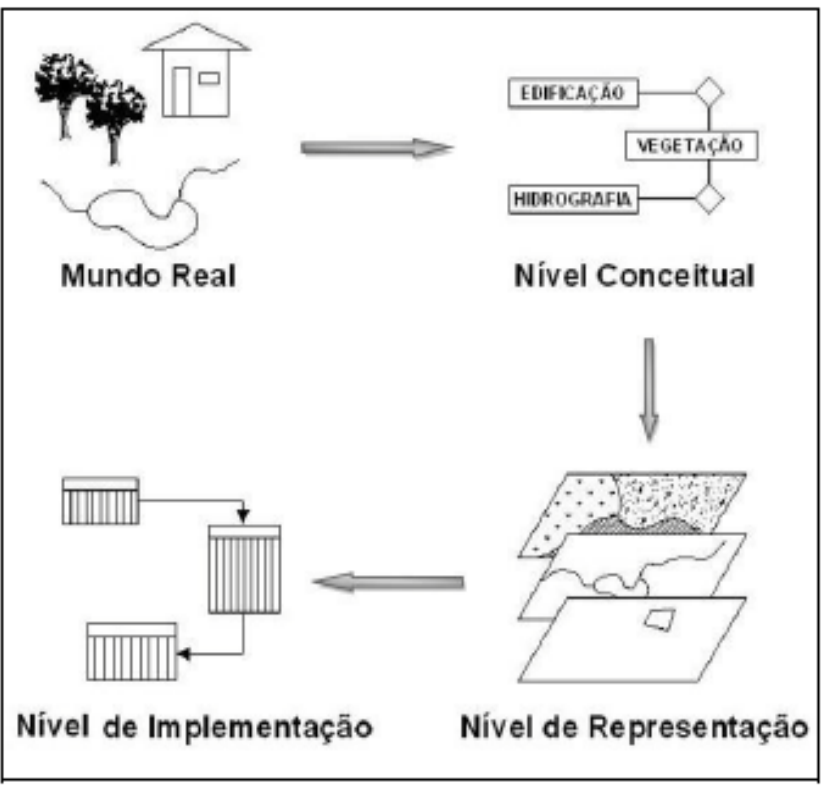

Figura 6: Níveis de representação do mundo real (Lisboa Filho \& lochpe, 1999)

A geomorfometria, definida como a ciência da análise quantitativa da superfície terrestre, juntamente com os Modelos Digitais de Elevação (MDE) são consideradas as principais fontes de informações em análises da paisagem a partir de parametrizações quantitativas.

Este tipo de análise tem sido utilizado para a compartimentação do relevo, como demonstrado por Oliveira et al. (2007) para compartimentar o relevo, utilizando a técnica estatística de análise de grupos no Parque Nacional da Serra dos Órgãos e Sodré et al. (2007) que testou o método de análise de grupos para classificar bacias hidrográficas, concluindo que o método é adequado para evidenciar padrões espaciais contínuos, cuja dinâmica ambiental é similar. 
Silva (2009), utilizando o desnivelamento altimétrico em bacias hidrográficas, realizou a compartimentação topográfica do estado do Rio de Janeiro, considerando a área das bacias de primeira e segunda ordem até sua confluência com a rede coletora.

Além desses trabalhos, outros estudos ressaltam a importância das variáveis morfométricas para caracterização de bacias hidrográficas (Yevjevich et al, 1972; Oliveira et al, 2007; Souza, 2009), a identificação de compartimentos geomorfológicos (Menke et al, 2013; Santos \& Morais, 2012; Adediran et al, 2004), na caracterização de unidades ambientais (Calvo et al,1990) e, para o entendimento da dinâmica ambiental local (Teodoro et al, 2007).

\subsection{PARÂMETROS MORFOMÉTRICOS PARA A DELIMITAÇÃO DAS UTB}

O estudo das bacias hidrográficas é a base para a compreensão da organização da paisagem e sua relação com o manejo dos recursos naturais (Menke, 2012). A distribuição dos elementos quantificados que descrevem as paisagens apresenta propriedades que se agrupam em padrões homogêneos que caracterizam unidades fisiográficas e pedológicas (Hermuche et al, 2002).

Diversos autores propuseram diferentes metodologias para a delimitação da paisagem com a consideração dos fatores físicos (Troll, 1966; Bertrand, 1968; Tricart, 1965), e para isso definiram um sistema de classificação hierárquica da paisagem, em função da escala. Tricart (1965) propôs um sistema de classificação dividido em oito níveis, tendo a geomorfologia como a base fundamental de integração dos demais atributos físicos. Entende-se que para a delimitação de unidades territoriais básicas (UTB) os parâmetros morfométricos são o insumo para a compreensão da dinâmica do ambiente natural, a partir de uma porção da paisagem que proporciona condições para compreendermos a distribuição, as fragilidades e potencialidades de recursos naturais presentes na paisagem.

Conhecer as feições e os padrões do terreno que compõe uma bacia hidrográfica proporciona condições favoráveis à materialização visual dos panoramas paisagísticos perceptíveis na superfície terrestre (Christofoletti, 1980), delimitando-as em unidades da paisagem - base conceitual para a concepção das UTB. Segundo Coelho Netto (2005), além da importância das bacias para a distribuição da água superficial, ela desempenha um importante papel na distribuição de sedimento e substâncias dissolvidas.

De acordo com Oliveira (2008), a espacialização das feições morfométricas por unidades de bacia de drenagem pode trazer uma perspectiva integradora dos diversos fatores que atuam sobre o modelado. Esses parâmetros podem revelar indicadores físicos específicos para determinado local, de forma a qualificar as alterações ambientais (ALVES e CASTRO, 2003). 


\section{3. ÁREA DE ESTUDO}

A área de estudo foi o do quadrilátero do Distrito Federal (Figura 7), no âmbito do projeto de Zoneamento Ecológico Econômico do Distrito Federal (ZEE-DF) que está em processo de elaboração e que tem como ponto de partida integrar a gestão dos recursos hídricos e do meio ambiente. A seguir será caracterizado o Distrito Federal de acordo com a geologia, geomorfologia, climatologia, pedologia e vegetação.

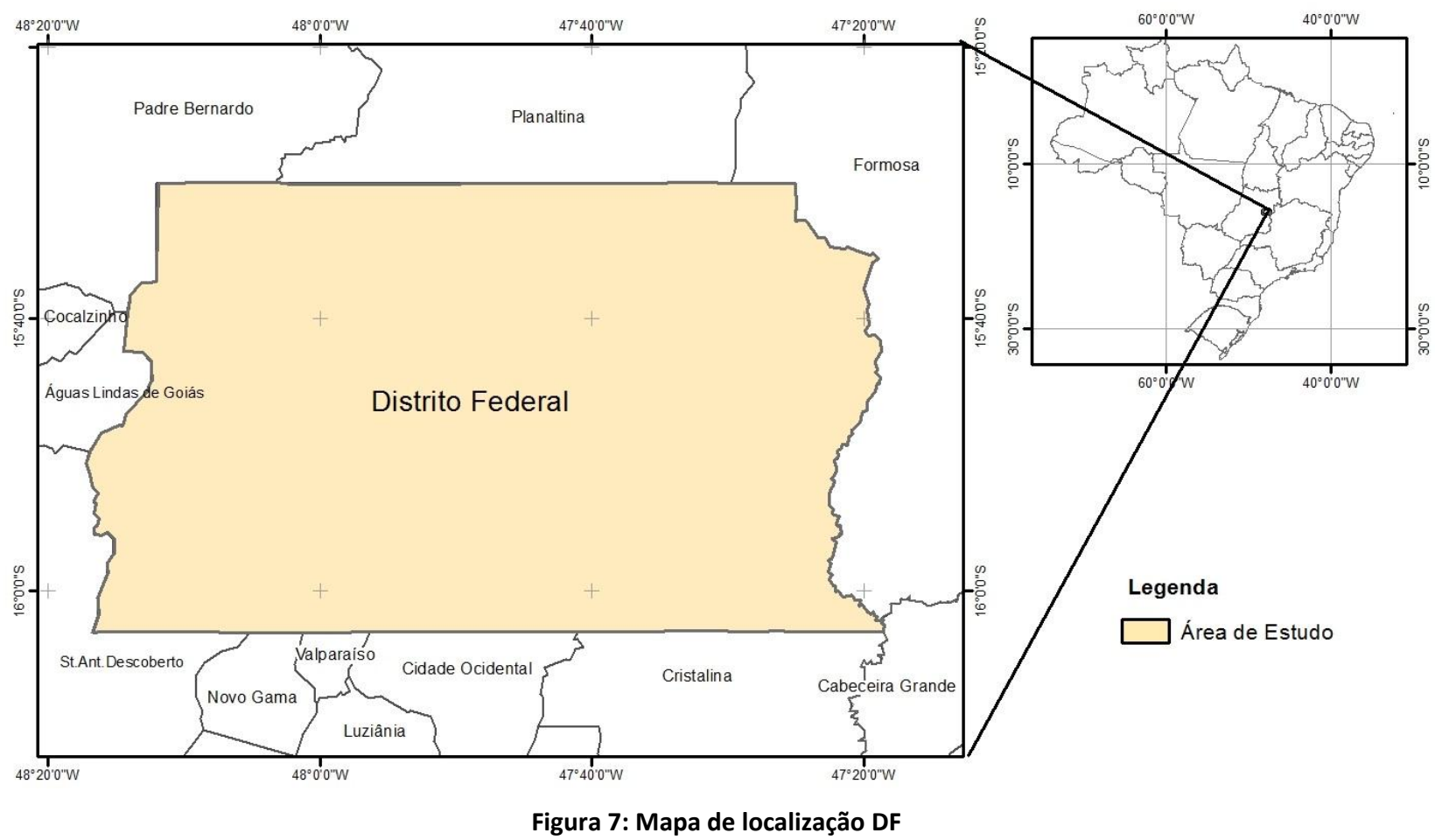

O Distrito Federal está localizado na região central da Faixa de Dobramentos e Cavalgamentos Brasília (Marini et al. 1981), e por estar na sua transição entre as porções internas (de maior grau metamórfico) e externas (de menor grau metamórfico) apresenta uma estrutura geral considerada complexa, onde estão distribuídas várias unidades regionais superpostas por importantes sistemas de falhas (empurrões e cavalgamentos).

A geologia é caracterizada por rochas metamórficas, recobertas por espessos solos. São diferenciáveis dois grandes grupos de aqǘferos classificados como os que possuem o maior dos reservatórios subterrâneos de água: o Domínio Aqüífero Poroso e o Domínio Aqüífero Fraturado (Campos, 2004).

É formado por quatro conjuntos litológicos distintos: os grupos Paranoá, Canastra, Araxá e Bambuí (Figura 08), cujas coberturas de solo se caracterizam como residuais ou coluvionares. Os grupos Paranoá e Canastra apresentam idade meso/neoproterozóica e os grupos Araxá e Bambuí, idade neoproterozóica. 


\section{MAPA DE GEOLOGIA DO DISTRITO FEDERAL}

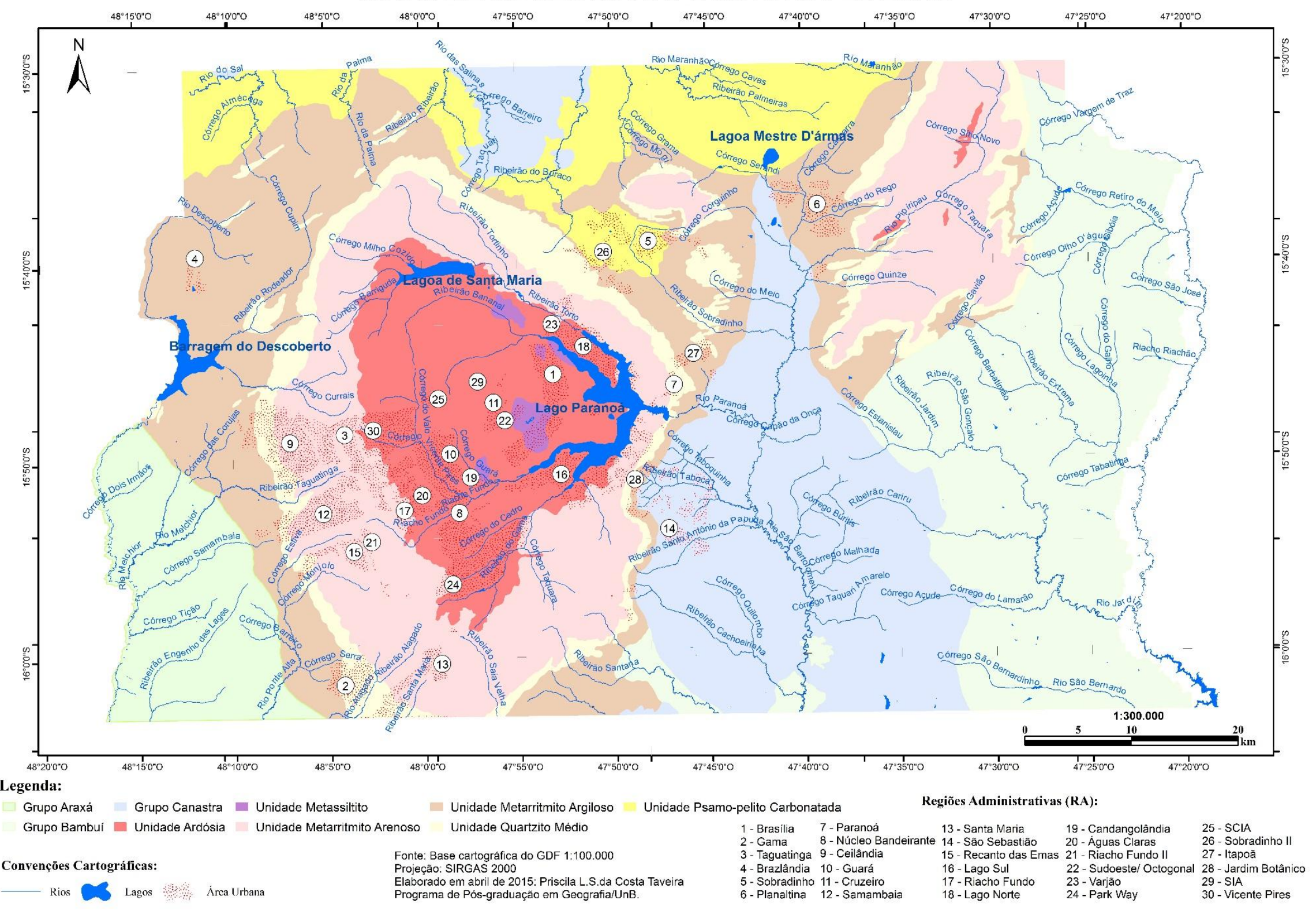

Figura 8: Mapa de Geologia DF (tamanho original: A3) 
O Grupo Paranoá ocupa cerca de 65\% da área total do Distrito Federal, restritamente na borda leste do Domo Estrutural do Pipiripau; o Grupo Canastra próximo de 15\%, distribuído pelos vales dos rios São Bartolomeu (porção central do DF) e Maranhão (porção centro-norte do DF); já o Grupo Araxá está limitado ao setor sudoeste do DF, ocupando apenas 5\% da área total do território; e por fim o Grupo Bambuí se distribui por cerca de 15\% da área total do DF, sendo observado na porção leste ao longo do Vale do Rio Preto (Campos, 2004). Por apresentar grande variação de tipos litológicos dentro das várias unidades litoestratigráficas, para uma melhor caracterização dos vários sistemas de aquíferos é necessário ser feita a subdivisão em subsistemas.

O Distrito Federal possui evolução estrutural caracterizada por cinco fases de deformação dentro de um único evento compressivo relacionado à Orogênese Brasiliana. Toda a deformação foi controlada por três sistemas de cavalgamentos denominados de Sistema de Cavalgamento Paranã (responsável pelo posicionamento do Grupo Paranoá sobre o Grupo Bambuí); Sistema de Cavalgamento São Bartolomeu/Maranhão (que coloca o Grupo Canastra sobre os grupos Paranoá e Bambuí) e Sistema de Cavalgamento Descoberto (o qual sobrepõe o Grupo Araxá ao Grupo Paranoá), conforme descrito por Freitas-Silva \& Campos (1998).

A geologia é apontada por Campos (2004) como o principal condicionante das variações de altitude, incisão de vales, densidade, forma da rede de drenagem e, principalmente, da evolução morfodinâmica e da paisagem atual do Distrito Federal. Logo, imprime forte controle em outros aspectos do meio abiótico, como o relevo, os solos e até a compartimentação climática, e por isso, implicitamente, o substrato deve ser levado em conta para a gestão e controle dos usos e da ocupação do território.

Localizado no Planalto Central do Brasil, o quadrilátero do DF está inserido nas cabeceiras de afluentes dos três maiores rios brasileiro - o Rio Maranhão (afluente do Rio Tocantins), o Rio Preto (afluente do Rio São Francisco) e os rios São Bartolomeu e Descoberto (tributários do Rio Paraná). Situado em um alto regional que não apresenta grandes drenagens superficiais, caracterizase como um divisor natural das três grandes bacias hidrográficas.

A sua compartimentação geomorfológica (Figura 09) inclui as Regiões de Chapadas, Regiões de Dissecação Intermediária, Regiões Dissecadas de Vales, Regiões de Rebordo e Regiões de Escarpas. Segundo Campos (2004) dentre os fatores responsáveis pela evolução morfodinâmica do Distrito Federal, destacam-se o clima, o tipo de vegetação, a evolução dos perfis de alteração, a estruturação neotectônica além de processos de incisão de vales nas amplas chapadas elevadas. Martins \& Baptista (1998) confrontaram os modelos de evolução geomorfológica existente até o período do estudo e propuseram uma proposta em função da altimetria e declividade. 


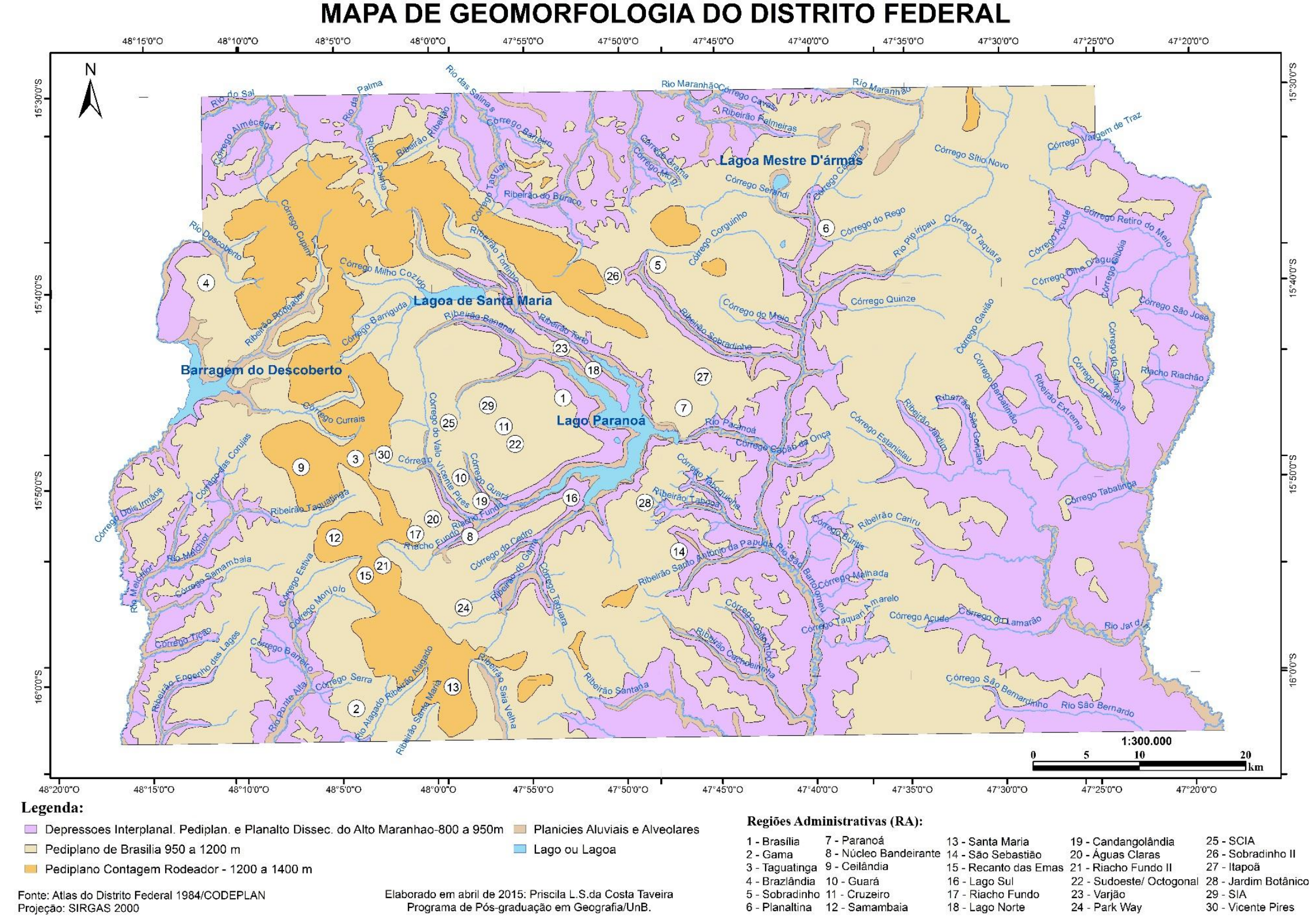


O Distrito Federal, localizado no Domínio Morfoclimático do Cerrado, possui características morfológicas de paisagem resultantes de uma interação do regime climático tropical semi-úmido com fatores litológicos, edáficos e bióticos.

O DF é marcado pela forte sazonalidade climática em dois períodos distintos. Entre maio e setembro, intervalo marcado pela baixa taxa de precipitação, baixa nebulosidade, alta taxa de evaporação, com valores muito baixos de taxa de umidade relativa diária (com registros inferiores a $15 \%)$. Já o período entre outubro e abril apresenta padrões contrastantes, em que se registra $47 \%$ da precipitação anual, concentrados entre os meses de dezembro a março (Codeplan, 1984).

A precipitação média anual é da ordem de $1500 \mathrm{~mm}$, com distribuição irregular, onde as menores alturas pluviométricas anuais ocorrem na porção leste e as taxas mais elevadas estão concentradas em dois pontos a NE e SE do Distrito Federal (Baptista 1998).

A partir de análise do mapeamento de solos realizado pelo Serviço Nacional de Levantamento de Solo (Embrapa, 1978), na escala 1:100.000, o DF teve sua superfície territorial distinguida em dois núcleos em função dos tipos de coberturas (figura 10).

O primeiro caracterizado pelo conjunto de tipos pedológicos mais abundantes, presente aproximadamente em $85 \%$ da área, é constituído pelas seguintes classes de solos: LATOSSOLO VERMELHO, LATOSSOLO VERMELHO-AMARELO e CAMBISSOLO HÁPLICO.

Já o segundo grupo, que abrange por volta de 15\%, refere-se aos demais tipos de solos identificados como: NITOSSOLO, CHERNOSSOLO, GLEISSOLO, ORGANOSSOLO, NEOSSOLO QUARTZARÊNICO, NEOSSOLO FLÚVICO e NEOSSOLO LITÓLICO, além de PLINTOSSOLO. No DF, as classes de solos mais abundantes apresentam diferentes sensibilidades à erosão e diferentes classes de tolerância às perdas por erosão.

Quanto aos tipos de solos e sua relação à questão hídrica, nas áreas em que se apresentam mais espessos (todas as classes de LATOSSOLO), a produção hídrica específica das bacias do DF registra-se elevada e a rede de drenagem perene. E nas áreas com solos rasos, notadamente CAMBISSOLO e NEOSSOLO LITÓLICO os cursos d'água encontrados são intermitentes.

Com relação à aptidão agrícola das terras, na maior parte da área ( $55 \%$ da área) a aptidão é considerada Boa para nível de Manejo Baixo. Outra porção do território com ampla área ( 30\%) é representada por solos com aptidão apenas para pastagens naturais. Nessa classe são incluídos os cambissolos que por ocorrer em terrenos de declividade moderada a elevada apresenta limitação ligada ao desenvolvimento de processos erosivos (GDF, 2012). 
MAPA DE SOLOS DO DISTRITO FEDERAL

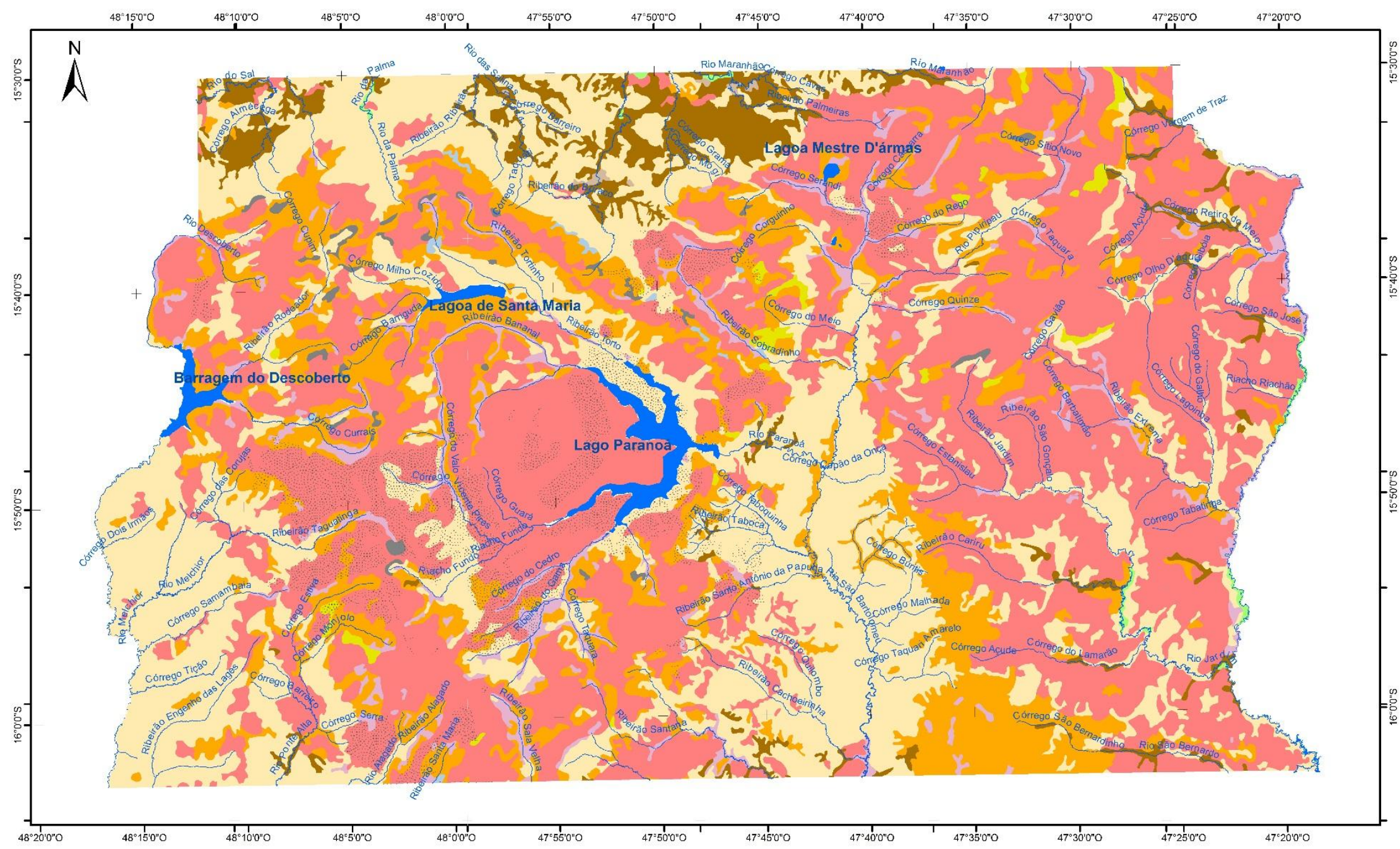

= ARGISSOLO VERMELHO EUTROFICO + CHERNOSSOLO HAPLICO $=$ ESPODOSSOLO FERRILUVICO $=$ LATOSSOLO VERMELHO NEOSSOLO FLÚVICO CAMBISSOLO HAPLICO - GLEISSOLO HAPLICO

- - LATOSSOLO VERMELHO-AMARELO $=$ NEOSSOLO QUARTZARÉNICO

Convençôes Cartográficas:

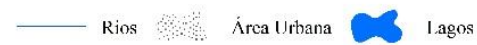

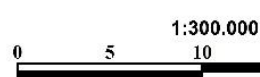

20 Fonte: Base cartográfica do GDF 1:100.000
km Projeçäo: SIRGAS 2000
Elaborado em abril de 2015: Priscila L.S. da Costa Taveira Programa de Pós-graduação em Geografia/UnB.

Figura 10: Mapa de Solos DF (tamanho original: A3). 
Segundo apresentado pela Semarh-DF (1996), o Distrito Federal está situado integralmente no domínio do bioma Cerrado, considerado o segundo maior bioma do País em área, e um dos 34 hotspots mundiais para a conservação da biodiversidade.

A biodiversidade do bioma Cerrado forma uma grande mancha contínua e serve como divisor de águas para quase todas as bacias hidrográficas do Brasil, tais como: Amazonas, Tocantins, Paraná, Paraguai, São Francisco e Parnaíba, desempenhando, com isso, importante papel no processo de distribuição dos recursos hídricos do País (WERNEC LIMA e SILVA, 2008). Esta situação é determinante e de grande influência na biogeografia e na diversidade da flora e da fauna de toda a região Neotropical.

Destaca-se o fato de ocorrerem no Distrito Federal todas as fitofisionomias descritas por Ribeiro e Walter (2008), todavia as formações rupestres (campo e cerrado), a mata seca, o parque de cerrado e as veredas são mais raras e apresentam ocorrências pontuais dentro do território.

A análise da paisagem do DF foi realizada na fase de diagnóstico do ZEE que está em processo de elaboração, tendo sido consideradas suas unidades hidrográficas, subdividindo as bacias hidrográficas (40 unidades delimitadas pelo Plano de Gerenciamento Integrado dos Recursos Hídricos do Distrito Federal - PGIRH) que se inserem no território do DF e que ultrapassaram os seus limites.

A delimitação das unidades territoriais básicas foi feita buscando-se a proposta de zonas homogêneas dentro de determinada escala de análise da paisagem (GDF, 2012), constituindo-se o relevo o aspecto de fundamental importância por representar o elemento resultante da interação de diferentes componentes biofísicos e agente condicionante das formas de uso e ocupação das terras e da apropriação dos recursos naturais.

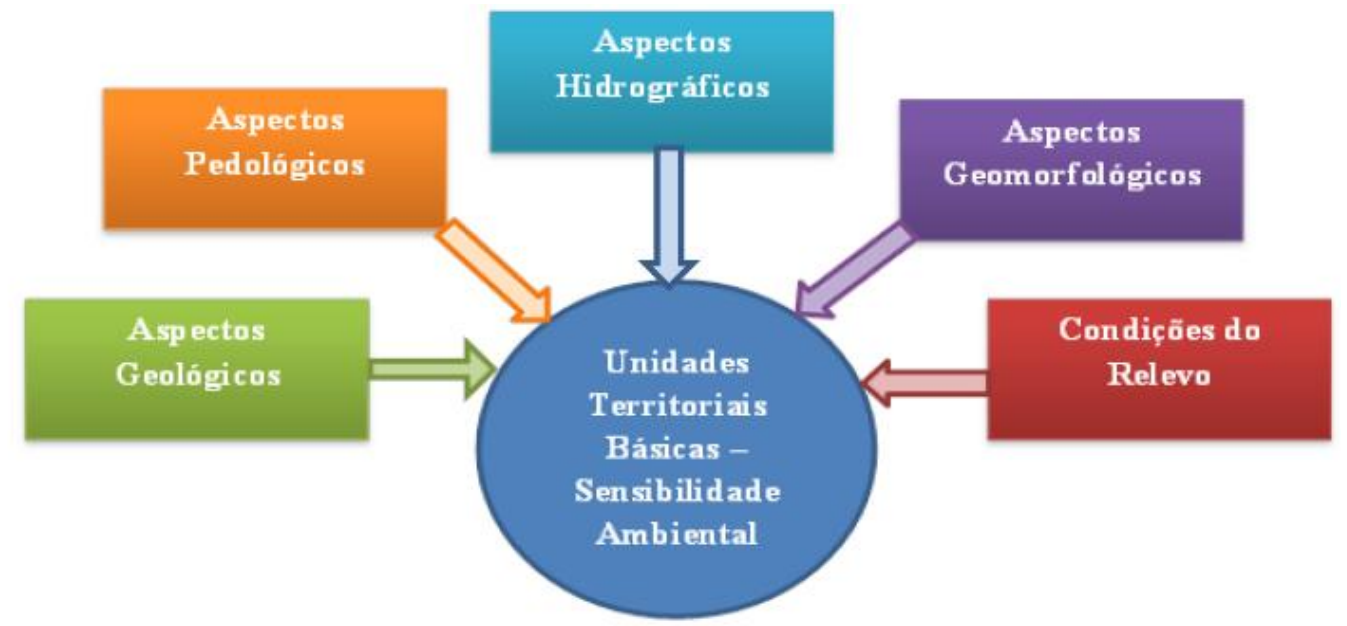

Figura 11: Variáveis de construção e da formulação das diretrizes para o ZEE/DF (GDF, 2014).

Segundo o relatório da proposta do ZEE-DF (GDF, 2014), a delimitação das UTB foi com a sobreposição dos planos de informação e da interpretação visual dos diferentes compartimentos da 
paisagem. Observamos que as zonas foram definidas tendo como limite orientador as unidades hidrográficas e o uso dos demais aspectos para a caracterização e alguns ajustes do mapa. 


\section{METODOLOGIA}

A metodologia foi dividida em quatro partes: (1) tratamento do produto do SRTM de 30 metros; (2) delimitação automatizada de bacias; (3) cálculo dos atributos morfométricos; e (4) classificação das bacias de drenagem a partir do método de agrupamentos.

\subsection{DADOS DO SPACE SHUTTLE TOPOGRAPHIC MISSION (SRTM)}

A partir de um projeto conjunto da NASA (National Geospatial-Intelligence Agency), do Centro Aeroespacial Alemão (Deutsches Zentrumfür Luft - um Raumfahrt - DRT) e da Agência Espacial Italiana (Agenzia Spaziale Italiana - ASI), o SRTM (Space Shuttle Topographic Mission) foi lançado a bordo do ônibus espacial Endeavour em fevereiro de 2000 e fez o levantamento de toda a superfície terrestre.

Inicialmente, para os Estados Unidos, os dados foram disponibilizados com 1-arc de resolução (aproximadamente 30 metros no Equador) e, para o restante do mundo degradada para 3 segundos de arco (aproximadamente 90m no Equador). No entanto, no final de 2014 a NASA disponibilizou os dados de 1-arc para a África e América do Sul.

O SRTM é um radar InSAR (Interferometric Synthetic Aperture Radar), composto de dois radares de abertura sintética contendo um sistema de banda C (5,6 centímetros, nomeado como Radar "C"), de responsabilidade da NASA, e um sistema de banda X (3,1 cm, Radar "X"), fruto da parceria da DRT com a ASI (Farr et al, 2004).

Os dados de 1-arc foram baixados da página eletrônica da USGS. Foi realizado o mosaico dos dados e na sequência recorte para além dos limites do Distrito Federal.

\subsection{DELIMITAÇÃO DAS BACIAS}

A utilização do processamento automatizado das informações para delimitação das bacias e sub-bacias possui como um dos principais aspectos os critérios de definição, que podem ser realizados segundo: o tamanho da área (Morris \& Heerdegen, 1988; Chorowicz et al., 1992) e a hierarquização fluvial, segundo o método estabelecido por Strahler (1952). O método de hierarquização de bacias hidrográficas definido por Strahler (1952) é um dos mais utilizados devido a sua simplicidade e funcionalidade (Smart, 1968) (Figura 12).

Para a extração dessas bacias foi utilizado o módulo Terrain Analysis Using Digital Elevation Models (TAUDEM), versão 5.1 para ArcGis. Este módulo está baseado no algoritmo 
desenvolvido por Tarboton (2002), para extração e análises de informações hidrológicas e topográficas a partir de um MDE.

Segundo o método de Strahler (1952), a junção dos canais de mesma ordem, dá origem a um canal de ordem superior, já o encontro de um canal com outro de ordem superior orienta a manutenção da ordem do canal de maior hierarquia. Isto significa que quando dois canais de ordem diferente se unem a jusante, permanece a ordem do canal de maior hierarquia, mas quando dois canais de ordem igual se juntam, a ordem do caminho a jusante é aumentada em 1 (Figura 12).

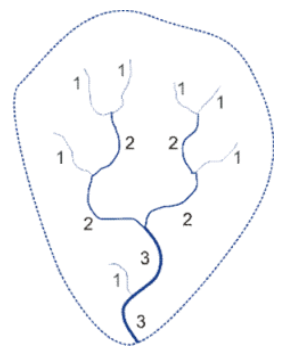

Figura 12: Hierarquia dos canais pelo método de Strahler .

Para a extração das bacias é necessária a realização de processos anteriores. Estes processos consistem na correção do MDE em áreas de depressões inexistentes (no caso, foi utilizado o módulo Fill Sink para esta correção) e, direção de fluxo (que é um módulo que define a direção do fluxo de água no relevo). Definidos estes parâmetros, o próximo passo foi identificar dos pontos de exutório de cada bacia na área de estudo para as diferentes ordens hierárquicas encontradas (conforme, método de Strahler de 1952). Na área de estudo foram identificadas bacias até a 5 a ordem de Strahler (Figura 13). 

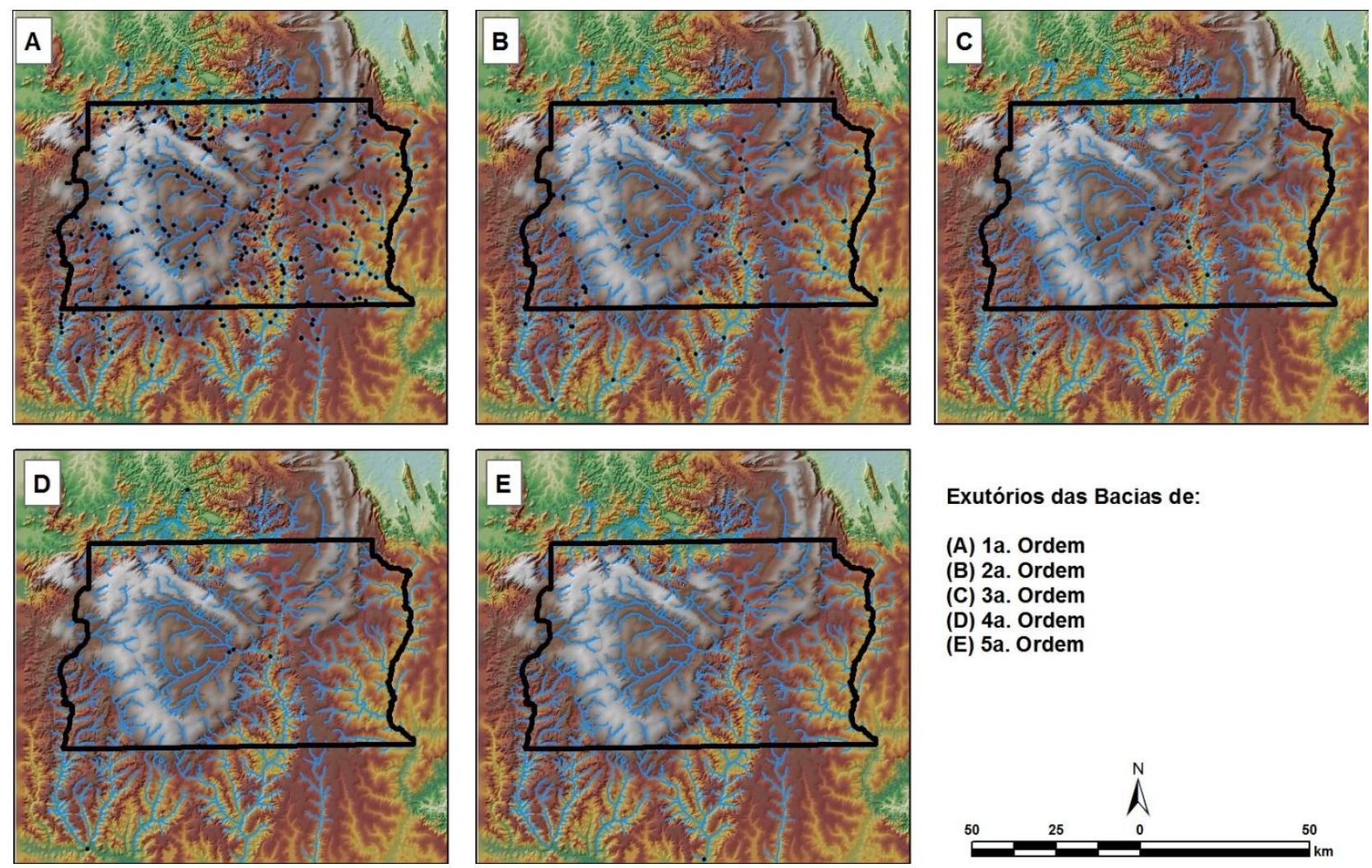

Exutórios das Bacias de:
(A) 1a. Ordem
(B) 2a. Ordem
(C) 3a. Ordem
(D) 4a. Ordem
(E) 5a. Ordem

Figura 13: Exutório das bacias hidrográficas, conforme a hierarquia de Strahler. 


\subsection{CÁLCULO DOS ATRIBUTOS MORFOMÉTRICOS DAS BACIAS DE DRENAGEM}

A espacialização dos atributos morfométricos em bacias de drenagem pode trazer, segundo Oliveira (2008), uma perspectiva integradora dos diversos fatores que atuam sobre o modelado. Vários destes atributos foram formulados para a análise e descrição quantitativa da bacia de drenagem, calculados a partir de características morfométricas, sendo geométricas ou zonais, do relevo e da rede de drenagem.

Neste trabalho foram utilizados diversos parâmetros. Estes parâmetros podem ser divididos em geométricos e geomorfométricos. Os parâmetros geométricos são aqueles definidos pela: área (em planta e, em 3D conforme o relevo), perímetro, índice de circularidade, eixo menor, eixo maior e, orientação da bacia. Já os parâmetros geomorfométricos são definidos pela: altimetria, declividade, curvatura (em planta e perfil), área de contribuição e o índice topográfico (definido por Beven \& Kirkby, 1979). Em todos os parâmetros geomorfométricos, para cada bacia hidrográfica, foram calculados os valores de máxima, mínima, amplitude, média e desvio padrão de cada parâmetro. A seguir descreve-se como cada parâmetro é obtido.

Inicialmente, foi obtido o parâmetro área (em metros quadrados) a partir de duas maneiras. A primeira considera a área total de cada bacia em planta (ou 2D). A segunda forma foi obtida seguindo a topografia interna de cada bacia, ou seja, a área em 3D ou área real. Outro parâmetro geométrico básico é o perímetro, que é a linha imaginária do limite de cada bacia hidrográfica. A razão entre a área (em 2D) e o perímetro é definido como o índice de circularidade (IC). Ele é definido, de acordo com Miller (1953), como o produto da seguinte equação:

$$
I C=\frac{4 \pi A}{p^{2}}
$$

Onde: $A$ é a área da bacia $\left(\mathrm{m}^{2}\right)$ e, $p$ é o perímetro da bacia $(\mathrm{m})$

O índice de circularidade varia de 0-1 em que, os valores próximos a 1 indicam que a bacia possui uma forma mais arredondada. Bacias mais alongadas irão apresentar valores de IC mais próximos a zero. A diferença na obtenção de bacias mais arredondadas ou alongadas é que, de acordo com Miller (1953) e, Schumm (1956), bacias mais arredondadas apresentam um comportamento da hidrógrafa no exutório da bacia de concentração de saída de água, num curto espaço de tempo, quando ocorrem altas precipitações na bacia. Já bacias mais alongadas, apresentam uma distribuição da saída da água, num espaço de tempo maior quando ocorrem precipitações mais intensas. Deste modo, bacias mais arredondadas possuem maiores probabilidades de enchentes na área de seu exutório se comparadas às bacias mais alongadas. 
Outros 3 parâmetros definidos foram: o eixo maior, o eixo menor de cada bacia e, o ângulo de orientação (Figura 14). Os eixos menor e maior são o comprimento dos eixos, em metros. Já a orientação é definida, em graus, entre o ângulo e o eixo maior. A orientação pode variar entre 0 à $180^{\circ}$.

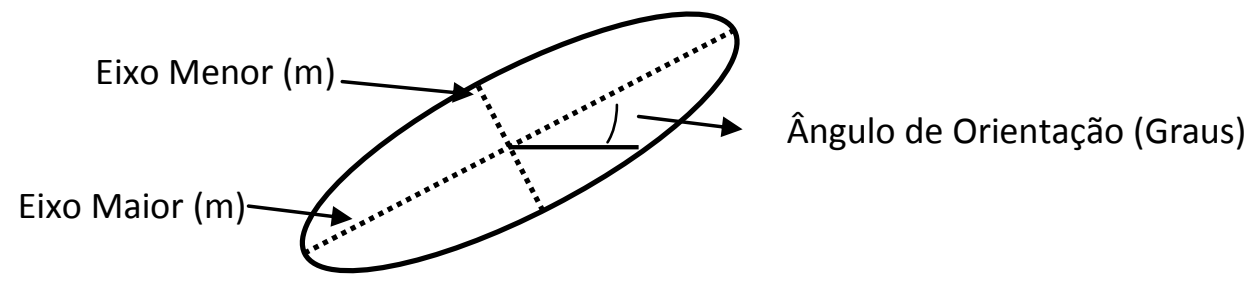

Figura 14: Figura demonstrativa de como é feito o cálculo dos parâmetros de: eixo maior, eixo menor e, orientação da bacia.

Dentre os parâmetros geomorfométricos foram elencados a altimetria, que propícia a identificação da posição topográfica da bacia em metros; a declividade, que é a medida de inclinação da superfície, medida aqui em radianos; a curvatura em planta e perfil, em que valores negativos indicam áreas côncavas, valores positivos área convexas e, valores próximos a zero áreas retilíneas (conforme podemos identificar na Figura 15); e a área de contribuição.

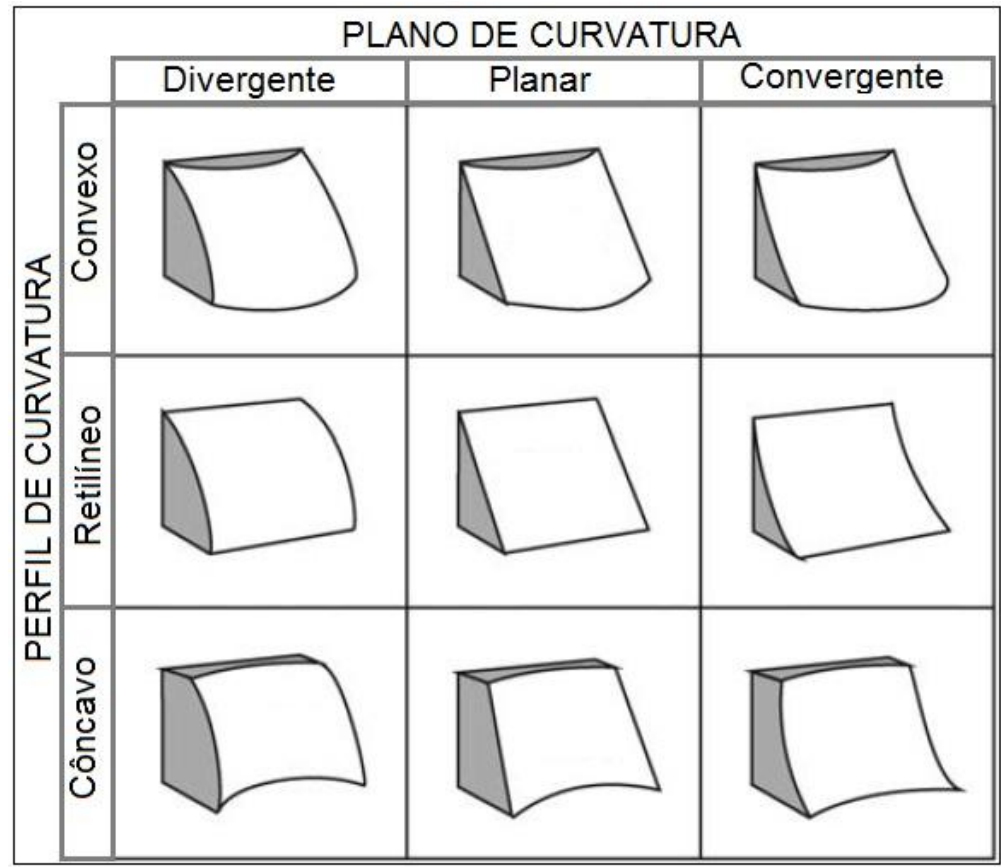

Figura 15: Formas do relevo obtidas a partir das curvaturas em planta e perfil do relevo (Adaptado de Dikau, 1989).

A área de contribuição é definida por toda a área que uma região pode contribuir (Figura 16). Para calcular a área de contribuição foi utilizado o módulo TAUDEM do ArcGis. Este módulo calcula a área de contribuição pelo método Dinf desenvolvido por Tarbon (2002). O último 
parâmetro a ser calculado foi o índice topográfico. O índice topográfico (IT), de acordo com Beven \& Kirkby (1979), é definido através da razão área de contribuição pela tangente da declividade (Equação 2).

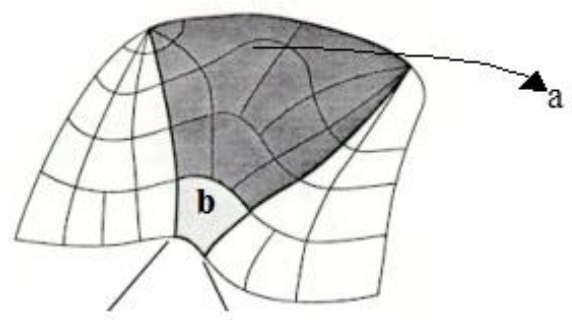

Figura 16: Esquema de como é calculado a área de contribuição em que, a é a área total que drena para b. Deste modo, a área de contribuição é dada pela razão $a / b$.

$$
I T=\ln \left(\frac{a / b}{\tan \beta}\right)
$$

Onde: $\mathrm{a} / \mathrm{b}$ é a área de contribuição, $\tan \beta$ é a tangente do ângulo da declividade $\mathrm{e}, \ln$ é o logaritmo natural.

Para o cálculo dos parâmetros geométricos foi utilizado a ferramenta Zonal Geometry do ArcGis 10.2. Já para a extração dos valores de máxima, mínima, amplitude, média e desvio padrão de cada parâmetro geomorfométrico para cada bacia foi utilizado a ferramenta Zonal Statistics do ArcGis 10.2.

\subsection{ANÁLISE DE GRUPOS PELO MÉTODO K-MÉDIAS}

A análise de agrupamento, proposta neste trabalho como o mecanismo para a classificação das bacias hidrográficas, realiza um processo de classificação similar à que fazemos mentalmente para organizar, agrupar, diferenciar e catalogar o que percebemos. A ferramenta utilizada neste trabalho foi a Grouping Analysis, através do software ArcGis 10.2, que busca encontrar aglomerados naturais dentro do conjunto de dados.

Definida a quantidade de grupos a ser criada, a ferramenta indica uma proposta em que todos os recursos dentro de cada grupo são tão semelhantes quanto possível, e os grupos os mais diferenciáveis entre eles. O recurso de similaridade faz a diferenciação e combinação dos dados com base em um conjunto de campos de atributos pré-definidos pelo usuário, com a opção de serem incorporadas propriedades espaciais e espaço-temporais.

Quando são especificadas restrições espaciais ou espaço-temporais, o algoritmo propõe um grafo de conectividade (minimum spanning tree) para encontrar agrupamentos naturais (Esri, 2012). 
Como exemplo, podemos citar o trabalho desenvolvido por Assunção et al (2006), que propôs um método de regionalização sócioeconômica chamado SKATER (Spatial 'K'luster Analysis by Tree Edge Removal), que combina o uso de uma árvore de cobertura mínima com técnicas de otimização das combinações.

Quando não é feita nenhuma especificação (NO_SPATIAL_CONSTRAINT), a ferramenta utiliza um algoritmo K-média. O método de K-mean, ou K-médias, realiza uma análise interativa, alternando processos de adaptação. Suas possíveis aplicações incluem métodos para agrupamento por similaridade, predições não-lineares, distribuição multivariada aproximada e testes nãoparamétricos (MacQueen, 1967). Conforme Shi \& Zeng (2014), a quantificação aproximada para a medição da distância dos objetos em um conjunto de dados é indispensável para a análise de agrupamento.

Por este método, cada ponto de uma tabela, que contenha todos os atributos morfométricos normalizados, é relacionado a um centróide. A partir de um método Euclidiano foi calculada a distância entre os pontos e o centróide. A classificação das bacias de drenagem foi feita mediante a aglomeração de pontos ao centróide mais próximo, em um sistema hard clustering, isto é, onde cada ponto está associado somente a um centróide, conforme ilustrado na figura 17.

a)

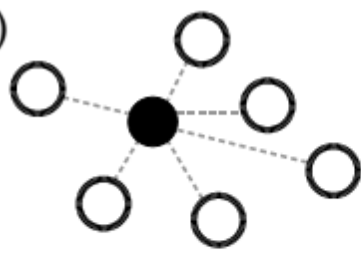

b)

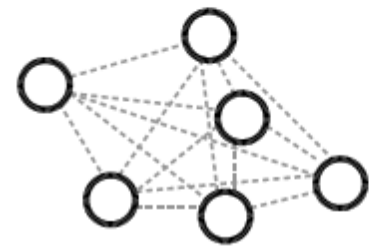

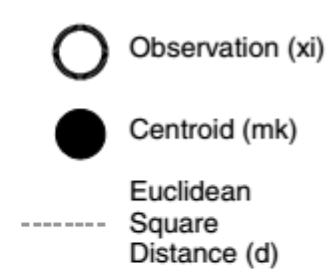

Distance (d)

Figura 17 - Visualização da quantificação pelo método K-médias pela distância Euclidiana (Weatherill \& Burton, 2009).

Na classificação das bacias feita neste trabalho foi utilizada a técnica de análise de grupos, ou de agrupamento, a partir do emprego do método k-média. Acredita-se que a partir desta técnica é possível identificar diferentes análises a partir da combinação e integração de uma diversificada variedade de dados (Esri 2012).

Para identificar quais variáveis são relevantes para a análise de agrupamentos foi feita antes uma análise de correlação entre as variáveis. Esta análise de correlação foi feita utilizando-se a correlação de Pearson e o gráfico de dispersão de pontos entre as variáveis. E o número de grupos 
utilizados foi de 8 grupos. Este valor foi definido, conforme a quantidade de unidades geológicas da área. Como destacado por Martins et al., (2004) a geologia é o substrato sustentador das variáveis sobrepostas. Além disso, conforme destacado por Crepani (1996) a geologia é uma das camadas definidoras das unidades de trabalho básicas. 


\section{RESULTADOS E DISCUSSÃO}

O primeiro resultado a ser analisado é com relação às bacias hidrográficas geradas (Figura 18). Para que toda a área de estudo pudesse ser mapeada, de acordo com alguma ordem de bacia, foi necessário identificar as bacias até a $5^{\mathrm{a}}$ ordem, conforme método de Strahler. Foram identificadas 339 bacias de $1^{\text {a }}$ ordem, 83 bacias de $2^{\text {a }}$ ordem, 24 bacias de $3^{\text {a }}$ ordem, 7 bacias de $4^{\text {a }}$ ordem e, 1 bacia de $5^{\mathrm{a}}$ ordem.
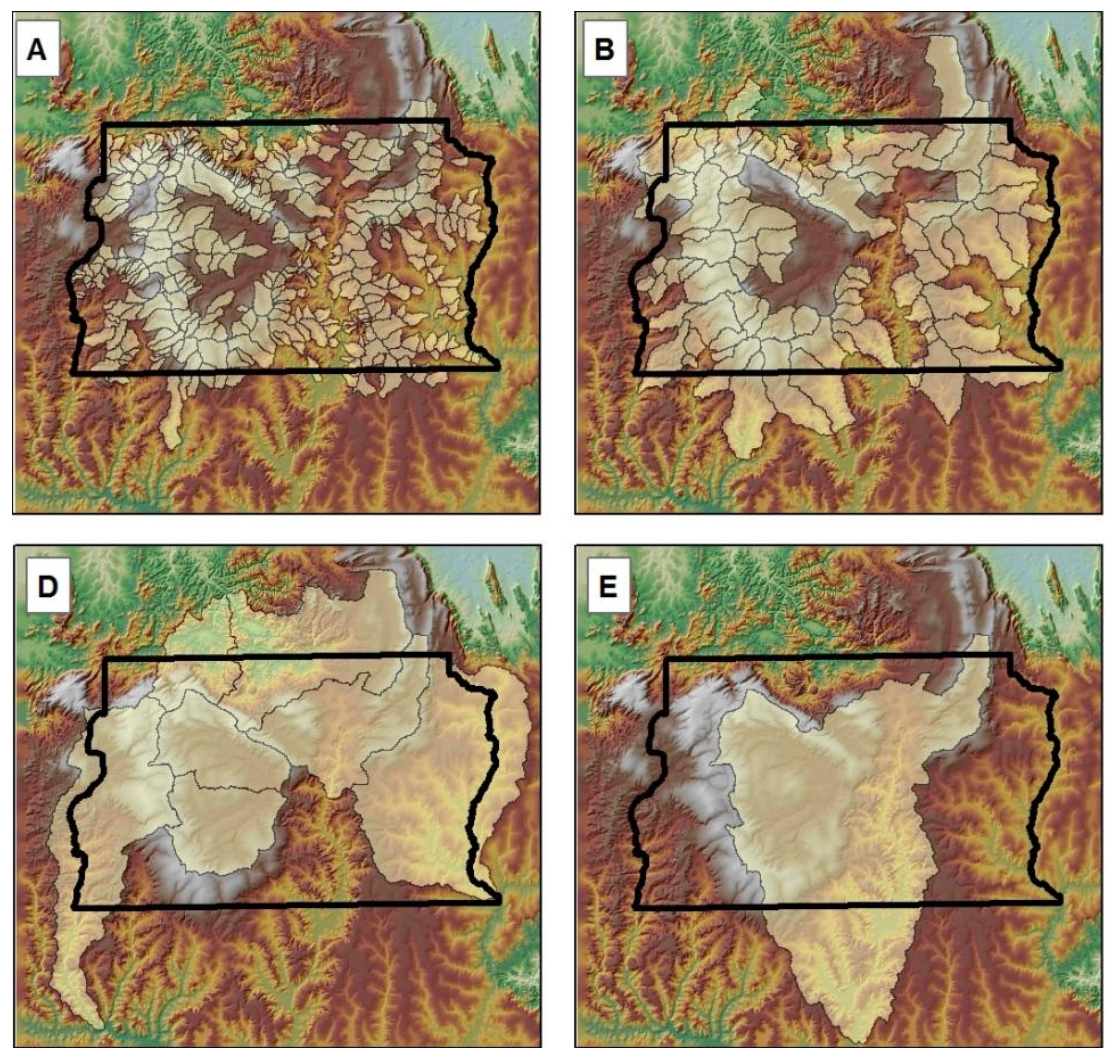

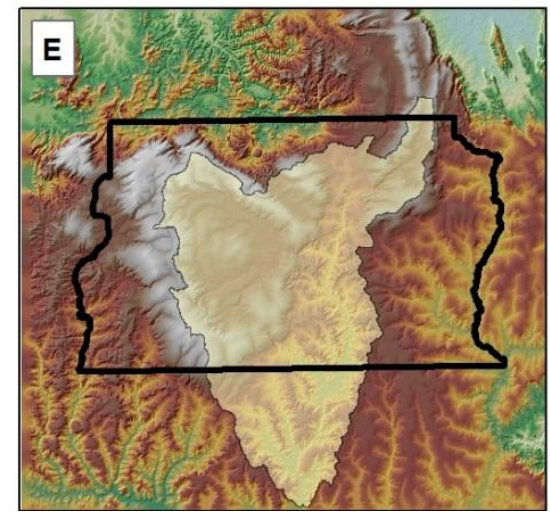

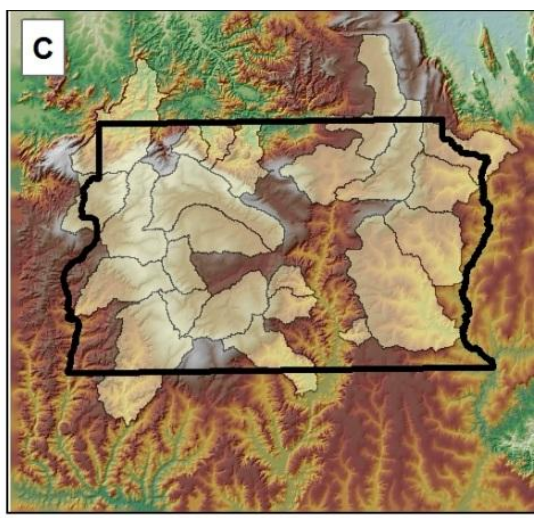

Limite das Bacias Hidrográficas, conforme método de Strahler (1952):
(A) Bacias de 1a. Ordem
(B) Bacias de 2a. Ordem
(C) Bacias de 3a. Ordem
(D) Bacias de 4a. Ordem
(E) Bacias de 5a. Ordem

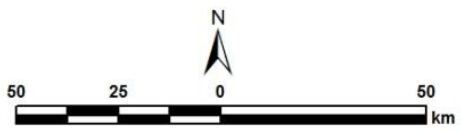

A primeira análise a ser feita é com relação aos parâmetros morfométricos da área estudada. Na tabela 2, verificamos a média e o desvio padrão desses parâmetros nas bacias analisadas. Nota-se que os valores são bem discrepantes nessas variáveis em que, o desvio padrão está sempre próximo à média dos resultados. Isto pode demonstrar que a área de estudo não tem um comportamento padrão. Por exemplo, os valores da média de área e do desvio padrão (tanto em 2D, como em 3D) são bem próximos um do outro. Outros parâmetros que chamam a atenção é o índice de circularidade, o eixo maior e menor. Tanto a média quanto o desvio padrão do índice de circularidade de todas as bacias se apresentam com valores muito baixos. Já o eixo menor possui um valor médio, quase sempre, o da metade do eixo maior. Isto pode demonstrar que, a área de estudo possui bacias mais alongadas do que circulares. Os valores referentes à bacia de quinta ordem não foram colocadas por esta bacia só apresentar uma bacia na área de estudado. 
Tabela 2 - Valores médios e de desvio padrão dos parâmetros morfométricas das bacias analisadas.

\begin{tabular}{|l|c|c|c|c|}
\hline & $\mathbf{1}^{\mathbf{a}}$ Ordem & $\mathbf{2}^{\mathbf{a}}$ Ordem & $\mathbf{3}^{\mathbf{a}}$ Ordem & $\mathbf{4}^{\mathbf{a}}$ Ordem \\
\hline Média da Área (2D) & 11.034 .369 & 59.140 .699 & 192.883 .029 & 877.783 .714 \\
\hline Desvio Padrão da Área (2D) & 9.298 .849 & 46.167 .523 & 117.321 .156 & 476.580 .657 \\
\hline Média da Área (3D) & 11.060 .796 & 59.279 .640 & 193.348 .036 & 880.711 .856 \\
\hline Desvio Padrão da Área (3D) & 9.308 .779 & 46.231 .121 & 117.494 .000 & 477.047 .741 \\
\hline Média do Perímetro & 20.743 & 51.619 & 101.538 & 239.923 \\
\hline Desvio Padrão do Perímetro & 9.484 & 24.348 & 36.391 & 80.692 \\
\hline Média do IC & 0,29 & 0,26 & 0,22 & 0,19 \\
\hline Desvio Padrão do IC & 0,06 & 0,06 & 0,04 & 0,04 \\
\hline Média do Eixo Maior & 2.479 & 5.680 & 10.241 & 22.234 \\
\hline Desvio Padrão Eixo Maior & 1.099 & 2.820 & 3.924 & 8.548 \\
\hline Média do Eixo Menor & 1.257 & 2.941 & 5.521 & 12.043 \\
\hline Desvio Padrão do Eixo Menor & 562 & 1.013 & 1.520 & 3.023 \\
\hline Média da Orientação & 80 & 85 & 90 & 59 \\
\hline Desvio Padrão da Orientação & 54 & 53 & 54 & 51 \\
\hline
\end{tabular}

A análise seguinte se refere aos parâmetros geomorfométricos obtidos a partir do MDE da área de estudo (Figura 18). Nota-se que a altimetria (Figura 18A) da área varia entre 575 à $1350 \mathrm{~m}$ de altitude. As áreas mais elevadas são áreas das unidades geomorfológicas do Pediplano Contagem Rodeador e, onde está a Unidade Geológica de Quartzito Médio do Grupo Paranoá. Já com relação à declividade (Figura 18B) verifica-se que a maior variação de declividades se encontra na Unidade Geológica de Psamo Pelito Carbonatada (do Grupo Paranoá) em que, encontramos solos do tipo Nitossolos e Cambissolo Háplico. O parâmetro de área de contribuição se assemelha muito a um mapa de hidrografia (Figura 18C). Isto ocorre, por serem as áreas de maior contribuição no relevo as de canais de drenagem. Já os parâmetros de curvatura (tanto em planta como em perfil) (Figura 18D e 18E) apresentam uma maior variabilidade de formas côncavas e convexas nas áreas onde encontramos os solos do tipo Camibissolo Háplico e os Nitossolos. Esta região é chamada de APA da Cafuringa, localizada no norte/noroeste do Distrito Federal. Por último temos o índice topográfico (Figura 18F), que demonstra com seus mais altos valores as áreas de possuem pouco declividade e grande área de contribuição. Isso acaba demonstrando que essas áreas podem sofrer com inundação. 

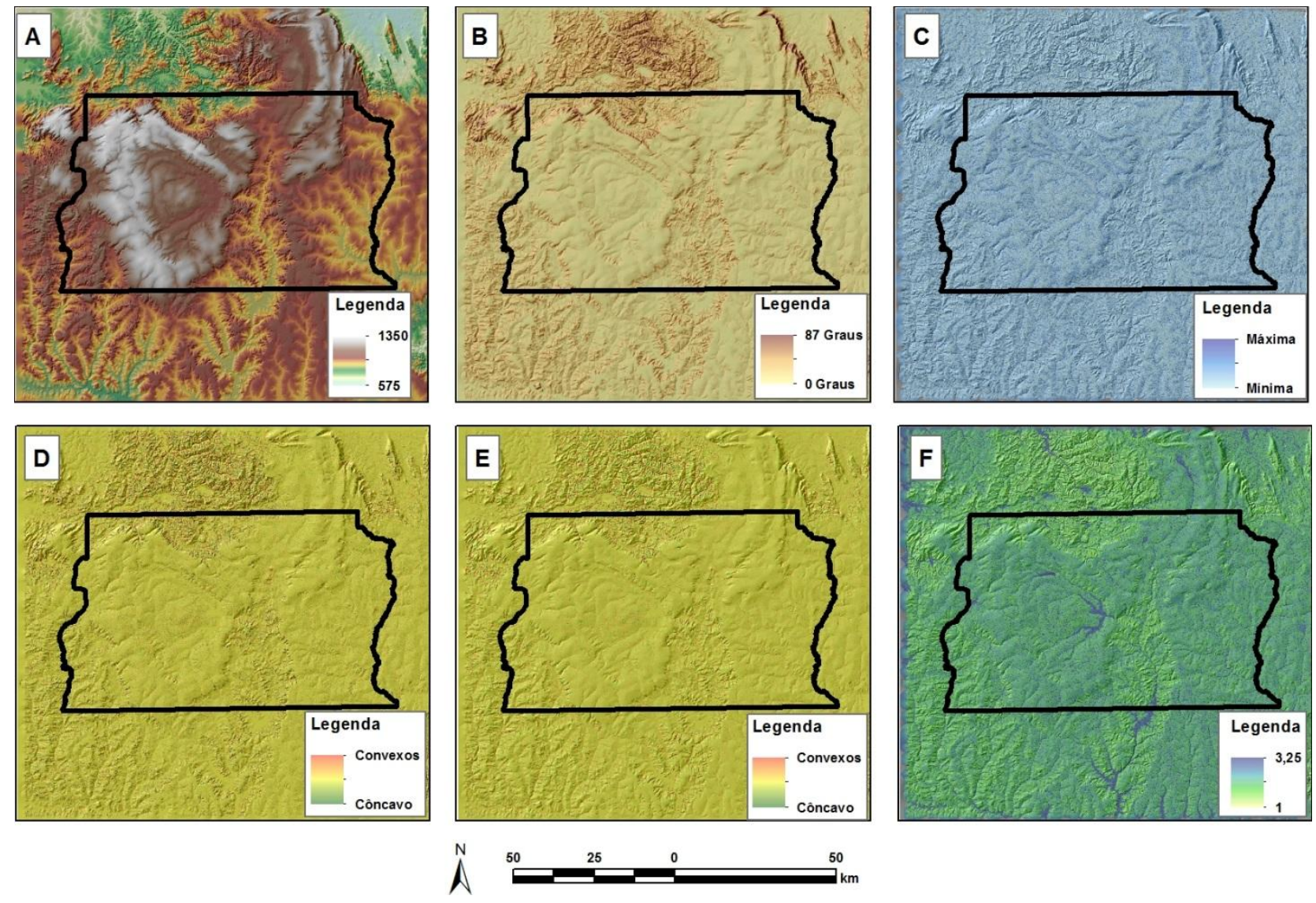

Figura 18 - (A) Mapa de elevação do relevo; (B) Mapa de declividade; (C) Mapa de área de contribuição; (D) Mapa de curvatura do relevo em planta; (E) Mapa de curvatura do relevo em perfil; (F) Mapa do índice topográfico.

Obtidos todos esses parâmetros, para cada bacia, de cada ordem analisada, seguiu-se para a análise do grau de correlação entre as variáveis. Esta análise foi feita através dos gráficos de correlação entre as variáveis (Figura 19) em conjunto, com a análise de correlação de Pearson (Tabela 3). E a partir destas análises, foram definidas quais as variáveis importantes para a análise de agrupamentos.

Ao analisarmos todos os gráficos (Figuras 19) e a tabela 3 verificamos que das 33 variáveis analisadas somente 25 obtiveram grau de correlação entre elas. Das variáveis morfométricas analisadas (Área em 2D e 3D, Perímetro, Eixo Maior e Menor, Orientação e, Índice de Circularidade) somente Orientação e Índice de Circularidade (IC) foram as variáveis que não possuíram correlação com nenhuma variável analisada. Já quando analisamos as variáveis geomorfométricas (Elevação, Declividade, Área de Contribuição, Curvatura em Planta e Perfil e, Índice Topográfico - todas estas variáveis foram analisadas com relação aos seus valores de máximo e mínimo, média, amplitude e desvio padrão) verificou-se que houve um maior número de variáveis que não obtiveram correlação entre as outras variáveis. As variáveis que não obtiveram correlação foram: Máximo e Mínimo da Elevação; Média da Curvatura em Planta e em Perfil; e, Desvio Padrão do Índice Topográfico (IT). 


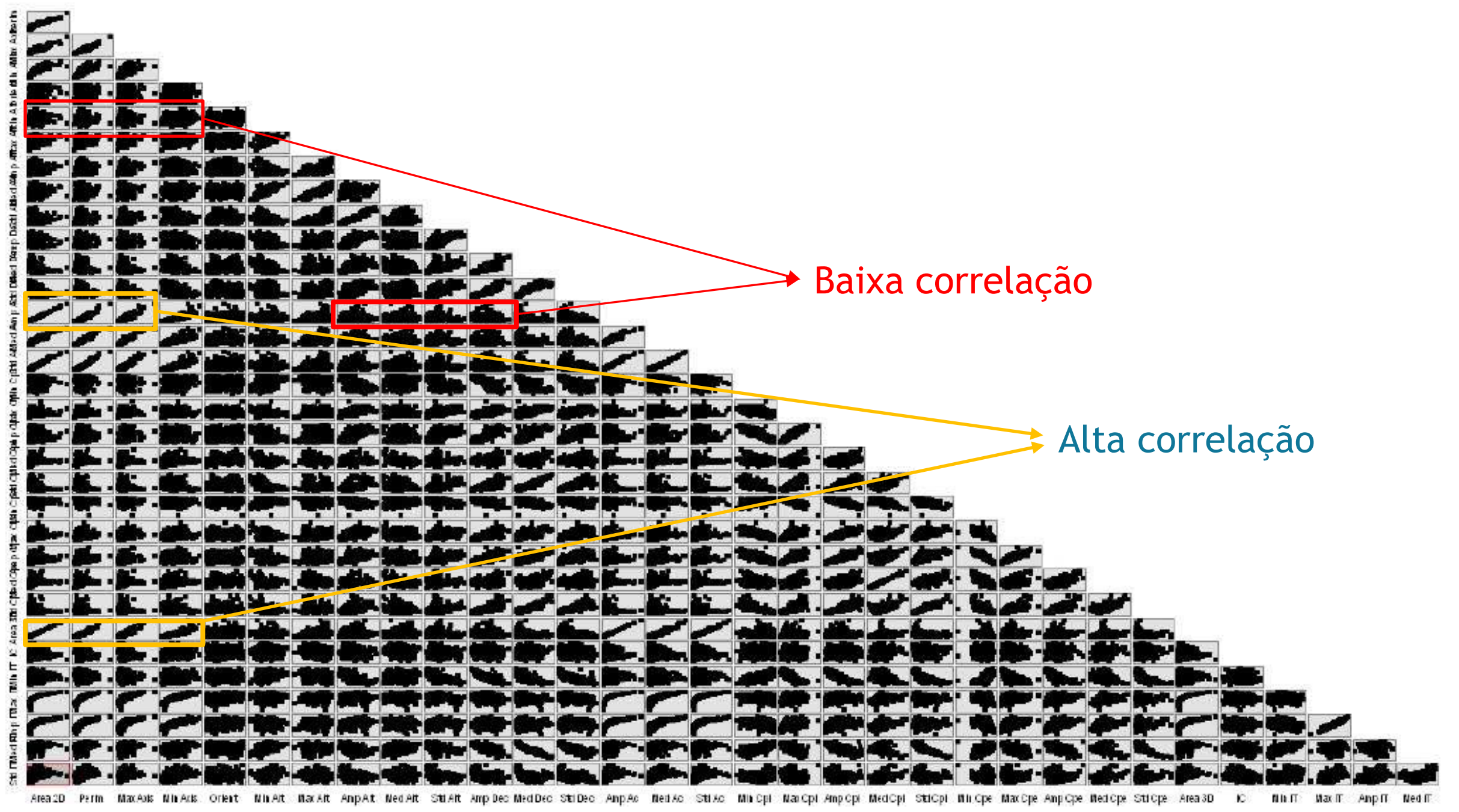

Figura 19 - Gráfico de correlação das variáveis analisadas. 


\begin{tabular}{|c|c|c|c|c|c|c|c|c|c|c|c|c|c|c|c|c|c|c|c|c|c|c|c|c|c|c|c|c|c|c|c|c|c|}
\hline & & & & & & 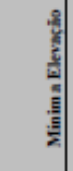 & 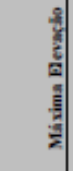 & 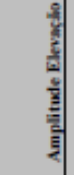 & : & 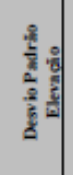 & 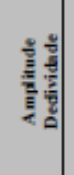 & 童 & 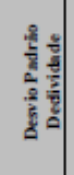 & 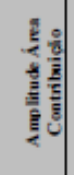 & 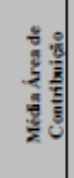 & 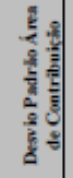 & 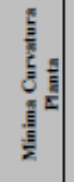 & 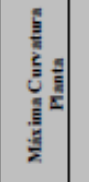 & 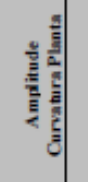 & 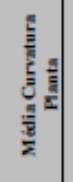 & 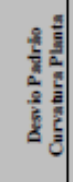 & 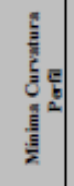 & 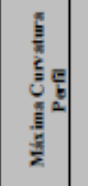 & 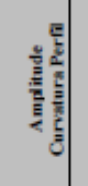 & 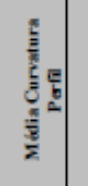 & 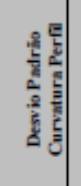 & & & 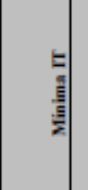 & & & 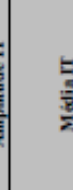 & \\
\hline Area 2D & & 0.96 & & 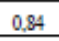 & 0,08 & 0,08 & 0,15 & 0,10 & 0.09 & 0,02 & 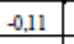 & 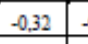 & $-0,30$ & 1,00 & 0.94 & 0.98 & 0,08 & 0.06 & $-0,01$ & 0,07 & \begin{tabular}{|l|}
$-0,31$ \\
\end{tabular} & $-0,10$ & 0.02 & 0.07 & 0.07 & -0.27 & 1,00 & 0.18 & .04 & 83 & 78 & 34 & \\
\hline Perimetro & & & & & & & \begin{tabular}{|l|}
0.17 \\
\end{tabular} & 0.12 & (1) & 80 & $-0,14$ & $-0,37$ & \begin{tabular}{|l|} 
\\
\end{tabular} & 0.96 & 0.96 & 0.97 & 0,09 & 0.06 & -0.01 & 0,11 & \begin{tabular}{|l|}
$-0,33$ \\
\end{tabular} & $-0,11$ & 0.04 & 0.08 & 0,11 & -0.28 & 0,96 & -0.35 & 0.06 & 0.86 & 80 & 0.39 & \\
\hline Maior & & 0.95 & & & & & 11 & 22 & 11 & 0.10 & $-0,06$ & 0.28 & -0.25 & 0,91 & 0.94 & 0.93 & 0,02 & 0.10 & 0.05 & 0,09 & -0.26 & $-0,13$ & 0.09 & 0.12 & 10 & -0.23 & \begin{tabular}{|l|}
0.92 \\
\end{tabular} & -0.38 & 0.01 & .79 & 75 & 30 & \\
\hline Eiro & 34 & 0.80 & 0.65 & & 0.10 & 14 & 0.05 & $-0,07$ & 0.06 & $-0,19$ & -0.21 & $-0,38$ & $\begin{array}{l}-0,39 \\
\end{array}$ & 0.85 & 0.77 & 0.81 & 0.15 & $-0,01$ & -0.09 & 0.10 & $-0,37$ & $-0,07$ & -0.02 & 0.03 & 0.10 & -0.31 & 0.84 & 0.13 & 0.10 & 0.89 & 81 & 0.39 & 0.40 \\
\hline Onier & & 0.06 & 0.04 & 0.10 & 1 & -0.05 & $-0,03$ & 0,01 & $-0,08$ & 0.02 & $-0,05$ & 0,01 & -0.07 & 0,08 & 0.05 & 0.07 & 0,09 & 0.02 & -0.03 & 0,11 & $-0,01$ & $-0,04$ & -0.05 & $-0,01$ & oll & 0,00 & 008 & 40 & 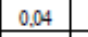 & & 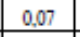 & nom & \\
\hline Min & 8 & 0.09 & 0.03 & 0.14 & -0.05 & 1 & 0,59 & -0.25 & 0.83 & $-0,25$ & $-0,38$ & 45 & $-0,36$ & 0,08 & 0.07 & 0.06 & 0.30 & $-0,33$ & -0.35 & -0.30 & $-0,44$ & 0.31 & -0.32 & $-0,35$ & 30 & -0.40 & 0,08 & $-0,07$ & 0.42 & 08 & 07 & 49 & \\
\hline Márima & . & 0.17 & 0.21 & 0.05 & \begin{tabular}{|l|}
-0.03 \\
\end{tabular} & $0,0.59$ & 1 & 0,64 & 0.89 & 0,59 & 0,31 & 0.11 & 0.266 & \begin{tabular}{l|l|}
0,15 \\
\end{tabular} & \begin{tabular}{l|l}
0.18 \\
\end{tabular} & 0.14 & $-0,29$ & 0.20 & 0.27 & -0.15 & 0.07 & $-0,14$ & 0.22 & 0.20 & -0.15 & 0,02 & \begin{tabular}{|l|l|l|} 
\\
\end{tabular} & \begin{tabular}{|l|}
-0.24 \\
\end{tabular} & $-0,19$ & .07 & 13 & 0.05 & \\
\hline & & 0.12 & (1) & 07 & & & 0,64 & 1 & 0.28 & 0.94 & 0,73 & 056 & 0.66 & 0.10 & 0.14 & 0.11 & $-0,62$ & 0.56 & 0.66 & 0.11 & 0,50 & $-0,46$ & \begin{tabular}{|l|l} 
\\
\end{tabular} & 0.57 & 0.10 & 0.41 & \begin{tabular}{|l|l|l|}
0.10 \\
\end{tabular} & -0.22 & $-0,63$ & $\infty$ & | & -0.41 & 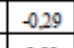 \\
\hline$\underline{M e}$ & & 0.11 & 0.11 & 06 & 08 & & 89 & 0.28 & 1 & 0.25 & 0,03 & -0.16 & 0.02 & 0,09 & 0.12 & 0.08 & $-0,06$ & $-0,07$ & -0.01 & -0.34 & $-0,19$ & 0.12 & \begin{tabular}{|l|}
-0.01 \\
\end{tabular} & $-0,07$ & -0.34 & -0.20 & 0.09 & -0.17 & 0.09 & 0.03 & $\infty$ & 28 & \\
\hline Der & 2 & $-0,01$ & 0.10 & $-0,19$ & 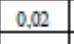 & 5 & 0,59 & 0.94 & 0.25 & 1 & 0,70 & \begin{tabular}{l|l}
0.56 \\
\end{tabular} & 0,68 & $-0,02$ & 0.01 & $-0,02$ & -0.55 & 0.51 & 0,59 & 0,03 & \begin{tabular}{|l|l|}
0.49 \\
\end{tabular} & $-0,39$ & 0.44 & 0.45 & 0.03 & 0.36 & \begin{tabular}{|l|}
$-0,02$ \\
\end{tabular} & \begin{tabular}{|l|}
$-0,20$ \\
\end{tabular} & $-0,59$ & $-0,13$ & 99 & 40 & \\
\hline & & - & 0, & & & & 0,31 & 073 & nem & & & 0.83 & 0.93 & -0.11 & & $-0,10$ & -0.82 & & & & 0. & \begin{tabular}{l|l|}
-0.62 \\
\end{tabular} & & & & & & & & & & & \\
\hline Métia D & -0.32 & $-0,37$ & -0.28 & .38 & & 45 & 0,11 & \begin{tabular}{l|l}
0,56 \\
\end{tabular} & -0.16 & 0,56 & 0.83 & 1 & 0,90 & $-0,32$ & $-0,35$ & -0.31 & $-0,69$ & 0.65 & 0,75 & 0,35 & 0,93 & $-0,60 \mid$ & 0.62 & 0.68 & 0,35 & 0.88 & \begin{tabular}{|l|}
-0.32 \\
\end{tabular} & 0.16 & -0.78 & . 399 & 09 & 94 & \\
\hline & -030 & -024 & 025 & 39 & -0.07 & 36 & 0.26 & 0.66 & nm & 0.68 & 0.03 & 0.90 & 1 & \begin{tabular}{|l|l|l|} 
\\
\end{tabular} & \begin{tabular}{|c|}
$-0,33$ \\
\end{tabular} & $-0,30$ & \begin{tabular}{|l|l|l|} 
\\
\end{tabular} & 0.63 & 0,77 & 0,14 & \begin{tabular}{|l|}
0.81 \\
\end{tabular} & \begin{tabular}{|l|}
$-0,52$ \\
\end{tabular} & 0.63 & 0.63 & 0.14 & 0.76 & \begin{tabular}{|l|}
$-0,30$ \\
\end{tabular} & 0.05 & -0.80 & 40 & 99 & 9 & \\
\hline & & & & & & & & (10 & & 2 & $-0,11$ & & $-0,36$ & 1 & 0.94 & 0.98 & 0.08 & & 001 & 0,07 & $-0,31 \mid$ & 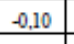 & & & & - & & & & & & & \\
\hline Métia & & 0.96 & 0.94 & 0.77 & 0.05 & 0.0 & 0,18 & 0.14 & 0.12 & 0.01 & $-0,13$ & $-0,35$ & -0.33 & 0.94 & 1 & 0.98 & 0.07 & 0.06 & 0,00 & 0.13 & $-0,31$ & $-0,10$ & 0.05 & 0.09 & 0.13 & -0.26 & 0.94 & -0.32 & 0.05 & 0.84 & 9 & 0 & \\
\hline & & 0.97 & 0.3 & & 07 & & 0.14 & 0.11 & 00 & $-0,02$ & $-0,10$ & \begin{tabular}{c|c}
$-0,31$ & -
\end{tabular} & $-0,30$ & 0.98 & 0.98 & 1 & 0.07 & 0.08 & 0,01 & 0.11 & $-0,29$ & $-0,12$ & 0.05 & 0.09 & 0.11 & -0.24 & 0.98 & -0.23 & no & & & & \\
\hline & & & & & & & & & & & -0.82 & & $-0,76$ & 0.08 & & 0.07 & & $-0,00$ & - & -0.1 & -1, & 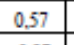 & $-0,82$ & $-0_{1.4}$ & & -0. & & & & & & & \\
\hline & 0.0 & - & 0.10 & $-0,01$ & 0.02 & -0.33 & 0.20 & 0.56 & $-0,07$ & 0.51 & 0.70 & 0.65 & 0.63 & 0.06 & 0.06 & 0.08 & $-0,60$ & 1 & 0.90 & 0,49 & 0,71 & -0.87 & 0.64 & 0.84 & 0,49 & 0.67 & 0.06 & -0.03 & -0.81 & .03 & 32 & .60 & \\
\hline & & & & & & & 27 & & & & 0.85 & & 0,77 & $-0,01$ & 0.00 & 001 & $-0,88$ & 0.90 & 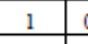 & 0,38 & \begin{tabular}{|l|l|}
0.79 \\
\end{tabular} & $-0,81$ & 0.81 & $0 s$ & & 0,77 & & & 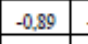 & 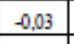 & & & \\
\hline & & 0.1 & & & & & -0.1 & & & 0.0 & 0.2 & & 0.14 & 0,07 & 0.13 & 0.11 & $-0,17$ & 0,49 & 0.38 & 1 & 0,51 & $-0,58$ & 0.34 & 0.52 & 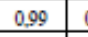 & 0.55 & 7 & & 135 & 107 & 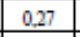 & & \\
\hline Derrio $P$ & -0.31 & -0.33 & -0.26 & $-0,37$ & $-0,01$ & 44 & 0.07 & 0.50 & $-0,19$ & 0,49 & 0,75 & \begin{tabular}{l|l}
0.93 \\
\end{tabular} & 0,81 & -0.31 & $-0,31$ & $-0,29$ & $-0,71$ & 0.71 & 0,79 & 0,51 & 1 & -0.66 & 0.06 & 0.73 & 0.51 & 0.94 & \begin{tabular}{|l|}
-0.31 \\
\end{tabular} & 0.07 & $-0,77$ & -0.35 & .06 & 90 & 0.3 \\
\hline & & & & & & & & & & & & & -0.52 & \begin{tabular}{|c|} 
\\
\end{tabular} & & & & & & -0.58 & \begin{tabular}{ll|}
-0.66 \\
\end{tabular} & 1 & -0.62 & & & st & & & 0.75 & & & & \\
\hline Matima & 0. & 0.04 & 0.09 & $-0,02$ & \begin{tabular}{|l|}
-0.05 \\
\end{tabular} & -0.32 & 0.22 & 0,57 & $-0,01$ & 0.44 & 0,72 & \begin{tabular}{l|l}
0.62 \\
\end{tabular} & 0,63 & 0,02 & 0.05 & 0.05 & $-0,82$ & 0.64 & 0.81 & 0.34 & 0.66 & $-0,62$ & 1 & 0.89 & 0.34 & 0.72 & 0,03 & 0,0 & $-0,0,4$ & 0.07 & 35 & -0.61 & \\
\hline & & 00 & 012 & 00 & 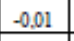 & 035 & 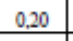 & 057 & 007 & 045 & 0.74 & 068 & 0.63 & 0.07 & 0.09 & 0.09 & -0.76 & 0.84 & 0,00 & 0,52 & \begin{tabular}{|l|l|} 
\\
\end{tabular} & $-0,91$ & 0.89 & & 0.51 & 0,77 & gon & & -0.83 & | & & & \\
\hline & & & & & & & & & & & & & & & & & & & & 0.5 & & & & & & 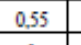 & & & -0.35 & & & & \\
\hline & -0 & -0. & -023 & -0.31 & 0 & -0.40 & 0.02 & 0.41 & $-0,20$ & 0.36 & 0,71 & 0.88 & 0,76 & -0.27 & $-0,26$ & -0.24 & $-0,72$ & 0.67 & 0.77 & 0.55 & 0.94 & \begin{tabular}{l|l|} 
& $-0,66$ \\
\end{tabular} & 0.72 & 0.77 & 0.55 & 1 & \begin{tabular}{|l|}
-0.26 \\
\end{tabular} & 0.05 & $-0,73$ & -0.28 & $\infty$ & 85 & \\
\hline & 1.0 & 0.9 & 0.92 & 0.84 & & & & & & & - & & & 10 & & & & & & 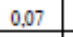 & & & & & & & & ara & & & & & \\
\hline IC & & -0 & -0.38 & 0,13 & & & & & & & - & & 0,0 & -0.2. & & & 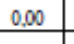 & &,- 0.03 & 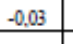 & 0,0 & $-0,01$ & 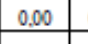 & 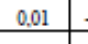 & & 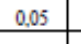 & & 1 & 年 & & $\infty$ & & \\
\hline Mi & 0.04 & 0.0 & $-0,01$ & 0.10 & \begin{tabular}{|l|l|}
0.04 \\
\end{tabular} & 0.42 & -0.19 & -0.63 & 0.00 & $-0,59$ & -0.88 & -0.78 & -0.80 & 0.04 & 0.05 & 0.03 & 0,78 & -0.81 & -0.89 & -0.35 & \begin{tabular}{|l|}
$-0,77$ \\
\end{tabular} & 0.75 & -0.74 & -0.83 & -0.35 & -0.73 & \begin{tabular}{|l|l|}
0.04 \\
\end{tabular} & -0.05 & 1 & \begin{tabular}{|l|l|}
0.07 \\
\end{tabular} & 0.30 & 7 & \\
\hline & & & & & & & & & & & & & & & & & & & & & & & & & & & & & & & & & \\
\hline & & 0.8 & 0.75 & 0.81 & 0. & -0. & & & 0.00 & 0.05 & $0,1-1$ & $-0,06$ & $-0,09$ & 0.7 & 0.7 & 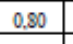 & $-0,4$ & 0.32 & 0.29 & 0.27 & -0.06 & $\begin{array}{l}-0.38 \\
\end{array}$ & 0.33 & 0.39 & 0.28 & 0.00 & 0.78 & 0,00 & -0.30 & & 1 & 7 & $0,5$. \\
\hline & 0.34 & 0.39 & 0.30 & 0.39 & 0.00 & 0,49 & 0,05 & -0.41 & 0.28 & $-0,40$ & $-0,74$ & $-0,04$ & $-0,79$ & 0.34 & 0.36 & 0.32 & 0.67 & -0.60 & -0.71 & -0.38 & $-0,90$ & 0.57 & \begin{tabular}{|l|l}
-0.61 \\
-1
\end{tabular} & -0.66 & -0.37 & -0.85 & 34 & 19 & 0.77 & 37 & 0.07 & 1 & \\
\hline Perrio Padrion & 0.36 & 0.46 & 0.38 & 0,40 & \begin{tabular}{|l|l|} 
& -0.01 \\
\end{tabular} & 0.20 & $-0,09$ & -0.29 & 0,00 & -0.36 & -0.43 & $-0,53$ & & 0.35 & 047 & 030 & 0.28 & -0.10 & & & 0.30 & 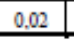 & 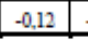 & 008 & & & & & & 0.46 & 32 & & \\
\hline
\end{tabular}

Tabela 3 -Tabela de correlação entre as variáveis analisadas. 
Com as variáveis selecionadas, a fase seguinte, foi feita a análise de agrupamentos (Figura 22). Foram definidas 8 classes para a análise de agrupamentos, conforme destacado na metodologia. Nota-se uma continuidade e proximidade dos grupos pelas bacias adjacentes, apesar do método Kmédias, não utilizar a proximidade para agrupar uma bacia. Isso denota um comportamento estatístico das variáveis analisadas. Quando comparamos este mapeamento com as unidades litológicas verifica-se que os grupos possuem uma correlação. Percebe-se a clara definição pela classe 8 ao norte do DF que é uma de litologia carbonática, com presença de nitossolos e geomorfologia de depressão. Nota-se também nesta região, ao norte do DF, a classe 4 que define a transição da região carbonática (de depressão geomorfológica) para a Chapada da Contagem que possuem uma elevação maior e forma o domo estrutural de Brasília. Verificamos também, a depressão do Paranoá sendo bem definida pela continuidade de bacias próximas da classe 3. Esta classe 3, possuí ocorrência em outras áreas do DF que estão associadas a áreas de planícies aluviais, conforme o mapa geomorfológico. Verifica-se também que a classe 2 ocorre em duas regiões específicas que são, as áreas de planície dos rios São Bartolomeu e Rio Preto. Nota-se que, os fragmentos menores possuem uma correlação direta com as unidades litológicas e, os fragmentos maiores sofrem influência das variações regionais da área.

As UTBs propostas para o ZEE-DF foram definidas, conforme consta no relatório técnico, segundo os riscos de perdas dos seguintes critérios: (a) solo por erosão, (b) áreas de recarga, vulneráveis à contaminação de aquíferos, e (c) áreas de vegetação nativa. Logo, podemos observar que os critérios foram definidos tendo como base parâmetros físicos apresentados através do mapa pedológico, do mapa geológico e o de vegetação, considerando as porções nativas preservadas de cobertura vegetal identificadas em mapa e verificadas em campo do cenário mais atual do Distrito Federal acessível. A delimitação das UTBs pelo ZEE-DF foi feita a partir da combinação destes três critérios, considerando os limites das unidades hidrográficas balizadoras em sua construção.

Nesta etapa foi feita a comparação das propostas de UTBs visando observar a compatibilidade dos agrupamentos obtidos a partir das variáveis morfométricas, considerando os valores de baixa e alta correlação, e das definidas no ZEE-DF para a proposição de subsídios ao processo de parametrização dos critérios estabelecidos. Nota-se que as unidades neste trabalho possuem uma maior continuidade, enquanto que as definidas pelo ZEE-DF são definidas basicamente pelo limite da unidade hidrográfica. O que se pode verificar que UTBs feitas pelo ZEEDF perdem algumas características intrínsecas a uma área. Exemplo, claro é quando ela define a Unidade Oeste Maranhão. Na metodologia definida por este trabalho, consegue-se diferenciar a parte carbonática desta região, além de identificar a área de rebordo do Domo de Brasília que é uma de processos erosivos intensos. 


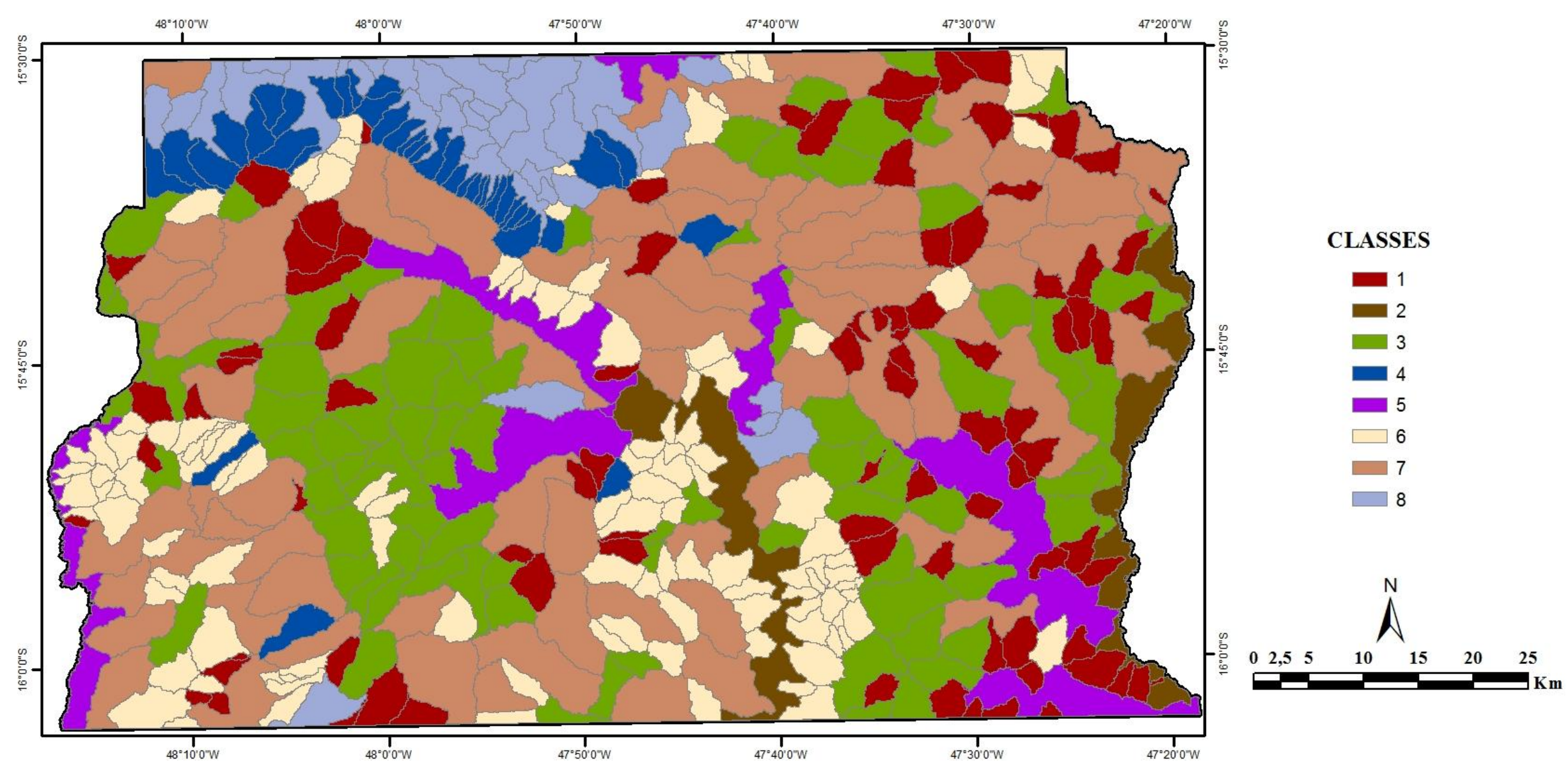

Figura 20 - Classificação por análise de agrupamentos por bacia hidrográfica analisada, através do método de K-médias. 
Unidades Territoriais Básicas (UTB) Propostas e do ZEE - DF

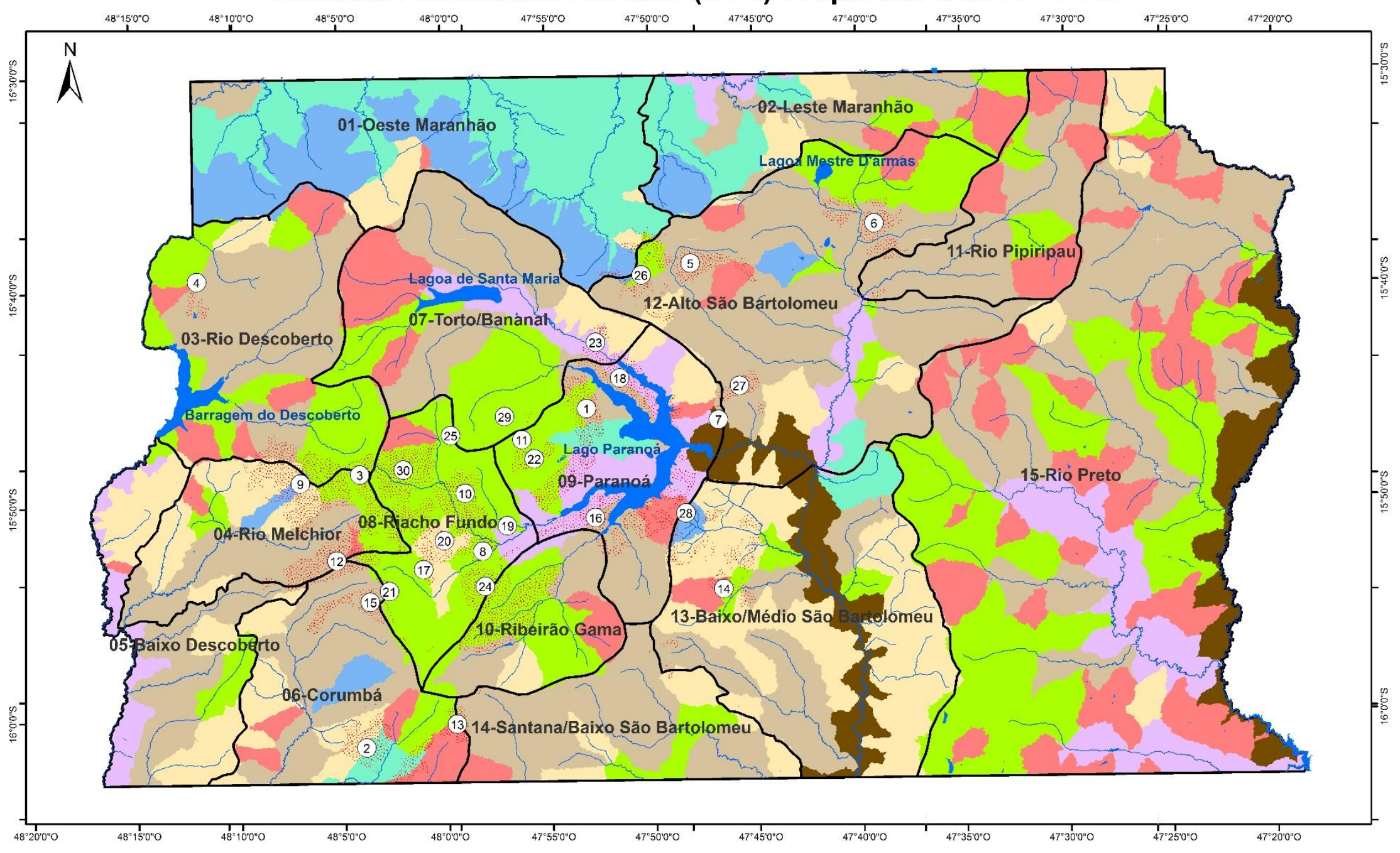

Legenda:

口 UTBs (ZEE-DF) $=$ UTB 1 UTB $2=$ UTB $3=$ UTB $4=$ UTB $5-$ UTB $6=$ UTB $7=$ UTB 8

Fonte: Base cartográfica do GDF 1:100.000 Processamento de MDE de imagens SRTM - resoluçăo de $30 \mathrm{~m}$ Projeçăo: SIRGAS 2000 .
Convencôes Cartográficas:

— Rios Lagos î. Área Urbana
1- Brasilia 7-Paranoá $\begin{array}{ll}\text { 2- Gama } & \text { 8- Núleo Ban } \\ \text { 3- Taguatinga } & 9 \text {-Ceilândia }\end{array}$ 4 - Brazlândia 10 - Guará 5- Sobradinho 11 - Cruzeiro
6- Planaltina 12 - Samambaia
Regiōes Administrativas (RA):

Figur:

$\begin{array}{lll}13-\text { Santa Maria } & 19 \text { - Candangolândia } & 25 \text { - SCIA } \\ 14-\text { Sãa Sebastiäo } & 20 \text { - Aguas Claras } & 26 \text { - Sobradinho II } \\ 15-\text { Re } & \end{array}$ 15 - Recanto das Emas 21 - Riacho Fundo II 27 - Itapoä 16- Lago Sul 22 - Sudoeste/ Octogonal 28 - Jardim Botânico $\begin{array}{lll}17 \text { - Riacho Fundo } & 23 \text { - Varjäo } & 29 \text { - SIA } \\ 18 \text { - Lago Norte } & 24 \text { - Park Way } & 30 \text { - Vicente Pires }\end{array}$ 


\section{CONCLUSÃO}

A falta de padronização ou o não estabelecimento de diretrizes metodológicas para a delimitação dos zoneamentos resultam em propostas distintas e até incompatíveis. Isto pode afetar a avaliação da qualidade, o nível de confiabilidade de cada zoneamento e o processo de integração dos dados e informações de ZEE's de todo o território nacional.

A ação estatal, muitas vezes pelos excessos em fragmentação de suas frentes de atuação, também não tem considerado questões essenciais para a execução de suas políticas, produzindo resultados distantes ao que se esperava, apesar de um conjunto demasiado de esforços e investimentos. Outro ponto a ser avaliado é a consideração tanto da agenda verde quanto da marrom para a construção de políticas e de suas respectivas diretrizes e estratégias. Somado ao panorama traçado, se observa a desconexão entre as iniciativas dos entes da Federação e suas respectivas pastas, o que tem ocasionado prejuízos na gestão das áreas rurais e urbanas, tanto de recursos financeiros como humanos, e que poderiam ser minimizados caso houvesse maior integração entre as políticas de gestão ambiental e territorial, nas diferentes instâncias de atuação Estatal.

O processo de agrupamentos e distinções espaciais são estabelecidos conforme a percepção geográfica e as técnicas de geoprocessamento utilizadas, bem como aos aspectos elucidados. Entende-se que a proposta e o enfoque de um zoneamento ambiental pode ser compreendido com maior facilidade a partir da definição das categorias geográficas utilizadas na delimitação das suas respectivas zonas.

As delimitações, bem como os agrupamentos de porções consideradas similares, são resultado de uma proposta metodológica que incorpora novas possibilidades de processamento e de análise. A elaboração de bases metodológicas para a construção de zonas e a sua documentação facilita a utilização dos produtos do zoneamento indo além do contexto do Programa de governo que se insere o instrumento, e contribui para um maior aporte de qualidade e consistência conceitual à base de dados do zoneamento.

O propósito da delimitação de UTB em zoneamentos ambientais a partir das bacias hidrográficas considera a dinâmica inerente ao ambiente natural (Lanna, 1995), suas fragilidades e potencialidades (Barbosa \& Soares, 2001), e pode associar e ser desenvolvido com a inclusão de dados relacionados à atuação antrópica (Amaral \& Ross, 2009).

Por ser uma unidade fundamental em estudos ambientais e objeto central em análise das unidades de paisagem, o uso da bacia hidrográfica na delimitação das UTB mostra-se como uma opção importante por integrar já na primeira proposta de desenho a dinâmica do recurso natural essencial para a manutenção e equilíbrio ecossistêmico e para o uso econômico e social do espaço - 
a água. Isso oferece melhores condições de integração de políticas de caráter territorial e ambiental, favorecendo assim o uso e a gestão dos recursos naturais.

Destaca-se que, as variáveis que obtiveram correlação foram as mesmas para as diferentes ordens analisadas, o que demonstra o forte controle litoestrutural da área estudada. Além disso, a metodologia proposta delimita as áreas de $1^{\mathrm{a}}, 2^{\mathrm{a}}, 3^{\mathrm{a}}, 4^{\mathrm{a}}$ e $5^{\mathrm{a}}$ ordem formando um mosaico. Acredita-se que a definição das UTB a partir desta proposta de mosaico poderá auxiliar o gestor na identificação e melhor qualificação da sua área de trabalho, a partir de critérios quantificáveis, logo, de fácil mensuração. A identificação das unidades via ordenamento hidrográfico e combinação com parâmetros morfométricos é de extrema importância para a gestão do território, em especial das áreas que necessitam de diretrizes e ações específicas, como as identificadas quando delimitadas as bacias de $1^{\mathrm{a}}$ ordem, referentes às áreas das nascentes de uma bacia hidrográfica.

O número de classes para a delimitação das UTB foi feito utilizando-se como base a geologia, mas entendemos que poderia ter sido feita a partir dos limites das grandes bacias hidrográficas, por exemplo, ou de outros aspectos correlacionados à paisagem, considerados de relevância para a proposta de zoneamento ambiental.

A proposta mostrou-se satisfatória devido ao rápido método de obtenção, mas para o seu emprego em toda e qualquer proposta de zoneamento ambiental há de se ter a garantia de um imageamento da área com qualidade espectral suficiente para a geração de unidades da paisagem de acordo com a escala cartográfica desejada.

Não foi o objetivo deste trabalho o apontamento do melhor método ou quais devam ser os parâmetros para a delimitação das UTB em zoneamentos ambientais territoriais, mas o de demonstrar uma proposta segundo critérios mensuráveis, replicáveis e que facilitem a delimitação de propostas de unidades da paisagem em zoneamentos ambientais.

Destarte, as UTB definidas demonstraram correlação com os atributos morfométricos e permitiram a definição de unidades da paisagem com base nesses atributos. A delimitação das UTB a partir dos limites das bacias hidrográficas demonstrou ser uma das possibilidades práticas para a integração dos ZEE com a PNRH, e permitiu a incorporação de dados quantificáveis já na fase de elaboração das unidades territoriais básicas. O método pode ser estendido a zoneamentos em diferentes escalas, como também em âmbito regional e local, e demonstra condições favoráveis para a sua incorporação na metodologia de elaboração de ZEE. 


\section{REFERÊNCIAL BIBLIOGRÁFICO}

ABARCA, M. R.; RAMÍREZ-DIAS, L. The Use of Multivariate Analysis for the Ecological Characterization of Landscape: the Mula River Watershed, South-east Spain. Journal of Environmental Management, v.34p. 297-308, 1990.

ADEDIRAN, A. O.; PARCHARIDIS, I., POSCOLIERI, M. e PAVLOPOULOS, K. Computer assisted discrimination of morphological units on north central Crete (Greece) by applying multivariate statistics to local relief gradients, Geomorphology n.58, p. 357-370, 2004.

ALBRECHTS, L., Healey, P., Kunzmann, K. R. Strategic Spatial Planning and Regional Governance in Europe. Journal of the American Planning Association Vol. 69, Iss. 2, 2003.

ALCÁNTARA-AYALA, Irasema. Geomorphology, natural hazards, vulnerability and prevention of natural disasters in developing countries. Geomorphology, v. 47, n. 2, p. 107-124, 2002.

AMARAL, R.; ROSS, J.L.S. As unidades ecodinâmicas na análise da fragilidade ambiental do parque estadual do morro do diabo e entorno. GEOUSP - Espaço e Tempo, São Paulo, No $^{\circ}$, pp. $59-78,2009$.

ALVES, J.M.P.; CASTRO, P.T.A. Influência de feições geológicas na morfologia da bacia do rio Tanque (MG) baseada no estudo de parâmetros morfométricos e análise de padrões de lineamentos. Revista Brasileira de Geociências, v. 33, n. 2, p. 117-127, 2003.

ASSUNÇÃO, R. M., NEVES, M. C., CÂMARA, G., \& DA COSTA FREITAS, C. Efficient regionalization techniques for sócio-economic geographical units using minimum spanning trees. International Journal of Geographical Information Science, v. 20, n. 7, p. 797-811, 2006.

BABCOCK, R. F. The Zoning Game. Madison, Milwaukee, and London: University of Wisconsin Press. 1966.

BAPTISTA, G. M. M. Caracterização climatológica do Distrito Federal. In: IEMA/SEMATEC/UnB, Inventário Hidrogeológico e dos Recursos Hídricos Superficiais do Distrito Federal. Brasília. Vol. 1, p.187-208, 1998.

BARBOSA, A. M.; SOARES, J. V. Zoneamento Ecológico-Econômico preliminar do município de São João Batista do Glória (MG). In: Anais X SBSR. Foz do Iguaçu: INPE, p. 909-913. 2001.

BECKER, B. K. \& MIRANDA, M. A geografia política do desenvolvimento sustentável. Rio de Janeiro: Editora UFRJ, 1997.

BERTRAND, G. Paysage et Geographie Physique Globale Esquisse méthodologique. Révue Geographique des pyrinées et Du Sud-Ouest, Toulose, 39 (3): 249-272, 1968.

BEVEN, K.J., Kirkby, M.J. A physically-based variable contributing area model of basin hydrology. Hydrology Science Bulletin 24(1), p.43-69, 1979. 
BISWAS, A.K. Integrated Water Resources Management: Is It Working? Water Resources Development, vol. 24, nº1, 5-22, Março de 2008.

BOYER, M. Christine. Dreaming the rational city: The myth of American city planning. Mit Press, 1986.

BOYLE, M. A., \& Kiel, K. A. A survey of house price hedonic studies of the impact of environmental externalities. Journal of Real Estate Literature, 9(2), 117-144. 2001.

CALVO, J.F.; PALAZÓN, J.A.; ESTEVE, M. A.; SUÁREZ, M. L.; TORRES, A.; VIDAL; CANIL, Kátia. Indicadores para monitoramento de processos morfodinâmicos: aplicação na bacia do Ribeirão Pirajussara (SP). Tese de Doutorado. Universidade de São Paulo. 2006.

CAMPOS, José Eloi Guimarães. Hidrogeologia do Distrito Federal: bases para a gestão dos recursos hídricos subterrâneos. Brazilian Journal of Geology, v. 34, n. 1, p. 41-48, 2004.

CANIL, Kátia. Indicadores para monitoramento de processos morfodinâmicos: aplicação na bacia do Ribeirão Pirajussara (SP). Tese de Doutorado. Universidade de São Paulo, 2006.

CARVALHO, Melissa; GHERARDI, Douglas Francisco Marcolino. Modelagem de um banco de dados geográficos para o mapeamento da sensibilidade ambiental ao derramamento de óleo na zona costeira. Simpósio Brasileiro de Sensoriamento Remoto (SBSR), v. 12, 2005.

CAVALCANTI, A. \& VIADANA, A. Organização do espaço e análise da paisagem. Rio Claro: UNESP-IGCE, Laboratório de Planejamento Municipal/ Programa de Pós-Graduação em Geografia, 2007.

COELHO, Silvério José. A PAISAGEM NO CONTEXTO DOS ASPECTOS LEGAIS E INSTITUCIONAIS E DAS LIMITAÇÕES ADMINISTRATIVAS PARA A IMPLANTAÇÃO DO APROVEITAMENTO HIDRELÉTRICO DO FUNIL, AHE FUNIL. Revista Espaço e Geografia, 2010.

CREPANI, E.; et al. Uso de sensoriamento remoto no zoneamento ecológico econômico. In: SIMPÓSIO BRASILEIRO DE SENSORIAMENTO REMOTO, 9, 1996, Salvador. Anais... Salvador: INPE, p.1-10, 1996.

CREPANI, E; Medeiros, J. S. de; Azevedo, L. G.; Hernandez, P.; Florenzano, T. G.; Duarte, V. Curso de Sensoriamento Remoto Aplicado ao Zoneamento Ecológico-Econômico. São José dos Campos. INPE. 2001.

CHORLEY R. J., MAIM, D. E. C., POGORZELSKI, H. A. A new standard for measuring drainage basin shape. American Jornal of Science, v.255, p.138-141, 1957.

CHOROWICZ, J.; ICHOKU, C.; RIAZANOFF, S.; KIM, Y. J.; CERVELLE, B.A combined algorithm for automated drainage network extraction. Water Resources Research 28 (5), 1923 1302. 1992. 
CHRISTOFOLETTI, A. Geomorfologia. São Paulo: Edgard Blucher Ltda, 2a. ed. 188p, 1980.

CODEPLAN. Atlas do Distrito Federal. Brasília. Secretaria de Educação e Cultura, v. 1. 78p, 1984.

COELHO NETTO, A.L. Hidrologia de Encosta na Interface com a Geomorfologia. In: GUERRA, A. J. T.; CUNHA, S. B. Da (org.). 6. ed. Geomorfologia: uma atualização de bases e conceitos. Rio de Janeiro: Bertrand Brasil, 472p, 2005.

DIKAU, R. (1989): The Application of a digital relief model to landform analysis in geomorphology. In: RAPER, J. (Ed.): Three Dimensional Application in Gcographic Information Systems: London, 5 I -77, 1989.

DONG, A., D. Q. Zhang, and Q. M. Yang. Technical directives for marine functional zoning. Beijing: Standardization Administration of China. 2006.

DOUGLAS, D.H., PEUKER, T. K. Detection of surface-specific points by local parallel processing of discret et errain elevation data. Comput. Graphics Image Process, n.4, p.375-387, 1975.

DOUVERE, F., and C. Ehler. New perspectives on sea use management: Initial findings from European experience with marine spatial planning. Journal of Environmental Management 90: 77-88. 2009.

EMBRAPA. Mapa de solos do Distrito Federal (1:100.000). Brasília: EMBRAPA-EPI. - Serviço de Produção de Informação. 1978.

EMBRAPA. Metodologia simplificada de zoneamento agroflorestal. Rio Branco: Embrapa Acre, 2000. 19 p. (Embrapa Acre. Circular Técnica, 35).

ESRI (2012) ArcGIS desktop help. Disponível em:

<http://webhelp.esri.com/arcgisdesktop/9.2/index.cfm?TopicName=welcome>. Acessado em: 05 de janeiro 2015.

EPA, United States Environmental Protection Agency. Green Zones for Economic and Environmental Sustainability: A new framework for community transformation. Disponível em: http://caleja.org/wp-content/uploads/2012/01/GZ_map_2pgrREVISED.pdf. Acessado em janeiro de 2015.

FANG, Q., Zhang, R., Zhang, L., \& Hong, H. Marine functional zoning in China: experience and prospects. Coastal Management, v. 39, n. 6, p. 656-667, 2011.

FARR, T.G.; ROSEN, P.A.; CARO, E.; CRIPPEN, R.; DUREN, R.; HENSLEY, S.; KOBRICK, M.; PALlER, M.; RODRIGUEZ, E.; ROTH, L.; SEAL, D.; SHAFFER, S.; SHIMADA, J.; UMLAND, J.; WERNER, M.; OSKIN, M.; BURBANK, D.; ALSDORF, D. 2007. The Shuttle Radar Topography Mission. Review of Geophysics, v.45, RG, 2004.

FERREIRA, G. F.; COSTA, A. P. R.; CANDEIAS, A. L. B. Análise comparativa de Modelos Digitais de Elevação. In: XV Simpósio Brasileiro de Sensoriamento Remoto, 2011, Curitiba-PR. 
Anais do XV Simpósio Brasileiro de Sensoriamento Remoto, 2011.

FIGUEIREDO, A.H. Proposta de atualização da legislação sobre zoneamento ecológico-econômico. Caderno de Referência Subsídio ao Debate. Brasília, Ministério do Meio Ambiente, 2006.

FILHO, Jugurta Lisboa; IOCHPE, Cirano. Um estudo sobre modelos conceituais de dados para projeto de bancos de dados geográficos. Revista IP-Informática Pública, v. 1, n. 2, p. 37-90, 1999.

FORMAN, R. T. T. Land Mosaics. The ecology of landscapes and regions. Combridge University Press, Cambridge, 1995.

FREITAS-SILVA F.H.; CAMPOS J.E.G. Geologia do Distrito Federal. In: IEMA/SEMATEC/UnB 1998. Inventário Hidrogeológico e dos Recursos Hídricos Superficiais do Distrito Federal. Brasília. IEMA/ SEMATEC/UnB. Vol. 1, Parte I. 86p. 1998.

FROGER, Géraldine; MÉRAL, Philippe. Towards an institutional and historical analysis of environmental policy in Madagascar. Environmental Policy and Governance, v. 22, n. 5, p. 369$380,2012$.

FRIEDEL, M. J. A data-driven approach for modeling post-fire debris-flow volumes and their uncertainty. In: Environmental Modelling \& Software, Volume 26, Issue 12, Pages 1583-1598, December 2011.

GDF. In: ZEE-DF - Zoneamento ecológico e econômico do Distrito Federal. Execução técnica Greentec Consultoria e Planejamento Ltda, vencedora do processo licitatório - Solicitação de Proposta $n^{\circ}$ 004/2008, por meio do contrato de serviço no 21/2009 (UGP/SEDUMA). Brasília, 2012.

GDF. In: ZEE-DF - Zoneamento ecológico e econômico do Distrito Federal. Subproduto 3.1 Relatório do Meio Físico e Biótico. Brasília, 2014.

GUIMARÃES, R. F.; CARVALHO, A.P.F.; MARTINS, E. S. Classificação de bacias de drenagem do Alto Jequitaí (Minas Gerais) a partir da análise de principais componentes e análise de grupos. Revista Brasileira de Geomorfologia, v.8, n. 2, p.73-86, 2007.

GÜTING, R. H. An introduction to spatial database systems. The VLDB Journal-The International Journal on Very Large Data Bases, v. 3, n. 4, p. 357-399, 1994.

HART. M. G. Geomorphology pure and applied. London: Allen \& Unwin, 228 p. 1986.

HERMUCHE, P. M.; GUIMARAES, R. F.; CARVALHO, A. P. F.; MARTINS, E. S.; DRUCK, S.; CARVALHO JUNIOR, O. C.; SANTOS, N. B. F.; REATTO, A. Morfometria como suporte para elaboração de mapas pedológicos: Bacias Hidrográficas Assimétricas. Planaltina, DF: EMBRAPA Cerrados, 2002.

HIRT, Sonia. The devil is in the definitions: Contrasting American and German approaches to 
zoning. Journal of the American Planning Association, v. 73, n. 4, p. 436-450, 2007.

HORTON, R. E. Erosinal development of stream sand their drainage basin: Hydrophysical approach to quantitative morphology. Geol. Soc. American Bulletin, v.3, n.56, 1945.

JEPSON JR, Edward J.; HAINES, Anna L. Zoning for Sustainability: A Review and Analysis of the Zoning Ordinances of 32 Cities in the United States. Journal of the American Planning Association, v. 80, n. 3, p. 239-252, 2014.

KERSKI, J .J. Geo-awareness, Geo-enablement, Geotechnologies, Citizen Science, and Storytelling: Geography on the World Stage. Geography Compass 9/1 (2015): 14-26, 10.1111/gec3.12193. Disponível em: http://onlinelibrary.wiley.com/doi/10.1111/gec3.12193/abstract. Acessado em fevereiro de 2015.

KETABCHI, Hamed; ATAIE-ASHTIANI, Behzad. Evolutionary algorithms for the optimal management of coastal groundwater: A comparative study toward future challenges. Journal of Hydrology, v. 520, p. 193-213, 2015.

LANNA, Antonio Eduardo et al. Inserção da gestão das águas na gestão ambiental. In: Interfaces da Gestão de Recursos Hídricos: desafios da Lei de Águas de 1997. Secretaria de Recursos Hídricos, 2000. p. 75-108.

LAURINI, R.; THOMPSON, D. Fundamentals of Spatial Information Systems. San Diego: Academic Press, 1999.

LEHNER, B.; VERDIN K.; JARVIS, A. HYDROSHEDS. Technical Documentation, v.1, Appendix to HYDROSHED data, 2006.

LEHNER, B.; VERDIN, K.; JARVIS, A. New Global Hydrography Derived From Space born e Elevation Data. E os Trans, AGU, v.89, n.10, 2008.

LEITE, C.M.C - Uma Análise sobre o Processo de Organização do Território: o caso do zoneamento ecológico-econômico in Revista Brasileira de Geografia, Rio de Janeiro, IBGE, 53(3): 67-90, julho/setembro de 1991.

LOGAN, Thomas H. The Americanization of German Zoning. Journal of the American Institute of Planners, v. 42, n. 4, p. 377-385, 1976.

MACQUEEN, J. B. Some Methods for classification and Analysis of Multivariate Observations. In: 5-Thberkeley Symposium on Mathematical Statistics and Probability, Proceedings..., Berkeley, University of California Press, v.1, p.281-297, 1967.

MANCUSO, Franco: Las experiencias del zoning. Barcelona: Ediciones Gustavo Gili S.A., 1980.

MANTAAY, Juliana. Zoning law, health, and environmental justice: what is the connection? The Journal of Law, Medicine \& Ethics, v. 30, n. 4, p. 572-593, 2002.

MARINI O.J., Fuck R.A., Danni J.C. A evolução geotectônica da Faixa Brasília e do seu 
embasamento. In: SBG, Simpósio sobre o Cráton do São Francisco e Suas Faixas Marginais, 1. Salvador, 1981. Anais..., Salvador, SBG/BA. p.100-113. 1981.

MARTINS, E.S.; BAPTISTA, G.M.M. Compartimentação geomorfológica e sistemas morfodinâmicos do Distrito Federal. In: Inventário Hidrogeológico e dos Recursos Hídricos Superficiais do Distrito Federal. IEMA/SEMATEC/UnB: Brasília, Vol. 1, Parte II. 53p. 1998.

MARTINS, E. S.; REATTO, Adriana; CARVALHO JÚNIOR, Osmar Abílio de; GUIMARÃES, Renato Fontes. Ecologia de Paisagem: conceitos e aplicações. Documentos. Embrapa Cerrados, v. 121, p. 1-35, 2004.

MENKE, A. B; CARVALHO JÚNIOR, O. A.; GUIMARÃES, R. F.; GOMES, R. A. T.; OLIVEIRA, S. N. Classificação pelo método k-médias das bacias de drenagem do rio Ipanema (AL/PE) considerando os atributos morfométricos. GeoUERJ (2007), v. 2, p.1-20, 2013.

MEDEIROS, V. S. Análise estatística de eventos críticos de precipitação relacionados a desastres naturais em diferentes regiões do Brasil. 2013. Dissertação (Mestrado em Engenharia Hidráulica) - Escola Politécnica, Universidade de São Paulo, São Paulo, 2013. Disponível em: <http://www.teses.usp.br/teses/disponiveis/3/3147/tde-04102013-113054/>. Acesso em: 201501-14.

MENKE, A. B. Análise de grupos para classificação de bacias hidrográficas do estado de Goiás, utilizando parâmetros morfométricos. Dissertação (Mestrado em Geografia) - Departamento de Geografia, Universidade de Brasília, Brasília: 86 p, 2012.

MILLER, V. C. A quantitative geomorphic study of drainage basin characteristics in the Clinch Mountain area, Virginia and Tennessee. Technical report, 3, New York: Office of Naval Research, Department of Geology, Columbia University, 1953.

MOORE, I. D.; GRAYSON, R. B. \& LADSON, A. R. Digital terrain modeling: are view of hydrological, geomorphological and biological applications. Hydrological Processes, v.5, p.3-30, 1991.

MORRIS, D. G.; HEERDEGEN, R. G. Automatically derived catchment boundaries and channel networks and their hydrological applications. Geomorphology 1, 131-141, 1988.

NEPSTAD, D. et al. The end of deforestation in the Brazilian Amazon. In: Science Magazine, vol. 326, p.1351, 4 december 2009.

NETUSIL, N. R. The Effect of Environmental Zoning and Amenities on Property Values: Portland, Oregon. Summary report prepared by the City of Portland, Bureau of Planning Portland, Oregon - May 2003. Disponível em: http://www.jstor.org/stable/4129666. Acessado em fevereiro de 2015.

NH-DES. New Hampshire Department of Environmental Services. Chaper 2: Environmental 
Characteristics Zoning. In:Innovative land use planning techniques: a handbook for sustainable development. October, $2008 . \quad$ Disponível em: http://des.nh.gov/organization/divisions/water/wmb/repp/documents/ilupt_complete_handbook.p df. Acessado em dezembro de 2014.

NOVAES PINTO M. Caracterização geomorfológica do Distrito Federal. In: Novaes Pinto M. (org.) Cerrado: caracterização, ocupação e perspectivas. $2^{\text {a }}$ edição, Brasília, Editora UnB, p. 285-320. 1994.

OLIVEIRA, S N; CARVALHO JUNIOR, O.A. ; SILVA, T. M. ; GOMES, R.A.T. ; MARTINS, E. S. ; GUIMARÃES, R. F.; SILVA, N. C. Delimitação automática de bacias de drenagens e análise multivariada de atributos morfométricos usando modelo digital de elevação hidrologicamente corrigido. Revista Brasileira de Geomorfologia, v.8, n.1, p.3-21, 2007.

OLIVEIRA, S. N. Metodologia para delimitação e análise multivariada de atributos morfométricos de bacia de drenagem usando modelo digital de elevação hidrologicamente corrigido. Dissertação de Mestrado, Departamento de Geografia, UNB, Brasília. 2008.

OREA, Domingo Gómez. Planificacion Rural. Madrid: Editorial Agrícola Española e Ministério de Agricultura, Pesca y Alimentación, 396 p., 1992.

PAHL-WEBER, E.; HENCKEL, D. (Eds.). The Planning System and Planning Terms in Germany.. Hanover: Studies in Spatial Development. Disponível em: http://shop.arlnet.de/media/direct/pdf/ssd_7.pdf. 2008. Germany, 2008.

QI, Ye; ZHANG, Lingyun. Local environmental enforcement constrained by central-local relations in China. Environmental Policy and Governance, v. 24, n. 3, p. 216-232, 2014.

QIN, Hua-Peng; SU, Qiong; KHU, Soon-Thiam. An integrated model for water management in a rapidly urbanizing catchment. Environmental Modelling \& Software, v. 26, n. 12, p. 1502-1514, 2011.

REMPEL, C.; Guerra, T., Porto, M. L., Périco, E., Eckhardt, R. R., \& Cemin, G. A ecologia da paisagem como base para o zoneamento ambiental da região político-administrativa-Vale do Taquari-RS-Brasil-um modelo de proposta metodológica. Revista Internacional de Ciencia y Tecnología de la Información Geográfica, n. 9, p. 102-125, 2008.

SANTOS, D. A. R. dos; MORAIS, F. de. Análise Morfométrica da Bacia Hidrográfica do Rio Lago Verde como Subsídio à Compartimentação do Relevo da Região De Lagoa Da Confusão - TO. In: Revista Geonorte, Edição Especial, V.3, N.4, p. 617-629, 2012.

SANTOS, R.F. dos. Planejamento Ambiental: teoria e prática. São Paulo: Oficina de Textos, 2004.

SAUER, O. A morfologia da paisagem. In: CORRÊA; ROZENDAHL (Orgs.). Paisagem tempo e cultura, Rio de Janeiro: EdUERJ, 1998. 
SCHUMM, S. A. Evolution of drainage systems and slopes in badlands of Perth Amboy. Geological Society of America Bulletin, n. 67, p. 597-646, 1956.

SEGAN, Daniel B. et al. An interoperable decision support tool for conservation planning. Environmental Modelling \& Software, v. 26, n. 12, p. 1434-1441, 2011.

SHI, W., ZENG, W. Application of k-means clustering to environmental risk zoning of the chemical industrial area. Frontiers of Environmental Science \& Engineering 8.1: 117-127. 2014.

SILVA, J. S. V. Análise multivariada em zoneamento para planejamento ambiental; estudo de caso: bacia hidrográfica do alto rio Taquari MS/MT. 307 p. Tese (Doutorado em Engenharia Agrícola) - Faculdade de Engenharia Agrícola, Universidade Estadual de Campinas, Campinas, 2003.

SILVA, J. S. V.; Santos, R. F. dos. Zoneamento para planejamento ambiental: vantagens e restrições de métodos e técnicas. Cadernos de Ciência \& Tecnologia, Brasília, v. 21, n. 2, p.221-263, maio/ago, 2004.

SMART, J. S. Statistical properties of stream lengths.WaterResourcesResearch4 (5), 932-936, 1968.

SOARES-FILHO, B. S.; NEPSTAD, D. C.; CURRAN, L. M.; CERQUEIRA1, G. C.; GARCIA, R. A.; RAMOS, C. A.; VOLL, E.; MCDONALD, A.; LEFEBVRE , P.; SCHLESINGER , P. Modelling conservation in the Amazon basin. In: Nature Publishing Group, vol.440, nature 04389, p. 520-523, 2006.

SODRÉ, R.; CARVALHO JUNIOR, O.A.; MACHADO, W. P.; OLIVEIRA, S. N.; GOMES, R.; A. T., GUimarÃES, R. F., CARVALHO, A. P. F., MARTINS, E. S. Classificação de baciasde drenagem do Alto Jequitaí (Minas Gerais) a partir da análise de principais componentes e análise de grupos. Revista Brasileira de Geomorfologia, v.8, n.2, p.73-86, 2007.

SOUZA, C. R. G. Flood risk assessment in coastal drainage basins through a multivariate analysis within a GIS-based model. Journal of Coastal Research, SI. 56. Proceedings of the 10th International Coastal Symposium, p.900-904. Lisboa, Portugal. 2009.

SPÖRL, Christiane; ROSS, JL Sanches. Análise comparativa da fragilidade ambiental com aplicação de três modelos. GEOUSP-Espaço e Tempo, v. 15, p. 39-49, 2004.

STRAHLER, A. N. Hypsometric (area-altitude) analysis and erosional topography. Bulletin of the Geological Society of America 63 (10), 1117-1142, 1952.

STRAHLER, A. N. Quantitative analysis of watershed geomorphology. Trans. Amer. Geophys. Union, v.38: p.913-920, 1957.

TARBOTON, D. G., D. P. AMES. Advances in the mapping of flow networks from digital elevation data. In: World Water and Environmental Resources Congress, Orlando, Florida, May 2001, p. 20-24, ASCE.

TCU. Tribunal de Contas da União. Acórdão no 2468/2009 - Plenário. Processo TC no 
024.500/2008-9. Relatório de Auditoria de Natureza Operacional para a análise da adequação do Zoneamento Ecológico-Econômico (ZEE) Federal e de alguns estados integrantes da Amazônia Legal. Brasília: 2009.

TONELLO, K.C. Análise hidroambiental da bacia hidrográfica da cachoeira das Pombas, Guanhães, MG. 2005. 69p. Tese (Doutorado em Ciências Florestal) - Universidade Federal de Viçosa, Viçosa, 2005.

TOPALOV, C. Da questão social aos problemas urbanos: os reformadores e a população das metrópoles em princípios do século XX. In: PECHMAN, R. M.; RIBEIRO, L. C. Q. (Org.). Cidade, povo e nação: gênese do urbanismo moderno. Rio de Janeiro: Civilização Brasileira, p. 23-51. 1996.

TRICART, J.J.L. Principes et méthodes de la geomorphologie. Paris: Masson et Cie. Editeurs. 460p, 1965.

TRICART, J. J. L. Ecodinâmica. In: Série recursos naturais e meio ambiente. SUPREN/IBGE, 1977.

TROLL, C. Landscape ecology. ITC-UNESCO Centre for Integrated Surveys, Paper S. 4, 23 p, 1966.

TURBAN, E. Decision support and expert systems: management support systems. New York: Macmillan, 833 p. 1995.

USGS - U.S Geological Service. Sítio eletrônico disponível pelo endereço: http://earthexplorer.usgs.gov/. Último acesso em janeiro de 2015

WEATHERILL, G.; BURTON, P. W. Delineation of shallow seismic source zones using K-means cluster analysis, with application to the Aegean region. In: Geophysic. Journal International 176, p.565-588, 2009.

WIELAND, Ralf et al. A new method for semi-automatic fuzzy training and its application in environmental modeling. Environmental Modelling \& Software, v. 26, n. 12, p. 1568-1573, 2011.

WILLIAMSON, I., P.; e HUNTER, G. J. The need for improved forms of conceptual models in geographical information system development. Australian Surveyor, 36(2):100-110, 1991.

YATES, Paul; HUMPHRIES, Mark. The Generation of Schematic Diagrams from Geographic Representations of Networks. In: Proc. Spatial Information Research Centre's 10th Colloquium. 1998.

YEVJEVICH, V.; DYHR-NIELSEN, M.; SCHULZ, E. F. An application of multivariate analysis in hydrology. Environmental Resources Center. Fort Collins, Colorado: Completion Report Series, n. $35,1972$. 